Florida International University

FIU Digital Commons

FIU Electronic Theses and Dissertations

University Graduate School

$11-7-2019$

\title{
The Role of Number Writing in Early Math Readiness
}

Giselle Hernandez

Florida International University, ghern009@fiu.edu

Follow this and additional works at: https://digitalcommons.fiu.edu/etd

Part of the Curriculum and Instruction Commons, Early Childhood Education Commons, and the Science and Mathematics Education Commons

\section{Recommended Citation}

Hernandez, Giselle, "The Role of Number Writing in Early Math Readiness" (2019). FIU Electronic Theses and Dissertations. 4331.

https://digitalcommons.fiu.edu/etd/4331

This work is brought to you for free and open access by the University Graduate School at FIU Digital Commons. It has been accepted for inclusion in FIU Electronic Theses and Dissertations by an authorized administrator of FIU Digital Commons. For more information, please contact dcc@fiu.edu. 


\section{FLORIDA INTERNATIONAL UNIVERSITY \\ Miami, Florida}

THE ROLE OF NUMBER WRITING IN EARLY MATH READINESS

A dissertation submitted in partial fulfillment of

the requirements for the degree of

\section{DOCTOR OF EDUCATION}

in

CURRICULUM AND INSTRUCTION

by

Giselle Hernandez 
To: Dean Michael R. Heithaus

College of Arts, Sciences and Education

This dissertation, written by Giselle Hernandez, and entitled The Role of Number Writing in Early Math Readiness, having been approved in respect to style and intellectual content, is referred to you for judgment.

We have read this dissertation and recommend that it be approved.

Laura Dinehart

Barbara King

Thomas Reio

Charles Bleiker, Major Professor

Date of Defense: November 7, 2019

The dissertation of Giselle Hernandez is approved.

Dean Michael R. Heithaus

College of Arts, Sciences and Education

Andrés G. Gil

Vice President for Research and Economic Development and Dean of the University Graduate School

Florida International University, 2019 


\section{DEDICATION}

I dedicate this work to my family, without whose love and support I would never have completed it, and to the children of Calvary Baptist Church Day Care Center, who have been my inspiration and deserve a fighting chance in life. 


\section{ACKNOWLEDGMENTS}

I wish to thank the members of my committee, Dr. Laura Dinehart, Dr. Barbara King, and Dr. Thomas Reio, for their enthusiasm for this project and guidance to carry it out in the most meaningful way possible. I would especially like to thank Dr. Charles Bleiker, my major professor, who always believed that I could achieve this from the beginning. Without his dedication, to me and to the children, this study would never have been conducted.

I also wish to thank Mercedes Ramos, the Director of Calvary Baptist Church Day Care Center, for allowing Dr. Bleiker and myself to conduct this research at the center. She has always been very supportive of my career efforts.

I would like to thank my family - especially my two children, Anaïs and Miriam, who are my driving force, as well as my husband, Carlos A. Tarifa, and my mother, Leonor Hernandez, who have been my strong support system throughout this process.

Lastly, but most importantly, I would like to thank God, for whom all things are possible, and who has graced me with the blessing of seeing this accomplishment through. 


\section{ABSTRACT OF THE DISSERTATION \\ THE ROLE OF NUMBER WRITING IN EARLY MATH READINESS}

by

Giselle Hernandez

Florida International University, 2019

Miami, Florida

Professor Charles Bleiker, Major Professor

The purpose of the present study was to understand how number writing in a class of low-income, pre-kindergarten children $(N=15)$ developed over the course of a school year, and to see what role that development played in their overall math readiness. The study used a mixed-methods approach. The target class was explicitly taught number writing as part of an early math intervention. Scores on a number writing inventory, and two math readiness assessments (Number Knowledge assessment, State of Florida VPK Assessment) were compared at the end of the year, both within the intervention group, and with a matched comparison group who did not participate in the intervention. The qualitative findings revealed that the characteristics necessary for preschool children to successfully write their numbers included: fine motor skills, cardinal and ordinal number knowledge, number symbol recognition, sensory tactile memory, and visual-spatial skills. Children demonstrated different paths and rates of success, but all made significant gains in their number writing abilities, especially when compared to those who did not receive the intervention. The quantitative findings confirmed that the children in the intervention outperformed those in the comparison group on number writing and number knowledge measures and revealed that number writing is predictive of early math knowledge overall, 
both on an individual and group level, suggesting that number writing is essential to overall math readiness and is a skill that can and should be taught. The findings further suggest that number writing is both a reliable indicator of overall early math knowledge, and an important driver of a young child's mathematical thinking. 


\section{TABLE OF CONTENTS}

CHAPTER

PAGE

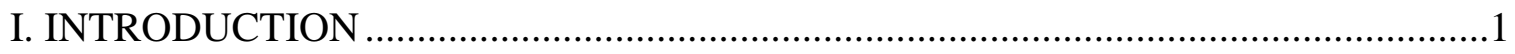

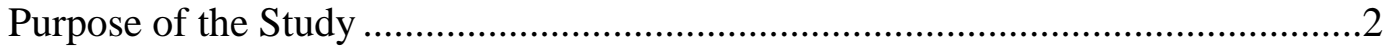

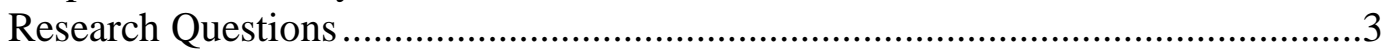

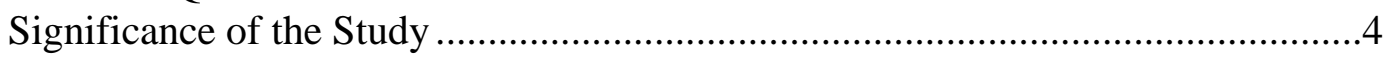

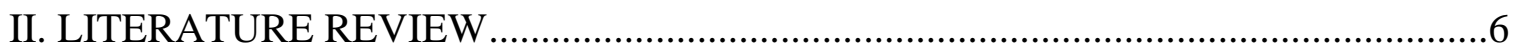

Theoretical Framework …………..............................................................

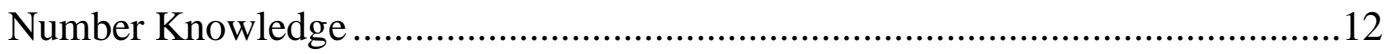

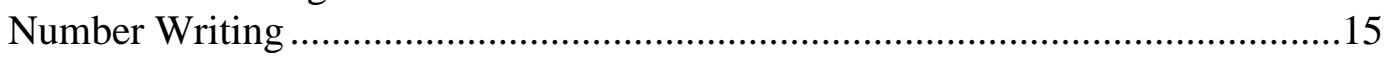

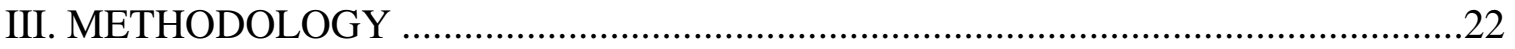

About the VPK Program .........................................................................22

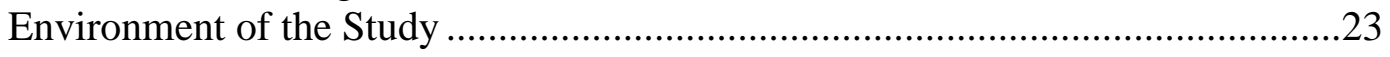

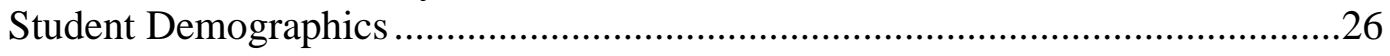

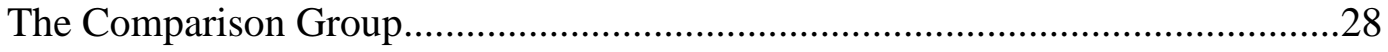

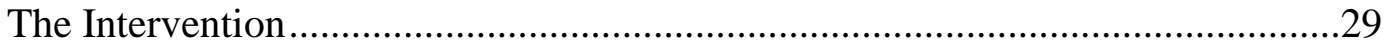

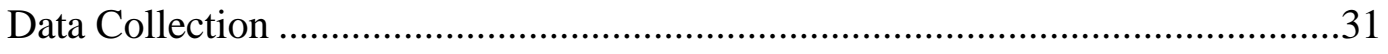

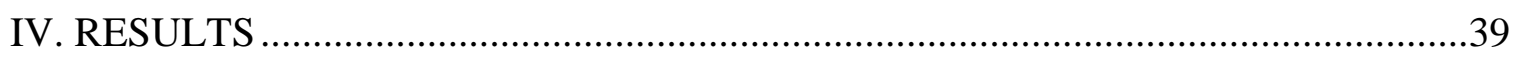

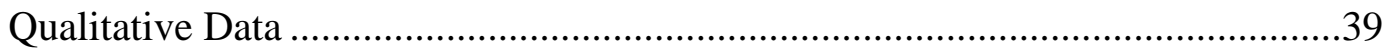

Overall Number Writing ..............................................................................4

Analysis of all children's number writing at pre-test...........................................48

Analysis of all children's number writing at mid-test ..........................................54

Analysis of all children's number writing at post-test ........................................58

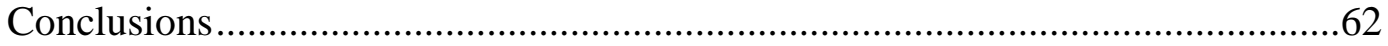

Case Studies of Three Children ......................................................................62

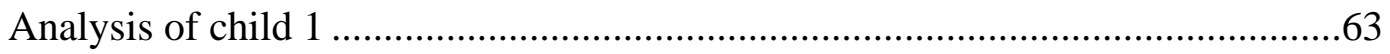

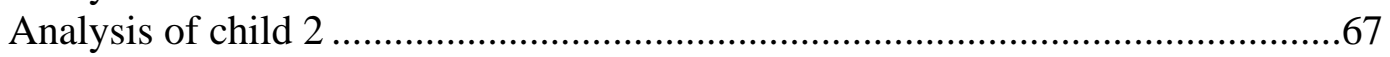

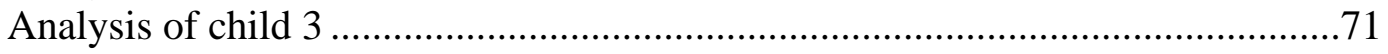

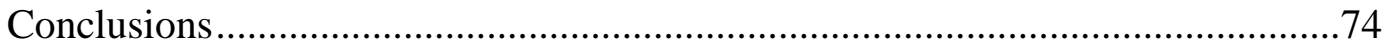

Comparison of Number Writing Post-Test with Matched Group..........................75

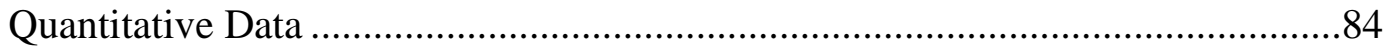

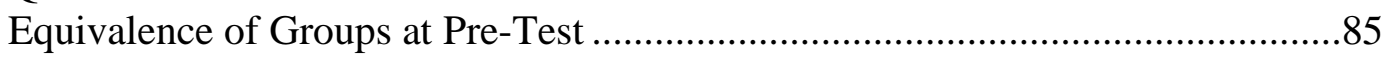

Performance Comparison at Post-Test...............................................................89

Predictivity of Number Writing .......................................................................91

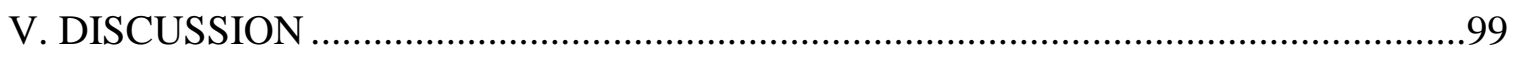

Addressing the Research Questions..............................................................102

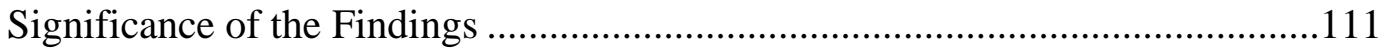

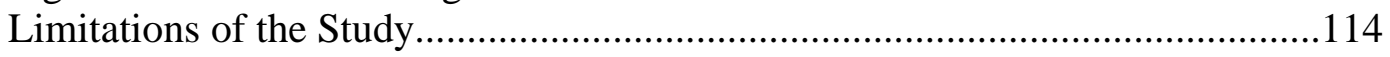




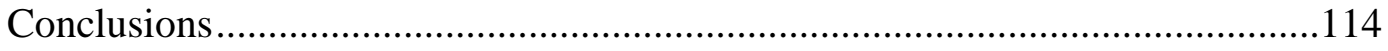

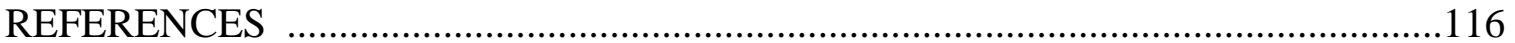

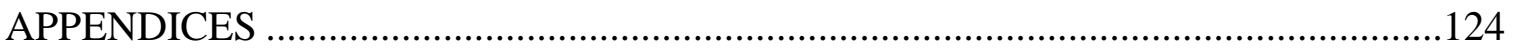

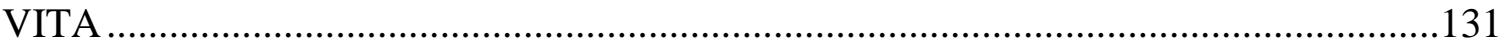




\section{LIST OF TABLES}

TABLE

PAGE

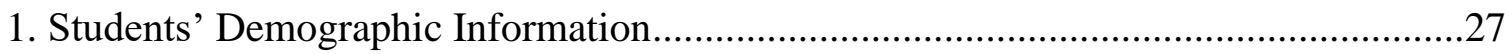

2. Tests of Normality for VPK Assessment Pre-Test Measures .........................................85

3. Descriptives of Variables for Print Knowledge and Phonological Awareness for

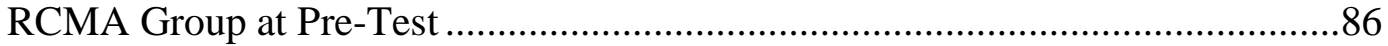

4. Group Statistics for VPK Assessment Pre-Test Measures .............................................86

5. Independent Samples T-Test for VPK Assessment Pre-Test Measures ..........................87

6. Descriptive Statistics for VPK Assessment Pre-Test Math Measure .............................88

7. Ranks for VPK Assessment Pre-Test Math Measure ……...........................................8

8. Test Statistics for VPK Assessment Pre-Test Math Measure ..........................................88

9. Tests of Normality for Various Math Measures at Post-Test ..........................................89

10. Descriptive Statistics for Various Math Measures at Post-Test....................................90

11. Ranks for Various Math Measures at Post-Test ……………………........................90

12. Test Statistics for Various Math Measures at Post-Test ..............................................90

13. Descriptive Statistics for Number Knowledge and Number Writing at Pre-Test........92

14. Correlations Between Number Knowledge and Number Writing at Pre-Test ............92

15. ANOVA Table for Number Knowledge and Number Writing at Pre-Test..................93

16. Model Summary for Correlation Between Number Knowledge and Number

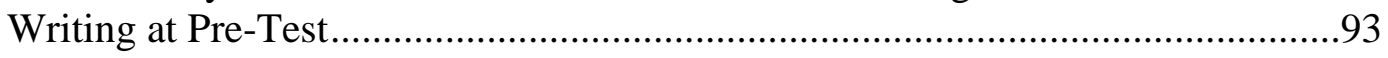

17. Coefficients for Linear Regression Between Number Knowledge and Number

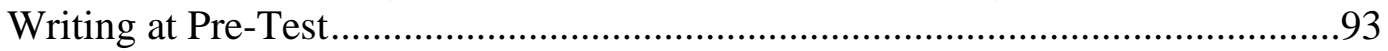

18. Descriptive Statistics for Number Knowledge and Number Writing at Mid-Test ......94

19. Correlations Between Number Knowledge and Number Writing at Mid-Test ...........94 
20. ANOVA Table for Number Knowledge and Number Writing at Mid-Test

21. Model Summary for Correlation Between Number Knowledge and Number Writing at Mid-Test

22. Coefficients for Linear Regression Between Number Knowledge and Number Writing at Mid-Test

23. Descriptive Statistics for Number Knowledge and Number Writing at Post-Test ......95

24. Correlations Between Number Knowledge and Number Writing at Post-Test .95

25. ANOVA Table for Number Knowledge and Number Writing at Post-Test .96

26. Model Summary for Correlation Between Number Knowledge and Number Writing at Post-Test .96

27. Coefficients for Linear Regression Between Number Knowledge and Number Writing at Post-Test

28. Descriptive Statistics for Number Knowledge and Number Writing Overall .97

29. Correlations Between Number Knowledge and Number Writing Overall

30. ANOVA Table for Number Knowledge and Number Writing Overall .97

31. Model Summary for Correlation Between Number Knowledge and Number Writing Overall

32. Coefficients for Linear Regression Between Number Knowledge and Number Writing Overall 


\section{LIST OF FIGURES}

FIGURE

PAGE

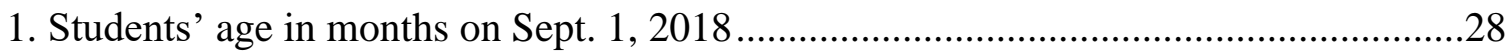

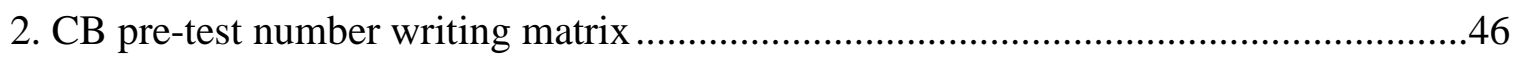

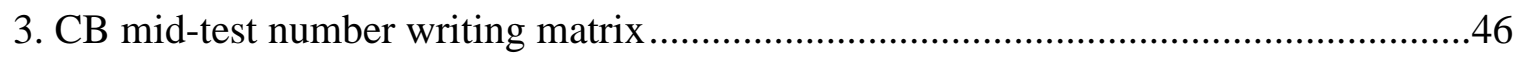

4. CB post-test number writing matrix ..............................................................47

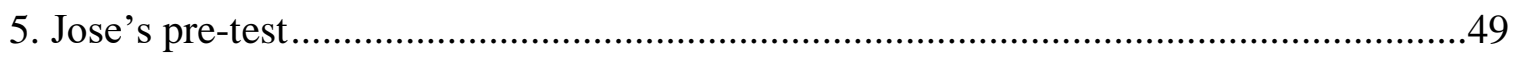

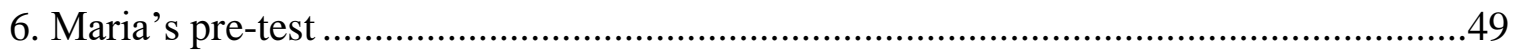

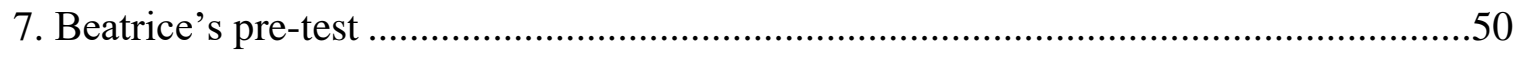

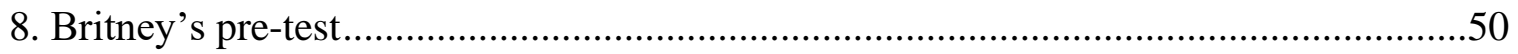

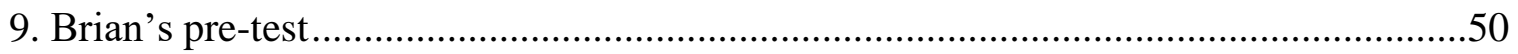

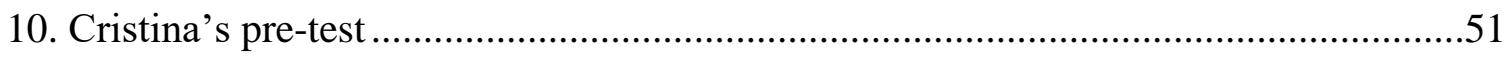

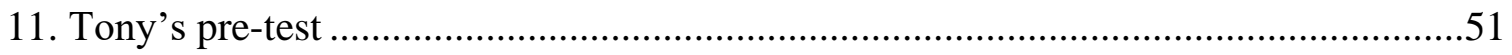

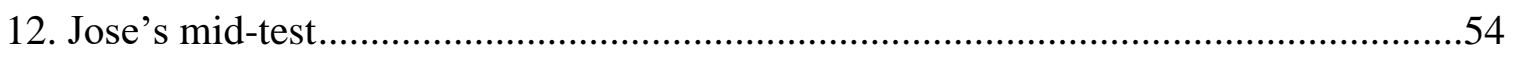

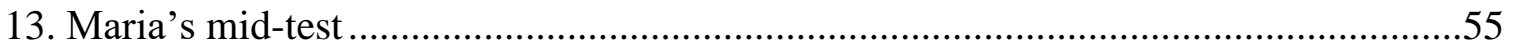

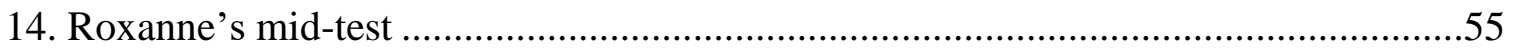

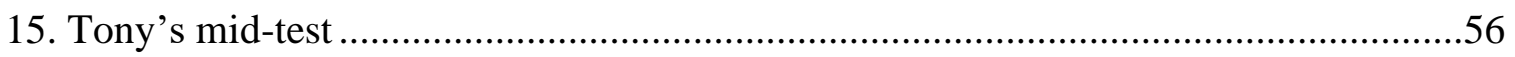

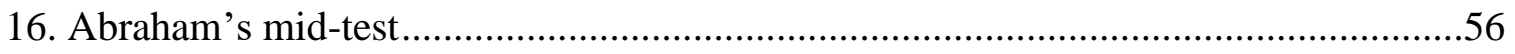

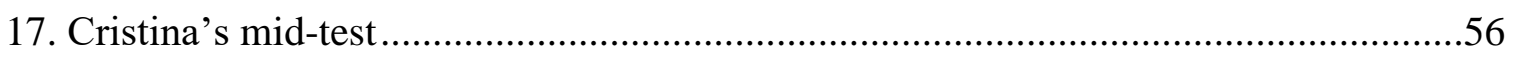

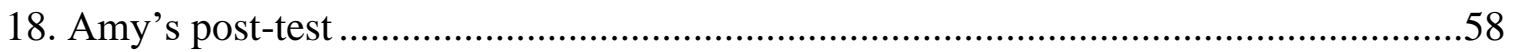

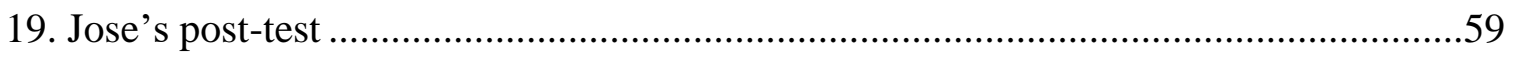

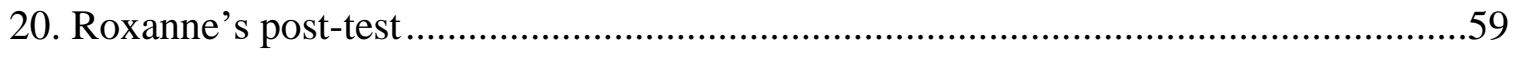

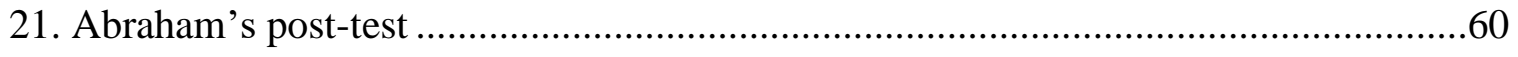




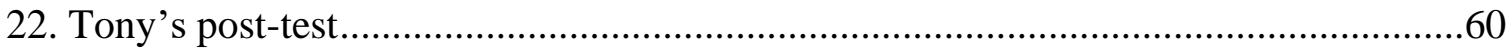

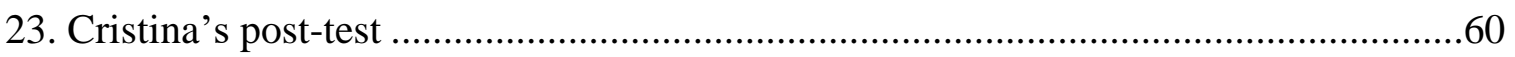

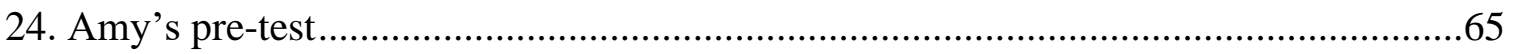

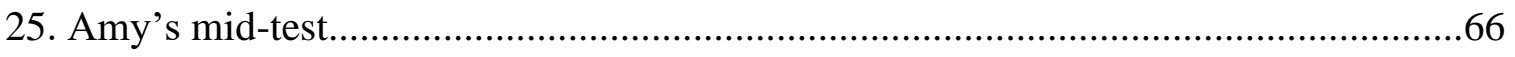

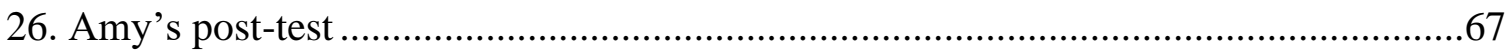

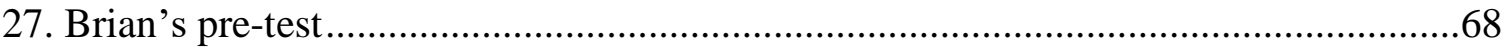

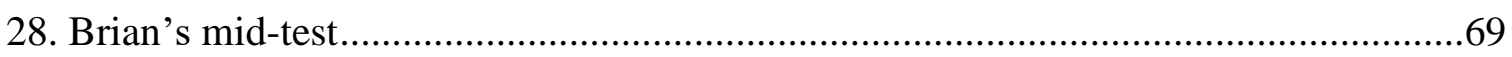

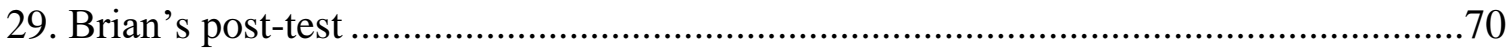

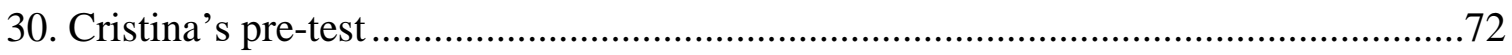

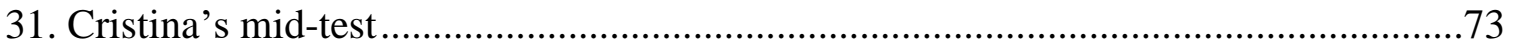

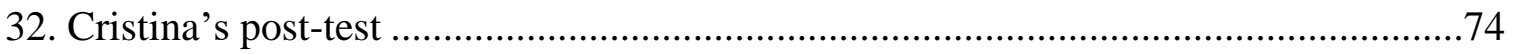

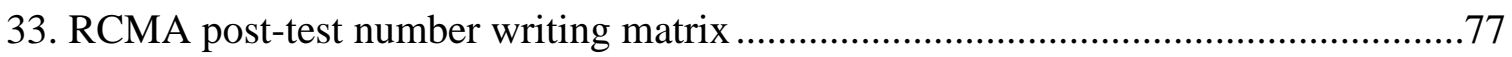

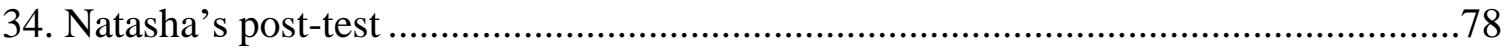

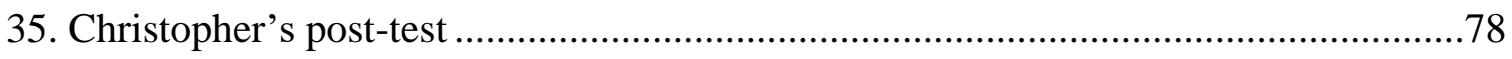

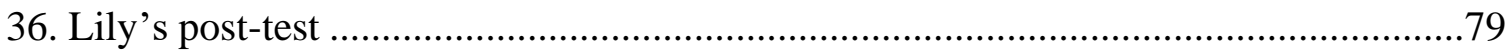

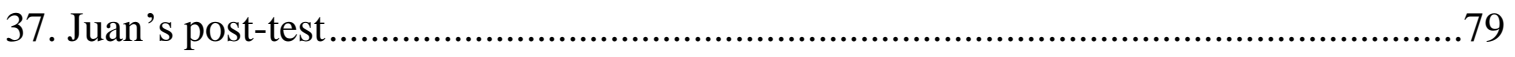

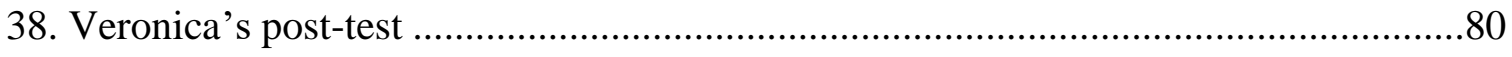

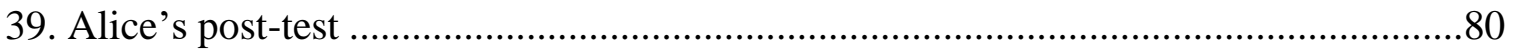

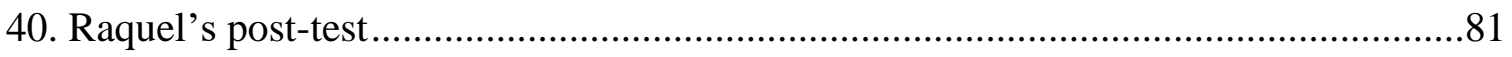

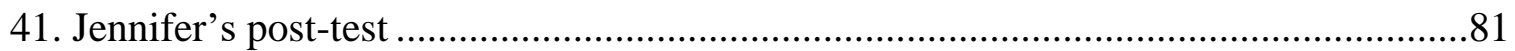




\section{CHAPTER I}

\section{INTRODUCTION}

Early mathematics education is an important component of school readiness because it is predictive of overall school achievement, not just in math, but in other areas of study as well (Duncan et al., 2007). Early math education is also directly linked to selfregulation and executive function, including its subcomponents inhibitory control and working memory, that are also important to overall school readiness (Clark, Sheffield, Wiebe, \& Espy, 2013; Harvey \& Miller, 2017).

The keystone for early math education is number knowledge (Bonny \& Lourenco, 2013; Locuniak \& Jordan, 2008; Sasanguie, Göbel, Moll, Smets, \& Reynvoet, 2013). Number knowledge is foundational to all areas of the early math curriculummeasurement, pattern recognition, geometry, classification. Early number knowledge is based on counting and quantifying, and encompasses the concepts of one-to-one correspondence, cardinality (Gelman \& Gallistel, 1978; Sarnecka \& Wright, 2013), ordinality (Bob \& Threlfall, 2004), and number identification (Lee, Lembke, Moore, Ginsburg, \& Pappas, 2012).

Number writing, the subject of the present dissertation, is an often overlooked component of early math that is key to helping children encode and access their overall number knowledge (Fosshage, 2011). Implicit in each number symbol is the discrete amount that each number represents, as well as the larger set of countable objects it identifies (Zhou \& Wang, 2004).

Number writing is not just number copying. It is a combination of fine motor skills, memory and visual perception (Hildreth, 1932; Rhodes, Branum-Martin, 
Washington, \& Fuchs, 2017). These three areas are involved in symbolic encoding, the process through which children translate and compress their early knowledge of counting into the abstract scheme of Hindu-Arabic numerals, the ten symbols that are the basis of our counting system (Stoianov, Zorzi, \& Umiltà, 2004). Once learned, these symbols become the alphabet to the larger language of math that children will need to master to succeed in school (Zhou \& Wang 2004). Their combinatorial power, and the inherent logic that connects each with the other, is what gives the number system its power to organize, structure, measure and think about the world.

Methodology of teaching has a strong influence on learning outcomes, especially in terms of student motivation (Zhao, 2017). Motivation has been found to lead to enhanced math achievement, and achievement in turn to increased interest in math (Viljaranta, Lerkkanen, Poikkeus, Aunola, \& Nurmi, 2009). The current study will compare number writing skills and math achievement between preschool students taught only using a regular classroom curriculum and those taught using a supplementary gamebased curriculum. The intervention teaches number writing as an organic part of the number knowledge process, whereas the non-intervention group is taught using teacher directed, and more rote kinds of instruction.

\section{Purpose of the Study}

The first aim of my study is to understand the path that children take to successful number writing during their pre-kindergarten (Pre-K) year, and to determine whether the methodology used to teach it has an effect on number writing skills and overall math readiness. Enrollment in Pre-K classes has become a priority for most states as a way to improve educational outcomes of all children, but especially those at risk for school 
failure. The pre-kindergarten year is often the first time children are in a formal school setting with academic instruction. For many it will be the first occasion that they are asked to write their numbers.

The second aim of the study is to investigate whether number writing itself predicts overall early math readiness, and whether there is any association between proficiency in number writing and overall math readiness. These are important issues to investigate as our early childhood curriculum undergoes a dramatic transformation from real to virtual, concrete to digital (Craig, 2000). It is not hard to imagine a near future in which young children are required only to mark representations of numbers on a touchsensitive screen.

\section{Research Questions}

The following research questions will be addressed in this study:

1. Does teaching number writing through math games produce better number knowledge development as well as number writing improvement than only traditional teaching methods?

2. What level of number writing do at-risk pre-kindergarten students have at the beginning and end of their pre-kindergarten year in a school that offers Florida's Voluntary Pre-Kindergarten (VPK)?

3. Is there a correlation between competency in number writing and achievement in early math scores at the beginning, middle, and end of the year of the preschool year?

4. What developmental stages can be observed in pre-kindergarten students' number writing? 


\section{Significance of the Study}

The study has relevance for teachers, policy makers and academics. If it can be shown that number writing can be mastered by the majority of pre-kindergarten children, and that it is associated with improved math readiness scores, then teachers could be encouraged to foster the skillset. An awareness of the progression of number writing could also help teachers to devise strategies to help students to achieve mastery in number writing. An analysis of data of five years of at-risk pre-kindergarten children's number writing will also provide policy makers and academics insight into the current state of number writing and its potential contribution to school readiness.

The analysis of number writing samples is important for teachers and policy makers as a comparison group for number writing in other VPK classrooms at the beginning of the VPK school year. The analysis can be the basis for a growing inventory of number writing from which a scale or typology can be created (the different variants that children come up with in their attempts to master their numbers), which could in turn lead to a valuable assessment tool for number writing that could help teachers and policymakers gauge the progress of their children. Such a scale can further give clues to the process that children go through as they pass from early attempts to mastery.

In academic terms, the research would serve to amplify the body of research available on number writing, which is somewhat limited, as well as inform about the role of teaching through games in learning to write numbers. In addition, it will add to a growing body of research on the importance of writing in the digital age and its role in the cognitive processes involved in learning, including those proposed in Robbie Case's theory. 
One possible conclusion of the study is that there is a right and a wrong way to teach number writing. One way is learning the numbers in a disconnected, rote way without symbolic encoding of meaning. The other way is with a clear objected and with and in the service of an authentic practice. If the children in the intervention group perform better in number writing and math readiness, as is predicted, then it can be suggested that the way number writing is taught does make a difference and that teachers, researchers, and policy makers should include experience-based number writing in their teaching of early childhood math. 


\section{CHAPTER II}

\section{LITERATURE REVIEW}

Research has revealed just how important early mathematics education is for school readiness. Studies from kindergarten show that early math has the ability to predict overall school achievement. For instance, one study found that increased instructional time in mathematics has an effect on overall student achievement (Fan \& Bains, 2008), and another study, using the ECLS-K (Early Childhood Longitudinal Study- Kindergarten) Cohort, found early mathematics ability able to predict reading, math, and science test scores up to eighth grade (Claessens \& Engel, 2013). These studies highlight the importance of school readiness in preparing the stage for future academic success. The conclusion that many early math researchers were making was that early math instruction was good preparation for organized thinking. The number system with its ten primary symbols and its nested base-ten framework, was a powerful tool for seeing patterns in all areas of the curriculum. When taught in an engaging and age appropriate manner, early math was a subject that appealed to young children in its predictability and its regularity.

Early math instruction has also been shown to promote another school readiness skill, self-regulation. In a Turkish study, number sense and self-regulation upon entry into kindergarten were both found to be strong predictors of academic achievement in middle school (Ivrendi, 2016). In another study with preschool students from Germany and Iceland, self-regulation skills correlated highly with early academic skills, including early mathematical skills (von Suchodoletz et al., 2013). In yet another one, self-regulation was found to predict math achievement gains from kindergarten to second grade, as well as 
predict the gap in math achievement that widened between kindergarten and second grade between high and low performers on self-regulation tasks in kindergarten (McClelland, Acock, \& Morrison, 2006). Early math skills and self-regulation are related, and teaching math from an early age is conducive to achievement through the fostering of selfregulatory skills. When learning math, children are taught sequence and order as well as specific routines (e.g., touching items as they are counted) that connect their thinking with doing. When they engage in solving math problems, they also use their growing math vocabulary to gain insight into their thinking and actions. This phenomenon can be obsreved in the increased amount of self-directed speech children exhibit when confronted by a challenging math problem.

Self-regulation is closely tied to the concept of executive function, which is typically subdivided into categories which include cognitive shifting, inhibitory control, and working memory. Research into some of these characteristics of executive function has yielded strong effects relative to mathematics as well. In a study using children from several Head Start classrooms, inhibitory control and working memory were significantly correlated to early math skills (Harvey \& Miller, 2017). Inhibition and working memory were also found to be closely related to early number knowledge (Shaul \& Schwartz, 2014). The link between working memory and early math skills is likely due to the notion that the memory load and information processing requirement are lessened by the internalization of early processes and information so early math foundational skills make the transition to operations much easier.

There are other ways in which self-regulation and executive function work to promote math achievement. Different measures of self-regulation and executive function 
are both correlated with fine motor skills and early academic achievement (Becker, Miao, Duncan, \& McClelland, 2014). Other studies have also found fine motor skills to be strongly correlated with later math achievement (Grissmer, Grimm, Aiyer, Murrah, \& Steele, 2010; Luo, Jose, Huntsinger, \& Pigott, 2007). Because of the concrete nature of children's early conceptions of numbers, math in early childhood classrooms is taught using manipulatives which enhance fine motor skills, as well as skills like number writing which are practiced on a regular basis. Fine motor skills have an inherent visual perception factor that enables this skill through hand-eye association (Luo, Jose, Huntsinger, \& Pigott, 2007). When fine motor skills, visual perception, and memory work efficiently together, number writing becomes automatic, which reduces the executive processing load, allowing for other operations to take place.

Another aspect of self-regulation, effortful control, has been correlated with later self-efficacy and mathematics achievement (Liew, McTigue, Barrois, \& Hughes, 2008). Early mathematics instruction has an effect upon this because children's self-efficacy goes up when they experience success and learn to attribute the cause of their success to their own knowledge and work.

Early mathematics instruction cannot be separated from self-regulation and executive function. These concepts are all intricately connected, and they are all at work as children learn about numbers and develop their understanding of the numerical system in the preschool years. Early mathematics instruction is essential not only for children to acquire the knowledge, but also to develop the cognitive mechanisms through which they can become ready to learn and succeed when they enter school. 


\section{Theoretical Framework}

Early learning in math is closely related to number knowledge, which describes how children understand the concept of number. It has been identified in various studies as having a strong correlation with later mathematical development. For instance, correlations have been found between basic number sense in kindergarten and arithmetic fluency in second grade (Locuniak \& Jordan, 2008), number sense and overall mathematics achievement (Sasanguie, Göbel, Moll, Smets, \& Reynvoet, 2013), and an approximate number system and later mathematics achievement (Bonny \& Lourenco, 2013).

Number knowledge describes how children understand the concept of number. The understanding of the concept of number moves from concrete to abstract, or from a counting principle at a very young age towards a number principle (Chi, Slotta, \& Leeuw, 1994). A counting principle limits children to very concrete mathematical experiences based on sets they can see, and often inaccurate representations of numerical magnitudes. However, when children move towards a number principle, they acquire the ability to carry out more abstract functions with numbers because they have an internalized notion of numbers and their meanings. It becomes possible for them to reason about numbers and more readily perform more elaborate calculations with them. Overall, it helps them to

lay a great foundation in mathematics that they can carry with them throughout the rest of their education.

Number knowledge is more than just a component of mathematical knowledge; it is foundational to all areas of the early math curriculum - measurement, pattern recognition, geometry, classification. Number knowledge is more like learning a 
language than a skill. Our number system (base-ten) has a specific alphabet, vocabulary, grammar and syntax just like spoken and written language. In fact, Asian-based languages that contain number words closely tied to the base-ten system have been linked to more accurate early representations of number (Chi et al., 1994). Number knowledge and language are intrinsically tied together.

Robbie Case's neo-Piagetian theory on central numerical structures describes these ideas thoroughly. Case proposed a theory of executive control structures with stages of development that correspond to Piaget's developmental stages. The executive control structures allow a person to represent a problem, articulate the objectives of problem solving, and create a strategy to solve the problem. The theory of central numerical structures is the direct application of the executive control structures to mathematical development. Case identified ages at which children progress through several different stages of number knowledge understanding, and identified the cognitive characteristics present at each stage (Case et al., 1996). As children progress in age, thy are able to comprehend and perform tasks that are increasingly abstract and complex.

The theory of central numerical structures posits that children have a conceptual system for understanding numbers analogous to a number line and that elements and relations are associated verbally through specific words, like "more than" (Case et al., 1996). The system is deemed to be procedural as well as conceptual, and as children move through stages in their development of number knowledge, their conceptual understanding of numbers changes and increases.

Case's theory suggests that number knowledge occurs as a result of the integration of separate but related conceptual understandings. When these conceptual 
underpinnings are interlinked, they create a powerful and flexible thinking frameworkin his work called a central conceptual structure for number. The framework acts like a semantic network in which each node of meaning activates all the others through their mutual shared connections. The more practice the child gets in using number, the stronger the connections. In this framework, the connections are just as important as the knowledge because they are able to communicate and share among themselves (Case et al., 1996).

Learning to read and write using the number system requires the same amount of exposure and use as any language. Certain number concepts and knowledge are inborn (Siegler, 2016), but once children start preschool they need to start learning the formal symbolic system that has been around for several thousand years. Just like language has foundational knowledge and skills that have to be mastered before children are able to be independent readers, number also has knowledge and skills that have to be mastered before children are able to move to operations.

Comparing the number system to a formal language is helpful to understanding how important it is and how it functions in the overall scope of mathematics learning. The number system, like any alphabet, maps abstract and mostly arbitrary symbols onto concrete amounts making quantity discrete rather than continuous, which is important for more exacting comparisons and combinations. Verbal languages do something similar by mapping symbols onto sounds (phonemes) that combine to create meanings and referents. Once the basics of the number system is learned it can then be expanded into a constantly evolving vocabulary with its own syntax (mathematical laws), grammar (operational symbols) and vocabulary. Early number knowledge leads to basic operations which lead 
to the use of multiples operations with rational number. Children who become good at math could be said to be fluent at it in the way that we say that children are fluent readers.

\section{Number Knowledge}

Number knowledge can be defined through concepts that describe how children understand numbers. Early number knowledge is centered around counting, as children move from a counting principle toward a number principle. The concepts that most broadly account for number knowledge in the early years are one-to-one correspondence, cardinality, ordinality, and number identification. Besides these, there are other important skills that build upon these basic concepts and correlate with math school readiness. These include counting, number comparison, number sequence, and number writing.

One-to-one correspondence is an integral component of early mathematics education. It is also called exact equality or equinumerosity. It is a concept that establishes that each number-word corresponds to only one object in a set. One-to-one correspondence was first identified by Gelman and Gallistel (1978) and, although it opposes Piaget's theory of early mathematics with respect to number conservation (1952), the concept of one-to-one correspondence has been shown to be implicit in children's ability to learn to count, and has laid the foundation for research in preschool mathematics since then (Sophian, 1988). One-to-one correspondence is intricately linked to cardinality. It is suggested that when they learn to count, children either employ oneto-one correspondence and cardinality or neither of the two (Sarnecka \& Wright, 2013).

Cardinality is critical to establish in the minds of young children and is closely tied to young children's conception of numbers, counting, and early mathematics. Cardinality refers to the number of items in a set. It has been juxtaposed with "the 
cardinal principle" which refers to the use of the last number-word to represent the amount of the sequence (Gelman \& Gallistel, 1978). Cardinality conceptually includes the cardinal principle to mean that children quantify the number of items in a set and assign the correct number-word to it. Seemingly simple, the cardinal principle is actually quite complex in the minds of children aged three to five. It not only involves attaching the quantity to the last number-word corresponding to a given set, but also works together with one-to-one correspondence to ensure that the last number-word is representative of the actual amount present (Bermejo, Morales, \& Garcia deOsuna, 2004). With experience, children can achieve an accurate conception of cardinality through counting. Once they have established cardinality, children can move on to the skill of number comparison.

Number comparison is important because it helps to establish an understanding of numerical magnitudes. Number comparison is the means by which children understand how big a number is in comparison to another. Several studies support the notion that a solid understanding of numerical magnitudes may lead to improved performance on other numerical tasks (Bonny \& Lourenco, 2013; Sasanguie et al., 2013). Interestingly, number line comparison studies among kindergarteners have found that they tend to exaggerate differences among smaller numbers and compress differences among larger ones. The tendency to exaggerate appears to be a developmental trait since they no longer tend to do this in second grade (Laski \& Siegler, 2007). Activities that provide practice with number comparison help overcome this perceptual deficiency. Number comparison is a skill that is important to the overall development of the concept of number. 
Ordinality, as the name implies, refers to the "operational understanding and significance of ordering, the principle of a numerical reference to position" (Bob \& Threlfall, 2004, p. 7). Yet, ordinality is not limited to learning the ordinal number names. Piaget's work on ordinality supports the notion that children acquire an understanding of the ordinal aspect of number without knowledge of the ordinal names (Piaget, 1952). Even so, other studies have shown that the use of ordinal names is a great aid in helping children understand the concept of ordinality (Bob \& Threlfall, 2004). Ordinality is linked to the notion of number sequence, which is tied to children's mental number line, and these are foundational to developing the concept of number.

Number sequence is related to the concept of ordinality in the sense that it deals with the order of the number-words used, but not in a positional manner. Here, it refers most importantly to a type of mathematical skill often called "counting on." The skill of counting on is considered the best predictor of performance on other numerical tests and plays a key role in the development of children's arithmetic performance (Johansson, 2005). Exposure to number sequence tasks is fundamental to the development from a counting principle to a number principle.

Number identification is a key concept that young children must learn to establish early numeracy. As a matter of fact, number identification is commonly found as a curriculum-based assessment measure of early numeracy, and there is a relatively high validity for this measure with respect to essential math skills required for school readiness (Lee et al., 2012). It requires children to associate number symbols with their corresponding number-words and cardinal amount. Number identification is an advanced, abstract concept that serves as an important tool in moving children from a counting 
principle to a number principle. It requires visual perceptive skills which can be developed and reinforced through repeated exposure using different media.

\section{Number Writing}

Number writing is an important skill in early mathematics that is key in helping children to identify number symbols, and also influences their concept of number. Zhou and Wang (2004) compared Chinese and English children's early conceptualizations of number and found that those with better symbolic representations of numerals performed better on math assessments because "children's ability to represent written number symbols closely relates to their cardinal concept" (p. 253). Also, it opens their number knowledge to communication with adults and the use of tools such as calculators. Number writing is a beneficial tool in moving children toward a number principle.

Number writing is conventionally considered a tool, closely linked to the abstract symbolic representations that children must learn to assign to numbers. Implicit in each number symbol is the discrete amount that each number represents, with the aim of facilitating numerical operations. These symbols were developed over thousands of years and have the intrinsic ability to enable communication between people who may not even speak the same language. However, there is something more to the process of learning to write these number symbols that plays an important role in children's conception of number.

Numbers are what are referred to in semiology as second order symbols (Laupa \& Becker, 2004). That is, they are mostly arbitrary abstractions of first order symbols that have a tangible or analogous relationship to the thing they represent. Tally marks, or fingers for that matter, are first-order symbols in that they have a one-to-one relationship 
with the objects they represent. They are limited in their power to represent larger numbers in that they cannot represent cardinality and cannot be regrouped into higher ordered place values. When learning to write true numbers, a child must cognitively see beyond the one to one relationship between tallies and fingers to embrace the idea that symbol stands for a class or set of objects.

Second order symbols typically are not grasped until around the age of four in language development, (Goodman, 1976; Rosenblatt \& Winner, 1988) when children move from bananas standing in for phones, to unicorns as symbols of magical beauty. Following Saussure's ("F. de Saussure's Theory of Language," 1984) ideas of a twotiered construction of language ("langue" or the invisible layer of meaning, and "parole" the actual speech) it is easy to understand a two-tiered or even a multi-tiered construction of number.

A further element of complication comes with the learning numbers representing higher amounts. It is relatively simple for a child to grasp the number symbol as representing sets of 1,2 , or 3 , but takes a greater ability to perceive the connection between the number 8 and its corresponding set of discrete objects. Even harder are twodigit numbers with their representations of two classes of numbers.

Given the complexity that surrounds number writing, it is a bit surprising that the body of research available on number writing as such is limited. Perhaps the low availability of research on number writing is because researchers have not given number writing the cognitive and procedural importance that it deserves. While there is ample and readily-available research on letter writing and the connection between it and letter recognition and other such measures, there is a limited body of works exploring the 
connection between number writing and number knowledge. Even so, research on letter writing may shed light on the effects number writing, and the processes through which it may influence the development of number knowledge. A study on children's ability to represent systems for both letters and numbers found that children are unable to distinguish between representational systems under the age of two, but rapidly develop after that age, primarily drawing, followed by numbers writing and then letter writing (Yamagata, 2007). In that study, it is suggested that children draw upon a "common core of indistinguishable products" when learning to produce items from number or letter representational systems (p. 255). This could signify that the early foundations of number writing are similar or concurrent with those for letter writing, although the implications for the development of learning mathematics are much different.

In a study with preschool children writing letters and numbers, it was found that children with strong letter-naming skills correlated with strong letter writing skills as well as strong number-writing skills (Molfese, Beswick, Molnar, \& Jacobi-Vessels, 2006). Further research on this found that grading the writing using a more rigorous scale that accounted for vertical orientation and left-to-right orientation had no effect on correlations between letter naming and letter writing (Molfese et al., 2011). The results of that study suggest that when children learn to represent letters symbolically, they learn to attach these components as well. In terms of writing numbers, these studies may signify that the same mental processes involved in representing letter symbols by association with letter names are present writing numbers as well.

There is a point in the early development of a child where they learn to distinguish between writing letters and writing numbers. They realize that they have 
different purposes and serve different functions. For example, when preschoolers were asked to identify notecards that were unreadable, they would identify the ones with repeated letters, such as "TTTT," but they were not as likely to pull out those with repeated numbers, such as “4444” (Tolchinsky Landsmann, 2003), suggesting that although there are aspects of number recognition that may be shared with letter recognition, children are able to identify differences between these two symbolic systems from an early age.

As far as research on number writing, it has been proposed that children develop early representational systems to identify numbers before they move on to learn the number symbols. Four types of number representations are identified: idiosyncratic, which includes scribbles and pretended writings that are not related to the quantity, pictographic, which represent the quantity as well as qualities of objects in a set, iconic, which are markings that in one-to-one correspondence the quantity in a set, and symbolic, which are the conventional numerals. Once children learn to read, write, and understand the meaning of written number symbols, they move from a concrete-based system to one defined by abstraction (Zhou \& Wang, 2004). At first, young children tend to resort to drawings and iterative marking to represent quantities, before they learn to use numerals (Tolchinsky Landsmann, 2003). In other words, children go from a general representation of a set that corresponds directly to the quantity as well as other characteristics, to a specific abstract representation that includes the inherent numerical information. When children learn to write number symbols, they learn to associate the concrete meaning of numbers with their symbol, (Stoianov et al., 2004) without needing a visual 
representation of the concrete, which, from a cognitive development perspective, is related to the notion that children learn numbers through symbolic encoding.

To achieve symbolic encoding of numbers through number writing, several components must be present, namely fine motor skills, visual perception, and memory (Hildreth, 1932; Rhodes et al., 2017). These components are all related to executive function. Executive function is involved in all the mental processes of the brain. It has been found, in several of its facets, including inhibition and working memory, to be closely related to number knowledge (Shaul \& Schwartz, 2014). Besides this, executive function has also been linked specifically to number writing. In one study, number writing is significantly correlated with three measures of working memory (Simmons, Willis, \& Adams, 2012). In another study, working memory and counting ability were positively correlated with math achievement (Passolunghi, Vercelloni, \& Schadee, 2007). It is very likely that working memory, or even executive function as a whole, works as a mediator between number writing and number knowledge, which is likely because proficiency in number writing may help reduce the cognitive load in associating cardinality and number symbols and lends itself to abstract processes such as arithmetic.

When number writing becomes automatic, it takes up very little executive processing load (Simmons et al., 2012). Automaticity, in turn, frees up working memory for other tasks like solving math problems. It is as if much of the work can be offloaded to muscle memory. More practice writing numbers also helps children to make quick and accurate distinctions between similar looking symbols (e.g., 6 and 9, 2 and 5) and helps to further decluttering the child's thinking (Barrouillet, Camos, Perruchet, \& Seron, 2004; Camos, 2008; Gavens \& Barrouillet, 2004). A further advantage may have to do with the 
compressing of number knowledge into a powerful symbol (Gelman \& Gallistel, 1978;

Stoianov et al., 2004), so that when a number is written, the number knowledge that has been accumulating becomes available to the child. Symbolic encoding of number becomes an efficient way of storing and accessing the information needed to solve early math problems.

Given the importance of number writing to young children's mathematical development, it is important to address the fact that writing by hand is an activity in danger of becoming extinct due to the increasing use of technology. Technology is being used as an aid in classrooms worldwide, and in almost every age group. Tablets, in particular, are considered very interactive for young children. Research has shown that when technology is integrated in the classroom from an early age, student achievement increases in the long term (Aronin \& Floyd, 2013). There are many apps available for children to hone a variety of mathematical skills using technology, and there are many ways to use technological devices within the classroom. An analysis of models for math technology use in preschool classrooms yielded various designs that account for the ways in which technology may be used in the classroom to teach math, including a model in which there is a limited number of devices and students rotate their use, and one in which each student has his own device (Craig, 2000). Either way, teachers are seeking ways to integrate technology into the way children learn, as well as prepare them to enter school with certain technological skills that are necessary in today's educational system. In 2018, Florida adopted a computer-based school readiness assessment upon entry into kindergarten, discarding the orally administered one that was formerly used. If students 
lack the skills necessary to demonstrate their knowledge through technological means, they may score lower than their actual level.

There are many ways to teach math concepts, including number writing. It is important to keep students motivated and interested in math to help them with their learning. In a Belgian study, characteristics of the learning environment, such as the extent to which the teacher motivates students to learn mathematics, were positively correlated with student enjoyment of mathematics (Vandecandelaere, Speybroeck, Vanlaar, De Fraine, \& Van Damme, 2012). Another study found a positive correlation between mathematics attitude, academic motivation, and mathematics achievement (Moenikia \& Zahed-Babelan, 2010). There is evidence that games as simple and Chutes and Ladders have an enormous impact on the way young children comprehend mathematical concepts (Cavanagh, 2008). Games can provide students with motivation and arm them with a positive disposition toward mathematics, which can help increase their academic achievement in this subject area. 


\section{CHAPTER III}

\section{METHODOLOGY}

The current study is a quasi-experimental mixed-methods study. It uses quantitative analysis of scores on standardized assessments, and scores from a number writing inventory, as well as qualitative analysis of videos of children writing their numbers, and an analysis of the children's actual number writing at the beginning, middle

and end of the school year. A classroom of 15 Pre-K children in a Florida VPK classroom form the primary unit of study. The scores of a comparison group of children is included at post-test to give contrast and meaning to the intervention group's number writing.

\section{About the VPK Program}

VPK is the abbreviation for the State of Florida Voluntary Pre-Kindergarten, the free, three-hour school readiness curriculum that is available to all four-year-old children in the state who turn four before September $1^{\text {st }}$. Voluntary Pre-K (VPK) began in 2005, three years after it was passed by voters in a state-wide citizen's initiative. Private, nonprofit, faith-based and public schools are eligible to apply for VPK funds, and parents can choose to send their children to any centers that meet state VPK qualification.

Florida's VPK initiative is part of the nation-wide universal Pre-K movement began with the school reforms of the late 1980s. In the Goals 2000 proposal first presented at the 1990's national governor's conference, and later included in the educational agendas of both President George H.W. Bush and Bill Clinton, the first goal was to "By the year 2000, all children in America will start school ready to learn," as stated by the National Educational Goals Panel in February 1998. Many states including 
Georgia, New Jersey, Oklahoma began to create different versions of universal access to pre-kindergarten. Florida's VPK followed in the wake of these efforts.

A VPK center was chosen because this program is the largest school readiness program in the State of Florida, serving approximately 180,000 children a year. Insights from Number Writing in this study could potentially benefit children in similar programs throughout the state. The Florida VPK program has been commended for making Pre-K accessible to large numbers of children, but criticized for spending too little on its programs, and providing poor quality, although this seems to be steadily improving (Bassok, Miller, \& Galdo, 2016; NIEER, 2013).

Most VPK centers, like the one in this study, serve and reflect their local community. The chosen center is a private, faith-based center with approximately 80 children enrolled. As part of the requirements for funding the program must adhere to the VPK Standards for Four-Year-Olds and administer the VPK Assessment three times a year (for more specifics on VPK standards see Appendix A).

\section{Environment of the Study}

The study takes place in a VPK center in a low-income neighborhood in Miami. The classroom is located in the basement of a church in a mostly immigrant neighborhood, a short drive from the towering skyscrapers of downtown Miami. Small Latin American restaurants and bodegas line the busy street fronting the school. Other small businesses e. g., car repair shops, check cashing, dollar stores, their signs in Spanish, complete the retail landscape. On side streets are the one- and two-story apartment buildings, painted in the greens, blues and pinks of the Caribbean, from which the majority of the children come. 
The daycare was once a private school, founded in 1967. The church building itself is even older than that, dating to the beginning of the twentieth century, about as old as the neighborhood itself. The neighborhood is in the heart of what is known as Little Havana, named for the large influx of Cuban exiles in the aftermath of the 1959 Cuban revolution. Today it is home to more recent waves of immigration from Central America and the Caribbean.

There are signs of economic renewal at the fringes of the old neighborhood (a new, ultra-modern baseball stadium has landed like a giant flying saucer where the crumbling county stadium used to rise), but the area is still largely poor, Hispanic, and immigrant. The economic status that makes up the residents of this neighborhood is significant because this neighborhood and this center are highly representative of Hispanic-serving centers across the nation. Over $90 \%$ of the families served at this center are poor Hispanics that live in the immediate area. Many of them walk their children to school and take public transportation to move around the neighborhood. Hispanics makeup a large sector of children in the school system, forecast to be $25 \%$ of school-aged children by 2030 (Garcia \& Miller, 2008). They are, however, a largely underperforming group. There is a considerable gap in academic achievement between Hispanics and Whites, in measures such as AP (Advanced Placement) class enrollment, SAT (Standardized Achievement Test) performance, high school graduation, and college enrollment (Burkham, 2019; Garcia \& Miller, 2008). Universal preschool programs serving Hispanic children are a great way to begin to close that gap.

The entrance to the center from the busy Seventeenth Avenue sidewalk is a few steps down into the main room. As soon as you walk in in the morning, the smell of 
home-made Cuban-style cooking greets you. A large multi-purpose room, bathed in florescent light, serves as the main hub, corridor, and assembly hall. Children and teachers criss-cross the large, open space to access bathrooms, kitchen and passage to the outside. The room also serves as rehearsal space, rainy day video viewing, and nap-time for the older children. The VPK classroom is located in the largest classroom at the far corner of the center.

The classroom has two teachers for 17 children. Both are themselves immigrants whose native language is Spanish but speak relatively fluent English. One of them is from Cuba. She completed three years of college in an unrelated (non-education) field before coming to the United States, the other immigrated as a young child and completed most of her schooling in the United States. She completed her high school diploma here. Both teachers have their Florida Child Care Professional Credential (FCCPC), but do not have a bachelor's degree. They are typical of many teachers in the VPK system, especially since teaching at private childcare centers is also a low-paying job, and it tends not to attract teachers with high credentials. In Miami there is a large selection of VPK teachers that are immigrants with the minimum qualifications required for the job and are not highly fluent in the English language.

Of the 17 children in the classroom, 15 are included in the present study. One child with special needs (Edward) who had an aide and began late in the school year was excluded from the study, as well as one child who left before the school year was over because she was extradited to her country of origin. 


\section{Student Demographics}

Most of the children in the center come from Hispanic, primarily Spanishspeaking households, whose parents have little education and low income, which is typical for many centers in Miami-Dade County, and other majority Hispanic counties throughout Florida. By choosing a program serving a Hispanic population, the study should generalize to an important and growing sector of the early childhood population in Miami, Florida, as well as other parts of the United States.

Issues of bilingualism and biculturalism are important to consider, even when working with mathematical concepts. Communication - whether it is from teachers to children, teachers to parents, or parents to children - is dependent on language.

The present study focuses on a population of low-income children in order to try to shine a light on a large percentage of the population that is most at risk for math failure. Low-income children also make up a large percentage of VPK programs in Miami and Florida.

Another important aspect of the center is that it enrolls a largely immigrant population. Recent immigrants, or even the children of recent immigrants are a growing population in Miami-Dade County, as well as in many other urban centers. The families come from many different countries from Central and South America and the Caribbean, bringing with them unique cultural practices.

Most of the 15 children are first-generation Americans. Only three of the children are second-generation Americans. Of the three, one has one parent who is a nonimmigrant. The children's families are from different parts of Central and South America 
and the Caribbean, including Nicaragua, Honduras, Guatemala, Colombia, Puerto Rico, Cuba, and the Dominican Republic.

The family structure of many of the students is varied. Seven, which is approximately half of the students in the study, have parents that are divorced or separated, and live with a single parent, or a parent and an unmarried partner.

\begin{tabular}{|c|c|c|c|c|c|}
\hline \multicolumn{6}{|c|}{ Students' Demographic Information } \\
\hline Student & Parents' Highest & Parents' & Income level & Primary & Parents' \\
\hline ID & Education Level & Country of Origin & & Language & $\frac{\text { Marital }}{\text { Status }}$ \\
\hline 11801 & High School & Colombia, Puerto Rico & Lower-Middle & Spanish/English & Married \\
\hline 11803 & $\begin{array}{l}\text { Less than High } \\
\text { School }\end{array}$ & Honduras & Low & Spanish & Married \\
\hline 11804 & High School & Honduras & Low & Spanish & Married \\
\hline 11805 & High School & Nicaragua & Low & & Married \\
\hline 11806 & Some college & Nicaragua & Lower-Middle & & Married \\
\hline 11807 & High School & Cuba & Low & & Single \\
\hline 11808 & Some college & $\begin{array}{c}\text { Dominican Republic, } \\
\text { USA }\end{array}$ & Lower-Middle & Spanish/English & Single \\
\hline 11809 & High School & Honduras & Low & Spanish & Married \\
\hline 11810 & High School & Honduras & Low & Spanish & Single \\
\hline 11811 & Some college & Cuba, USA & Lower-Middle & English & Separated \\
\hline 11812 & High School & Honduras & Low & Spanish & Married \\
\hline 11813 & High School & Cuba & Low & Spanish & Single \\
\hline 11814 & High School & Honduras & Low & Spanish & Single \\
\hline 11815 & High School & Honduras & Lower-Middle & Spanish & Married \\
\hline 11816 & High School & Guatemala & Low & Spanish & Single \\
\hline
\end{tabular}

Besides the students' families, other important demographic information includes age and gender of the children. Of the fifteen children included in the study, five are boys and ten are girls, which is a bit disproportionate. With respect to age, although all the children were four years old upon entry to preschool, some of them turned five as early as September and others as late as June. The difference of nine months can have appreciable developmental implications (F. L. Huang \& Invernizzi, 2013). The children's age in 
months on September $1^{\text {st }}, 2018$ are plotted in Figure 1. Nine of the students turned five years old in the first half of the school year and six of them did so in the second half of the school year. There are no students who turned five in July or August. The difference is not so great between the oldest and the youngest child in the class, and a vast majority of the students have a certain level of developmental maturity.

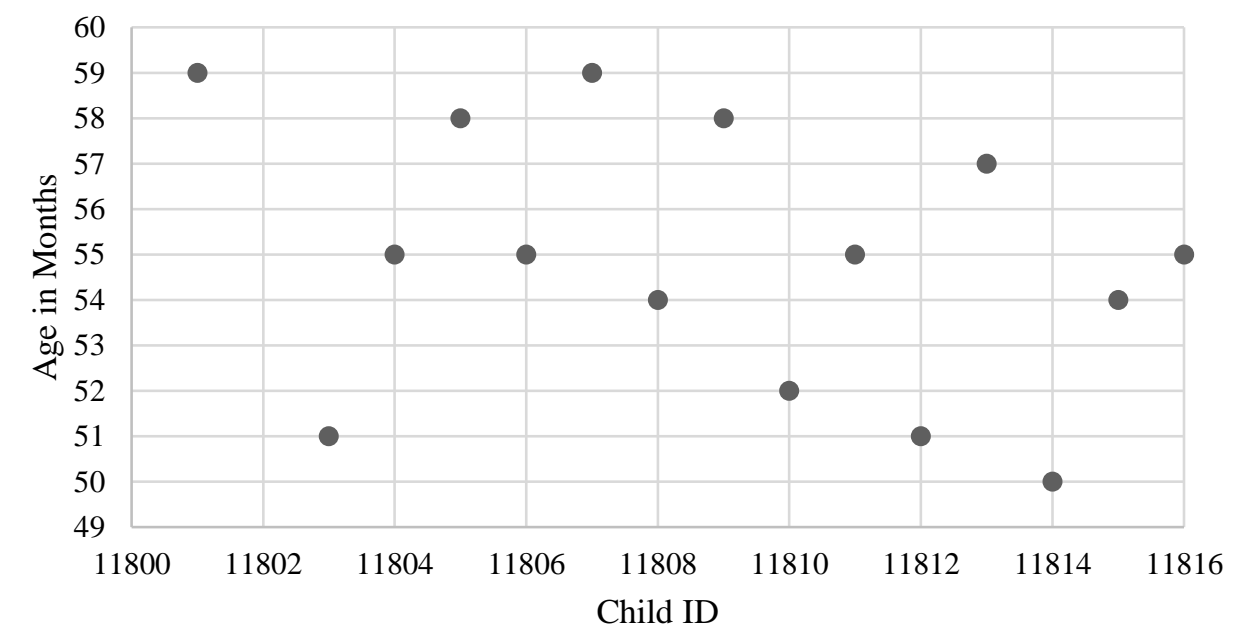

Figure 1. Students' age in months on Sept. 1, 2018.

\section{The Comparison Group}

For the comparison group, children were selected from three centers belonging to the Redlands Christian Migrant Association (RCMA). These centers are part of a group of centers that cater to low-income migrant worker population throughout the state of Florida. The four centers are located in Homestead. A majority of the students in these centers come from families in which the parents are agricultural workers who stay in the Homestead Area. The small number of children who are migrant workers' children were not included in the study because they are very low performers and did not make for an equitable comparison to the intervention group. The other children are approximately 
equivalent to the children in the intervention group, except their parents work in agriculture in Homestead.

Most of the children in the RCMA centers also come from Hispanic, primarily Spanish-speaking households whose parents have little education and low incomes. The biggest difference is that the parents of the RCMA students are mostly field workers, whereas those from Calvary Baptist tend to work different types of jobs, such as construction, housemaids, etc. These centers also participate in the state's VPK program and assess their children three times a year using the standardized VPK Assessment. They did not receive the intervention, so they will be treated as an approximately equivalent control group. The RCMA centers use the long running High Scope Curriculum, which is constructivist in nature and emphasizes "that children construct their own learning by doing and being involved in working with materials, people and ideas" (Nutbrown, 2011, p. 70), whereas Calvary Baptist uses the Creative Curriculum, which is similarly constructivist, and aims to "foster the development of the whole child through teacher-led small and large group activities" (What Works, 2009, p. 1). Both are approved for use by VPK and are widely used early childhood curriculums. Children in both groups learn to write numbers as part of each of these curricula, but only one group had the added experience of learning and practicing number writing as part of the supplementary curriculum.

\section{The Intervention}

The NumberWays Pre-K intervention is a supplementary math curriculum based on 24 games that were taught to a group of preschool students. These games focus on building the concepts of number identification, number comparison, number writing, and 
number sequence. As part of this intervention children were systematically taught number writing in the service of the games they played. The games were taught in small groups following a specific sequence- board game, active game, activity, and card game. The cycle was completed twice with each number group, starting with 0 through 9 , later 0 through 19, and 20-29. Approximately two weeks were spent on each game, in order to complete the intervention with all children in the experimental group. The program lasted from the beginning of the school year, in September, to the end of the school year, in May. For a complete list of the games and their descriptions, see Appendix B. The games were recorded in video for qualitative analysis of the progression of math learning and number writing.

Number writing was integrated as part of each game. It was not taught by rote, but rather incorporated into each game such that the writing of numbers facilitated each game. To name some examples, in the "Rainbow Ruler" game, students had to construct their own (non-standardized) ruler by writing the numbers along a line with markings, each in a different color. In the "Monkey Math" game, students had to create their own paper bills by writing the numbers on paper and cutting them out in order to buy bananas based on the quantity represented on each bill. Similarly, the students designed their own decks of cards to play the "Card Game" and the "Memory Card Game". In short, the number writing is integral to the playing of the games, and lends a sort of importance to the task of number writing, not just practice of the skill.

Pre-K-aged children (ages four to five) were selected for the present study for a specific reason. The preponderance of evidence from developmental studies of children's number knowledge (Case et al., 1996; Y. T. Huang, Spelke, \& Snedeker, 2013; Sarnecka 
\& Carey, 2008) have shown that before the age of four children have a hard time conceiving of the concept of numbers beyond the number three. They also do not connect number words with their referents or have an understanding the there is an invariant sequence with universal rules (e.g., each number is exactly one more or less than the next number, as numbers go up the scale they refer to larger quantities, the last number is the set or cardinal number). Even though a two-year-old may hold up two fingers and proudly, and correctly state that she is two, this declaration amounts to little more than a nominal use of the term. At the age of around four-years-old, though, children start to understand that numbers operate in a rule-governed system that has multiple representations, and that maintains its relations beyond the first few numbers. As children approach four years of age, they make a leap in conceptual, organizational and memory prowess that allows them to learn the beginnings of the base ten number system. Not coincidently, at four years of age, children also learn pre-reading skills.

As it relates to number writing, the fourth birthday marks a turning point in the ability to understand that the number symbol refers to a certain amount, and that that symbol is part of a symbolic system to describes in precise terms quantity.

Number writing at four-years of age, even though it is possible developmentally, does not happen without growing up in a culture in which such a system is used, and without it being directly taught (Yamagata, 2007).

\section{Data Collection}

The data for the present study were collected throughout the 2018-2019 school year. For the experimental group, number writing was collected at pre-, mid-, and posttest, as well as an overall measure of math readiness, the Number Knowledge assessment, 
and a simple number counting measure (the highest number children can count up to without skipping a number) at these three intervals as well. For the control group, these data were collected only at the end of the year. The assessments were all recorded in video for qualitative analysis as well. The VPK Assessment results for the three assessment periods were collected for all participants in the study. Raw scores from the Florida VPK Assessment were used to measure school readiness. This assessment also serves to establish equivalency between the experimental and control groups.

The VPK Assessment, a school readiness assessment, is administered three times a year by a trained assessor. It is used throughout Florida in all VPK classrooms. The VPK Assessment is a research-based progress monitoring assessment that looks at specific early literacy and math skills that are predictive of children's future educational success developed by The Florida Center for Reading Research (Lonigan, 2011). It was developed in 2010 and field tested from 2010 to 2012 before it was made mandatory as a pre- and post-assessment by law. The VPK Assessment consists of four measures: print knowledge, phonological awareness, mathematics, and oral language/vocabulary. It is designed so that the questions become increasingly difficult with each of three assessment periods - a pre-test in September, a mid-test in January, and a post-test in May. Training for classroom teachers and school administrators is readily available.

The development of the VPK Assessment Measures consisted of "an iterative process of item development, field testing of items, and item selection that culminated in a field trial of the measure by VPK Classroom teachers" (Lonigan, 2011, pp. 1-5). The research team from Florida State University used an Item-Response Theory (IRT) approach for final item selection, with "item selection governed by both the goal of 
retaining items that spanned a wide range of difficulty levels and that maximized the reliability of the specific measure" (p. 2-1). For the reliability of the math measures in particular, it was determined that the three versions of the Math measure provide adequate measurement precision across a wide range of abilities. The math measure also had the highest test-retest reliability across assessment periods of all the assessment measures.

In terms of validity, content validity was derived by aligning the measures with content from the Florida VPK Standards (Lonigan, 2011). The predictive validity of the VPK Assessment Measures was measured by examining how well children's scores on the VPK Assessment Measures predicted scores on other measures administered to children when they entered kindergarten, included the measures used to establish kindergarten readiness (i.e., FAIR-K, ECHOS). These measures of kindergarten readiness were the ones when the assessment was developed. They are no longer in use in the state of Florida. They have been replaced by the STAR Earl Literacy Assessment, which is an online, adaptive instrument that students complete independently in approximately $15-20$ minutes. The content validity of the VPK Assessment with respect to this new assessment is unclear.

The Number Knowledge test is a developmental test created by Okamoto and Case in 1996 (Case et al., 1996). It was developed using students from kindergarten through fourth grade from two private schools in the San Francisco Bay area. Items in the assessment were designed to include students in a developmental level above typical fourth grade students, as well as below kindergarten level. The latter are suitable to measure number knowledge in pre-kindergarten students and as early as three years old. 
The Number Knowledge test was later standardized and used in 436 kindergarten and 483 first-grade students in seven schools in the Pacific Northwest (Chard et al., 2005).

The Number Knowledge test (Case et al., 1996) is designed to measure students' progression through various stages of development in number knowledge, particularly with regards to central numerical structures. The first level is denoted "pre-dimensional," and is limited to an understanding of rote counting without actual quantification. The level is most common in preschool-aged children. The second level is "uni-dimensional," and denotes a basic understanding of the mental number line. The level begins to include abstract concepts, and necessarily involves a conceptualization of the quantifiable value of numbers and their magnitude. It is common for children up to age 6 to be at this level. The third level, "bi-dimensional," represents a higher level of thought, in which children are able to coordinate two number lines in order to reason about problems. Associated with the bi-dimensional stage is the ability to add tens and ones in a base-ten structure, and the ability to view the difference between two numbers as an "object." The level was more attainable by children at least 8 years of age. The last stage is called "integrated bidimensional," and it goes even further than the previous bi-dimensional level to construct and compare two sums or differences, rather than just one, as well as that the same additive principle applies to each successive pair of columns, and situations where two variables "trade off" or "compensate" for each other's operation in a subtractive manner. During the assessment, students must correctly answer at least half of the items for each level correctly in order to move on to the next one. The last level was more commonly achieved by children at least 10 years of age. 
The predictive validity of the Number Knowledge test with respect to Stanford Achievement Test, Ninth Edition (SAT-9) was investigated in a later study (Baker et al., 2002). Researchers found that spring of kindergarten performance on the Number Knowledge test correlated highly with the Problem Solving and Procedures subtests of the SAT-9. The study by Baker et al. has been the only study of its kind with respect to the Number Knowledge test.

In addition to the use of the VPK Assessment and the Number Knowledge test, a number counting and number writing item were added by Bleiker (2015) in his study on the effects of a Pre-K early math intervention. Number counting is a question on recall of the naming of the numbers without skipping any. The highest number recounted without skipping any is the score. The number writing item is the recall and ability to write the number 1-9 with left-right orientation.

The assessors in the present study were Dr. Charles Bleiker and myself, Giselle Hernandez. We are familiar faces at the school, since we have been working with preschool students at this center for several years. Over the course of several years, we have been administering the Number Knowledge test, so we are quite familiar with it. We have both worked with students in the preschool classrooms at the school over the span of five years, developing the NumberWays curriculum.

The assessment process is simple. The students are called one-by-one to a separate, unused classroom where the assessor and an aide for video recording are waiting for the student to begin. The student walks in, takes a seat, the aide begins recording and the assessor begins the assessment. In the first assessment period, the assessor first introduces himself or herself and asks the child in which language the child 
feels more comfortable doing the assessment. The introduction was not done in subsequent assessments because the students already know the assessors well and have been undergoing a constant learning process in English, so it is safely assumed that their performance in English would be adequate. First, the children are asked to count as high as they can, without being given any help. Then, they are handed a white piece of paper and prompted to write the numbers from one to nine, pointing out where to write, and giving prompts about the following number. After they are done with this task, the paper is collected, and the Number Knowledge assessment begins directly. The process is recorded using a high-resolution phone camera.

Number Writing assessments were scored using the Early Number Writing Scale (Bleiker, 2015) by four scorers. The scale has been shown to be reliable and easy to score with only minimal instruction. The 5-point scale (1 being rudimentary and 5 being mastery) was derived from a qualitative evaluation of 80 number-writing samples of prekindergarten aged children. It considers whether the markings made by the children resemble the actual number symbols, whether numbers written are reversed, and whether the numbers are approximately the same size and written along an approximately straight line (see Appendix C). It provides a comprehensive notion of the level of preschool students' number writing.

This assessment is in the process of being standardized, but more data is required for this process. However, it serves as a good heuristic for evaluating preschool number writing samples. The inter-rater reliability for the number writing scale on this study was $87.5 \%$ for the pre-test, $81.25 \%$ for the mid-test, and $80.56 \%$ for the post-test using the 
number writing scale. The overall average inter-rater reliability for this measure of assessing number writing was $83.10 \%$.

Descriptive analysis of writing samples was used to answer the following question: What level of number writing do at-risk pre-kindergarten students have at the beginning and end of their pre-kindergarten year in a school that offers Florida's VPK? It is also used to address the question about the developmental stages of number writing. Number writing is a graphic medium that has some similarities to children's drawing. Even though children are often inventive and creative in their drawing of iconic shapes (Kellogg, 1973), certain patterns do emerge that can help track the variant in the development of drawing. It is highly likely that a similar progression takes place in number writing. It is anticipated that as children struggle with the problem of writing their numbers, they will go through some of the same graphical variants as they do in their progression of scribbling or drawing figures. The best way to test number writing is to actually look at the drawings from a large enough sample (e.g., 100) and describe the patterns that emerge. It is assumed that the children will vary by age, home environment, and education, so no attempt will be made to control for these factors, just as teachers cannot control for the variance of the children they get at the beginning of the year. This analysis gives a snapshot of what a teacher in a VPK program serving low-income families in Miami might find.

Videos of Pre-K children throughout the year attempting to write their numbers analyzed using task analysis (Gagne, 1974) addresses the question: What are the developmental stages in number writing? Task analysis allows for close examination of how the process of writing numbers unfolds throughout the learning process. A list of all 
the necessary steps for successful number writing was compiled from these data. Prerequisite skills for successful number writing were also extracted through this type of analysis, and each child's number writing pre-, mid-, and post-tests (as applicable) were analyzed for presence or absence of these skills. In addition, other features such as body language and verbal comments were noted for further insight into the child's train of thought while carrying out this activity.

The other two research questions - Does teaching number writing through math games produce better number knowledge development as well as number writing improvement than only traditional teaching methods? Is there a correlation between competency in number writing and achievement in early math scores at the beginning, middle, and end of the year of the preschool year? - are answered statistically. The first of these is answered using a quasi-experimental design, in which the control and experimental groups are compared to determine which had better number writing and math scores on the VPK Assessment at the end of year. The second of these questions is answered through statistical analysis using a repeated measures design with number writing scores being the independent variables and VPK Assessment scores the dependent variables. Additionally, regression analysis is used to determine if children at different levels of number writing increase at the same levels or at different levels. A regression analysis sheds light on whether children's scores are stable or if they improve at the same level. 


\section{CHAPTER IV}

\section{RESULTS}

\section{Qualitative Data}

One of the first questions this analysis seeks to answer is what is the pathway that children go through on their way to mastery of number writing. There are few studies that have actually studied children's number writing from the beginning of Pre-K to the end (Tolchinsky Landsmann, 2003; Yamagata, 2007; Zhou \& Wang, 2004). Number writing for adults is something that is second nature, and it is easy for us to forget the difficulties or misconceptions we had. Writing numbers involves a motor component, a memory component, and a conceptual or cognitive component.

The qualitative analysis in this study focuses primarily on the experimental group. I first analyze the 16 number writing samples of the children at the beginning, middle and end of the school year to describe the range and variety of number writing as a crosssectional study. Secondly, I describe the development of three separate children from the beginning of the year to the end, drawing on their writing samples but also video of their number writing. I chose one child at the low end of the number writing scale, another in the middle, and the third at the high end of the scale at the beginning of the year in order to see if the starting point is a main determinant of where you end up.

These two analyses attempt to answer different but complementary questions. The

first attempts to uncover the range of abilities a teacher might expect at the beginning of Pre-K with respect to number writing, and the subsequent change over time during the Pre-K year. This is important for teachers to know if they are going to be able to adequately prepare all children for writing their numbers. One logical hypothesis is that 
the gap between children would be larger in the beginning based on the differences in experiences before arriving in Pre-K. Some children will have been in preschool the year before. Some might have parents or older siblings who taught them at home. Other children might not have had any school prior to Pre-K and therefore know little or nothing about numbers or number writing. The instruction and practice during the year should help them to close the gap with children who come to Pre-K with more preparation. It may also be that the lowest children will have a harder time reaching mastery based on cognitive, memory or motor deficits. Some children may struggle more than others with this skill. Another possible finding is that some children are much better at graphical representation and learn to write and remember the symbols easily, while others will struggle with a kind of graphical dyslexia. In this case practice and instruction would show differential outcomes. Exposure and instruction (nurture, effort) would reign in the first and ability (nature) in the second.

The second analysis focuses on the specific steps that individual children go through as they struggle to master number writing. One hypothesis is that children would follow a similar progression and timetable with only slight variations. This would suggest strong underlying systemic restraints (memory, processing ability). Another might propose that number writing is more of an individual journey, with each child plotting his or her own course. This would suggest fewer stage-like biological constraints, and more influences of teaching and personal interest.

Added to these possible outcomes are potential gender differences associated with small motor difference and attention and executive functioning. There is a common perception that boys have a harder time with fine motor activities that include writing 
(Comuk-Balci, Bayoglu, Tekindal, Kerem-Gunel, \& Anlar, 2016). It is not known if this is due to lack of instructions and practice, or just disinterest. This analysis looks at possible gender differences to test whether the boys and girls in this classroom start off at different skill levels and follow the same trajectories.

\section{Overall Number Writing}

The first week of VPK is a hectic one. Children who turn 4 years old by September $1^{\text {st }}$ are eligible for Florida's free, 9-month school readiness program. That means that many children whose parents were not able to afford preschool can now enroll them. These children have often been cared for at home or in custodial care with little academic focus. VPK, with its focus on school readiness is often the first time that these children have been in a classroom setting. They are not used to following directions, sitting for extended periods of time, or engaging in academic activities. Typically, they have little or no formal knowledge about number, counting, or quantifying. They may have watched television programs or played phone Apps that had math objectives, but they appear to have little practice with math beyond this. One thing that appears to be missing is a lack of number writing practice, or even practice at making marks with a pen or paper. What may be happening is that even the act of scribbling on scrap paper enjoyed by generations of children is being replaced by tapping on a screen.

For other children, VPK is just an extension of preschool. The center at which these children attended has classes for children beginning at 1 year of age. Many of the children will stay in the school until they are ready to move on to kindergarten. This creates a wide range of behaviors and academic preparations. 
The children involved in the present study are mostly of Hispanic origin, with very few exceptions. For most of them, the primary home language is Spanish. Many of them have been in the center for several years, but this is the first year that they are fully immersed in an English-speaking classroom. Some of them are extremely shy, which holds them back from demonstrating their knowledge at times, while others are very talkative and tend to verbalize everything they are learning. A few of them are active, impatient children, who have trouble waiting their turns for activities and have difficulty engaging in tasks for extended periods of time. In addition, there is an age difference of more than nine months between the youngest and the oldest children in the class. The children who turn five early in the school year tend to be more mature and have a certain advantage over those who turn five in the summer after their preschool year.

Number Writing assessments were conducted during the second week of school, in early September. They occur directly after children were asked to count as high as they could. Children were told the name of the number so that recall of a specific number was not important. This was done to isolate the task of number writing from number recall.

There are a lot of unseen steps that go into successful number writing. On the motor side, a child must be able to hold the marker and make lines and circle. The child must have a perception of the visual field to place each number next to the previous one from left to right in a way that makes each number approximately the same size. This also implies that child is aware that the number symbols, being just that, do not represent quantities by their size, but by abstraction.

The following numbered list describes the steps to a successful Number Writing assessment: 
1. Pull up in memory a mental perception of what the number one looks like.

2. Grasp marker between thumb and forefinger (pincer grasp).

3. Start on the left side of the paper in upper quadrant.

4. Access the image of what a number 1 looks like including its top to bottom and left to right orientation.

5. Coordinate the eye and hand to control start a downward motion.

6. Notice when the desired length is achieved.

7. Lift the marker and move over to the right to begin the next number.

8. Access the image of what a number 2 looks like including its top to bottom and left to right orientation.

9. For the number 2, leaving a space from number one, begin with a hook at the top left and continue with a curved line that ends where the number one ended, and then change directions.

10. Access the image of what a number 3 looks like including its top to bottom and left to right orientation.

11. For the number 3 , leaving a space from number 2 , begin at the top left and make a semi-circle clockwise to mid height, change directions without lifting the marker and make another semi-circle clockwise.

12. Access the image of what a number 4 looks like including its top to bottom and left to right orientation.

13. For the number 4 , leaving a space from number 3 , begin at the top left and make a line down to mid height, change directions and make a line to the 
right, then lift the marker to the top of where the last line ended and make a line that goes down to the bottom.

14. Access the image of what a number 5 looks like including its top to bottom and left to right orientation.

15. For the number 5, leaving a space from number 4 , begin at the top left and make a line down to mid height, change directions and make a semi-circle clockwise, then lift the marker to the starting point and make a line to the right the width of the semi-circle.

16. Access the image of what a number 6 looks like including its top to bottom and left to right orientation.

17. For the number 6 , leaving a space from number 5 , begin at the top right and make a semi-circle clockwise all the way to the bottom that spirals to mid height and meets the original semi-circle to the left.

18. Access the image of what a number 7 looks like including its top to bottom and left to right orientation.

19. For the number 7 , leaving a space from number 6 , begin at the top left, make a line to the right, and without lifting the marker change directions to make a line that goes down diagonally to the left.

20. Access the image of what a number 8 looks like including its top to bottom and left to right orientation.

21. For the number 8 , leaving a space from number 7 , begin at the top right corner to make a semi-circle counter-clockwise to mid height, then changes direction to loop into a semi-circle clockwise to the bottom, that continues to loop into a 
full circle at mid height, that changes directions to counter-clockwise to loop into a full circle at the top.

22. Access the image of what a number 9 looks like including its top to bottom and left to right orientation.

23. For the number 9 , leaving a space from number 8 , begin at the top right corner and make a circle to the counter-clockwise to mid height, return to starting point without lifting the marker, and change direction to make a line that goes down to the bottom.

The following matrix has been produced to track the presence of these steps in three assessment periods, pre- mid-, and post-test. The observed markers and behaviors have been coded and described in a legend. The $\mathrm{M}$ codes represent the presence of motor skills. The V ones represent the presence visual-spatial skills in the task. The $\mathrm{S}$ codes signify that the correct symbol was produced for each number, regardless of how the symbol was made. The $\mathrm{O}$ codes show the correct orientation for each number. Finally, the $\mathrm{D}$ codes indicate the correct directional tracing of each of the numbers. Each $\mathrm{X}$ denotes the presence of the specific marker and an empty space its absence.

\section{Legend}

M1: Uses Pincer Grasp

M2: Applies Appropriate Writing Pressure

V1: Numbers Approximately the Same Size

V2: Numbers in a Straight Line

V3: Writing Starts at Top Left Corner and Continues to the Right

S1-S9: Produces Correct Symbol for Each Number

O1-O9: Correct Orientation for Each Number

D1-D9: Correct Direction in Writing Each Number 


\begin{tabular}{|c|c|c|c|c|c|c|c|c|c|c|c|c|c|c|c|c|c|c|c|c|c|c|c|c|c|c|c|c|c|c|c|c|}
\hline Child & $\mathrm{M}$ & $\mathrm{M}$ & $\mathrm{V}$ & $\mathrm{V}$ & $\mathrm{V}$ & $\mathrm{S}$ & $\mathrm{S}$ & $\mathrm{S}$ & $\mathrm{S}$ & S & $\mathrm{S}$ & $\mathrm{S}$ & $\mathrm{S}$ & $\mathrm{S}$ & $\mathrm{O}$ & $\mathrm{O}$ & $\mathrm{O}$ & $\mathrm{O}$ & $\mathrm{O}$ & $\mathrm{O}$ & $\mathrm{O}$ & \begin{tabular}{l|l}
$\mathrm{O}$ & $\mathrm{s}$ \\
\end{tabular} & \begin{tabular}{l|l}
$\mathrm{O}$ \\
\end{tabular} & $\mathrm{D}$ & $\mathrm{D}$ & $\mathrm{D}$ & $\mathrm{D}$ & $\mathrm{D}$ & $\mathrm{D}$ & $\mathrm{D}$ & $\mathrm{D}$ & $\mathrm{D}$ \\
\hline ID & 1 & 2 & 1 & 2 & 3 & 1 & 2 & 3 & 4 & 5 & 6 & 7 & 8 & 9 & 1 & 2 & 3 & 4 & 5 & 6 & 7 & 8 & 9 & 1 & 2 & 3 & 4 & 5 & 6 & 7 & 8 & 9 \\
\hline 11801 & $\mathrm{X}$ & $\mathrm{X}$ & & & $\mathrm{X}$ & $\mathrm{X}$ & $\mathrm{X}$ & $\mathrm{X}$ & & & & $\mathrm{X}$ & $\mathrm{X}$ & $\mathrm{X}$ & $\mathrm{X}$ & $\mathrm{X}$ & $\mathrm{X}$ & & & & $\mathrm{X}$ & \begin{tabular}{l|l}
$\mathrm{X}$ & \\
\end{tabular} & $\mathrm{X}$ & $\mathrm{X}$ & $\mathrm{X}$ & $\mathrm{X}$ & & & & $\mathrm{X}$ & & $\mathrm{X}$ \\
\hline 11803 & $\mathrm{X}$ & & & & $\mathrm{X}$ & & & & & & & & & & & & & & & & & & & & & & & & & & & \\
\hline 11804 & & & & & $\mathrm{X}$ & $\mathrm{X}$ & $\mathrm{X}$ & $\mathrm{X}$ & & & & & $\mathrm{X}$ & & & & & & & & & & & $\mathrm{X}$ & & & & & & & & \\
\hline 11805 & & & $\mathrm{X}$ & $\mathrm{X}$ & $\mathrm{X}$ & $\mathrm{X}$ & $\mathrm{X}$ & $\mathrm{X}$ & $\mathrm{X}$ & $\mathrm{X}$ & $\mathrm{X}$ & $\mathrm{X}$ & $\mathrm{X}$ & $\mathrm{X}$ & $\mathrm{x}$ & \begin{tabular}{l|l}
$\mathrm{X}$ \\
\end{tabular} & $\mathrm{X}$ & & $\mathrm{x}$ & $\mathrm{X}$ & $\mathrm{X}$ & $\mathrm{X}$ & $\mathrm{X}$ & $\mathrm{X}$ & & & & & & & & \\
\hline 11806 & $\mathrm{X}$ & & & & $\mathrm{X}$ & & & & & & & & & & & & & & & & & & & & & & & & & & & \\
\hline 11807 & $\mathrm{X}$ & $\mathrm{X}$ & $\mathrm{X}$ & $\mathrm{X}$ & $\mathrm{X}$ & $\mathrm{X}$ & $\mathrm{X}$ & $\mathrm{X}$ & $\mathrm{X}$ & $\mathrm{X}$ & $\mathrm{X}$ & $\mathrm{X}$ & & & $\mathrm{X}$ & \begin{tabular}{l|l}
$\mathrm{X}$ \\
\end{tabular} & \begin{tabular}{l|l}
$\mathrm{X}$ & 3 \\
\end{tabular} & $\mathrm{X}$ & $\mathrm{X}$ & $\mathrm{X}$ & $\mathrm{X}$ & & & $\mathrm{X}$ & $\mathrm{X}$ & $\mathrm{X}$ & $\mathrm{X}$ & & & $\mathrm{X}$ & & \\
\hline 11808 & $\mathrm{X}$ & $\mathrm{X}$ & & & $\mathrm{X}$ & $\mathrm{X}$ & & & & & & & & & $\mathrm{X}$ & & & & & & & & & $\mathrm{X}$ & & & & & & & & \\
\hline 11809 & $\mathrm{X}$ & $\mathrm{X}$ & $\mathrm{X}$ & $\mathrm{X}$ & $\mathrm{X}$ & $\mathrm{X}$ & $\mathrm{X}$ & & & $\mathrm{X}$ & & $\mathrm{X}$ & $\mathrm{X}$ & & $\mathrm{X}$ & $\mathrm{X}$ & & & & & \begin{tabular}{l|l}
$x$ \\
\end{tabular} & $\mathrm{X}$ & & $\mathrm{X}$ & $\mathrm{X}$ & & & & & $\mathrm{X}$ & & \\
\hline 11810 & & & $\mathrm{X}$ & $\mathrm{X}$ & $\mathrm{X}$ & $\mathrm{X}$ & $\mathrm{X}$ & $\mathrm{X}$ & $\mathrm{X}$ & $\mathrm{X}$ & $\mathrm{X}$ & $\mathrm{X}$ & $\mathrm{X}$ & $\mathrm{X}$ & $\mathrm{x}$ & & & & $\mathrm{X}$ & & & $\mathrm{X}$ & & $\mathrm{X}$ & $\mathrm{X}$ & & & & & & & \\
\hline 11811 & $\mathrm{X}$ & $\mathrm{X}$ & & & $\mathrm{X}$ & $\mathrm{X}$ & $\mathrm{X}$ & & $\mathrm{X}$ & & & $\mathrm{X}$ & $\mathrm{X}$ & $\mathrm{X}$ & $\mathrm{X}$ & $\mathrm{X}$ & $\mathrm{X}$ & & & & $\mathrm{X}$ & $\mathrm{X}$ & $\mathrm{X}$ & $\mathrm{X}$ & & & & & & & & \\
\hline 11812 & & & & & $\mathrm{X}$ & $\mathrm{X}$ & & & & & & & & & $\mathrm{X}$ & & & & & & & & & $\mathrm{X}$ & & & & & & & & \\
\hline 11813 & $\mathrm{X}$ & $\mathrm{X}$ & & & $\mathrm{X}$ & $\mathrm{X}$ & & & & & & & & & & & & & & & & & & $\mathrm{X}$ & & & & & & & & \\
\hline 11814 & $\mathrm{X}$ & & & & $\mathrm{X}$ & $\mathrm{X}$ & & & & & & & & & $\mathrm{X}$ & & & & & & & & & $\mathrm{X}$ & & & & & & & & \\
\hline 11815 & $\mathrm{X}$ & $\mathrm{X}$ & & & $\mathrm{X}$ & $\mathrm{X}$ & & & & & & & & & $\mathrm{X}$ & & & & & & & & & $\mathrm{X}$ & & & & & & & & \\
\hline 11816 & & & & $\mathrm{X}$ & $\mathrm{X}$ & $\mathrm{X}$ & & & & & & & & & $\mathrm{X}$ & & & & & & & & & & & & & & & & & \\
\hline
\end{tabular}

Figure 2. CB pre-test number writing matrix

\begin{tabular}{|c|c|c|c|c|c|c|c|c|c|c|c|c|c|c|c|c|c|c|c|c|c|c|c|c|c|c|c|c|c|c|c|c|}
\hline Child & $\mathrm{M}$ & & & V & V & S & S & S & S & & $\mathrm{S}$ & $S$ & S & & $\mathrm{O}$ & & $\mathrm{O}$ & & $\mathrm{O}$ & & & $\mathrm{O}$ & & $\mathrm{D}$ & & & & & & & & \\
\hline ID & 1 & 2 & 1 & 2 & 3 & 1 & 2 & 3 & 4 & 5 & 6 & 7 & 8 & 9 & 1 & 2 & 3 & 4 & 5 & 6 & 7 & 8 & 9 & 1 & 2 & 3 & 4 & 5 & 6 & 7 & 8 & 9 \\
\hline 11801 & $\mathrm{X}$ & $\mathrm{X}$ & $\mathrm{X}$ & $\mathrm{X}$ & $\mathrm{X}$ & $\mathrm{X}$ & $\mathrm{X}$ & $\mathrm{X}$ & $\mathrm{X}$ & X & $\mathrm{X}$ & $\mathrm{X}$ & $\mathrm{X}$ & $\mathrm{X}$ & $\mathrm{X}$ & $\mathrm{X}$ & $\mathrm{X}$ & $\mathrm{X}$ & $\mathrm{X}$ & $\mathrm{X}$ & & $\mathrm{X}$ & & $\mathrm{X}$ & $\mathrm{X}$ & $\mathrm{X}$ & $\mathrm{X}$ & & $\mathrm{X}$ & & & \\
\hline 11803 & $\mathrm{X}$ & $\mathrm{X}$ & & $\mathrm{X}$ & & $\mathrm{X}$ & $\mathrm{X}$ & & $\mathrm{X}$ & $\mathrm{X}$ & $\mathrm{X}$ & $\mathrm{X}$ & $\mathrm{X}$ & $\mathrm{X}$ & $\mathrm{X}$ & & & $\mathrm{X}$ & $\mathrm{X}$ & $\mathrm{X}$ & $\mathrm{X}$ & $\mathrm{X}$ & & $\mathrm{X}$ & & & $\mathrm{X}$ & & $\mathrm{X}$ & $\mathrm{X}$ & $\mathrm{X}$ & \\
\hline 11804 & $\mathrm{X}$ & $\mathrm{X}$ & $\mathrm{X}$ & $\mathrm{X}$ & $\mathrm{X}$ & $\mathrm{X}$ & $\mathrm{X}$ & $\mathrm{X}$ & $\mathrm{X}$ & $X$ & $\mathrm{X}$ & $\mathrm{X}$ & $\mathrm{X}$ & & $\mathrm{X}$ & & & & $\mathrm{X}$ & $\mathrm{X}$ & & $\mathrm{X}$ & & $\mathrm{X}$ & & & & $\mathrm{X}$ & & & & \\
\hline 11805 & $\mathrm{X}$ & $\mathrm{X}$ & $\mathrm{X}$ & $\mathrm{X}$ & $\mathrm{X}$ & $\mathrm{X}$ & $\mathrm{X}$ & $\mathrm{X}$ & $\mathrm{X}$ & X & $\mathrm{X}$ & $\mathrm{X}$ & $\mathrm{X}$ & $\mathrm{X}$ & $\mathrm{X}$ & $\mathrm{X}$ & $\mathrm{X}$ & $\mathrm{X}$ & $\mathrm{X}$ & $\mathrm{X}$ & $\mathrm{X}$ & $\mathrm{X}$ & $\mathrm{X}$ & $\mathrm{X}$ & $\mathrm{X}$ & $\mathrm{X}$ & & & $\mathrm{X}$ & $\mathrm{X}$ & & \\
\hline 11806 & $\mathrm{X}$ & $\mathrm{X}$ & $\mathrm{X}$ & $\mathrm{X}$ & $\mathrm{X}$ & $\mathrm{X}$ & $\mathrm{X}$ & $\mathrm{X}$ & $\mathrm{X}$ & $X$ & $\mathrm{X}$ & $\mathrm{X}$ & $\mathrm{X}$ & $\mathrm{X}$ & $\mathrm{X}$ & $\mathrm{X}$ & $\mathrm{X}$ & $\mathrm{X}$ & $\mathrm{X}$ & $\mathrm{X}$ & $\mathrm{X}$ & $\mathrm{X}$ & $\mathrm{X}$ & $\mathrm{X}$ & $\mathrm{X}$ & $\mathrm{X}$ & $\mathrm{X}$ & & $\mathrm{X}$ & $\mathrm{X}$ & & \\
\hline 11807 & $\mathrm{X}$ & $\mathrm{X}$ & & & $\mathrm{X}$ & $\mathrm{X}$ & $\mathrm{X}$ & $\mathrm{X}$ & $\mathrm{X}$ & $\mathrm{X}$ & $\mathrm{X}$ & $\mathrm{X}$ & $\mathrm{X}$ & $\mathrm{X}$ & $\mathrm{X}$ & $\mathrm{X}$ & $\mathrm{X}$ & $\mathrm{X}$ & $\mathrm{X}$ & $\mathrm{X}$ & $\mathrm{X}$ & $\mathrm{X}$ & $\mathrm{X}$ & $\mathrm{x}$ & $\mathrm{X}$ & $\mathrm{X}$ & $\mathrm{X}$ & $\mathrm{X}$ & $\mathrm{X}$ & $\mathrm{x}$ & $\mathrm{X}$ & \\
\hline 11808 & $\mathrm{X}$ & $\mathrm{X}$ & & $\mathrm{X}$ & $\mathrm{X}$ & $\mathrm{X}$ & $\mathrm{X}$ & $\mathrm{X}$ & $\mathrm{X}$ & $\mathrm{X}$ & $\mathrm{X}$ & $\mathrm{X}$ & $\mathrm{X}$ & $\mathrm{X}$ & $\mathrm{X}$ & & & & $\mathrm{X}$ & $\mathrm{X}$ & & $\Lambda$ & & $\mathrm{X}$ & & & & $\mathrm{X}$ & $\mathrm{X}$ & & $\mathrm{X}$ & \\
\hline 11809 & $\mathrm{X}$ & $\mathrm{X}$ & $\mathrm{X}$ & $\mathrm{X}$ & $\mathrm{X}$ & $\mathrm{X}$ & $\mathrm{X}$ & $\mathrm{X}$ & $\mathrm{X}$ & $\mathrm{X}$ & $\mathrm{X}$ & $\mathrm{X}$ & $\mathrm{X}$ & $\mathrm{X}$ & $\mathrm{X}$ & $\mathrm{X}$ & $\mathrm{X}$ & $\mathrm{X}$ & $\mathrm{X}$ & $\mathrm{X}$ & $\mathrm{X}$ & $\mathrm{X}$ & & $\mathrm{X}$ & $\mathrm{X}$ & $\mathrm{X}$ & $\mathrm{X}$ & & $\mathrm{X}$ & $\mathrm{X}$ & & \\
\hline 11810 & $\mathrm{X}$ & $\mathrm{X}$ & & & & $\mathrm{X}$ & $\mathrm{X}$ & $\mathrm{X}$ & & $\mathrm{X}$ & $\mathrm{X}$ & $\mathrm{X}$ & $\mathrm{X}$ & $\mathrm{X}$ & $\mathrm{X}$ & & & & $\mathrm{X}$ & $\mathrm{X}$ & & $\mathrm{X}$ & & $\mathrm{X}$ & & & & & $\mathrm{X}$ & & & \\
\hline 11811 & $\mathrm{X}$ & $\mathrm{X}$ & $\mathrm{X}$ & $\mathrm{X}$ & $\mathrm{X}$ & $\mathrm{X}$ & $\mathrm{X}$ & $\mathrm{X}$ & $\mathrm{X}$ & $X$ & $\mathrm{X}$ & $\mathrm{X}$ & $\mathrm{X}$ & $\mathrm{X}$ & $\mathrm{X}$ & & & $\mathrm{X}$ & $\mathrm{X}$ & $\mathrm{X}$ & & $\mathrm{X}$ & & & & & $\mathrm{X}$ & & & & $\mathrm{X}$ & \\
\hline 11812 & $\mathrm{X}$ & $\mathrm{X}$ & $\mathrm{X}$ & & $\mathrm{X}$ & $\mathrm{X}$ & $\mathrm{X}$ & $\mathrm{X}$ & $\mathrm{X}$ & $\mathrm{X}$ & $\mathrm{X}$ & $\mathrm{X}$ & $\mathrm{X}$ & & $\mathrm{X}$ & $\mathrm{X}$ & $\mathrm{X}$ & $\mathrm{X}$ & & $\mathrm{X}$ & & $\mathrm{X}$ & & & $\mathrm{X}$ & $\mathrm{X}$ & $\mathrm{X}$ & & $\mathrm{X}$ & & $\mathrm{X}$ & \\
\hline 11813 & $\mathrm{X}$ & $\mathrm{X}$ & $\mathrm{X}$ & $\mathrm{X}$ & & $\mathrm{X}$ & $\mathrm{X}$ & $\mathrm{X}$ & $\mathrm{X}$ & $X$ & $\mathrm{X}$ & $\mathrm{X}$ & $\mathrm{X}$ & $\mathrm{X}$ & $\mathrm{X}$ & & & $\mathrm{X}$ & $\mathrm{X}$ & $\mathrm{X}$ & & $\mathrm{X}$ & $\mathrm{X}$ & $\mathrm{x}$ & & & $\mathrm{X}$ & $\mathrm{X}$ & $\mathrm{X}$ & & $\mathrm{X}$ & \\
\hline 11814 & $\mathrm{X}$ & $\mathrm{X}$ & $\mathrm{X}$ & $\mathrm{X}$ & $\mathrm{X}$ & $X$ & $\mathrm{X}$ & $\mathrm{X}$ & $\mathrm{X}$ & $\lambda$ & $\mathrm{X}$ & & $\mathrm{X}$ & $\mathrm{X}$ & $\mathrm{X}$ & $\mathrm{X}$ & $\mathrm{X}$ & $\mathrm{X}$ & $\mathrm{X}$ & $\mathrm{X}$ & & $\mathrm{X}$ & & $\mathrm{X}$ & $\mathrm{X}$ & $\mathrm{X}$ & $\mathrm{X}$ & & $\mathrm{X}$ & & & \\
\hline 11815 & $\mathrm{X}$ & $\mathrm{X}$ & $\mathrm{X}$ & & $\mathrm{X}$ & $\mathrm{X}$ & $\mathrm{X}$ & $\mathrm{X}$ & $\mathrm{X}$ & $x$ & $\mathrm{X}$ & $\mathrm{X}$ & $\mathrm{X}$ & $\mathrm{X}$ & $\mathrm{X}$ & & $\mathrm{X}$ & $\mathrm{X}$ & $\mathrm{X}$ & $\mathrm{X}$ & & $\mathrm{X}$ & $\mathrm{X}$ & $\mathrm{X}$ & & & $\mathrm{X}$ & & $\mathrm{X}$ & & & \\
\hline 11816 & $\mathrm{X}$ & $\mathrm{X}$ & $\mathrm{X}$ & $\mathrm{X}$ & $\mathrm{X}$ & $\mathrm{X}$ & $X$ & $\mathrm{X}$ & $\mathrm{X}$ & 8 & $\mathrm{X}$ & $X$ & X & $\mathrm{X}$ & $\mathrm{X}$ & $x$ & $\mathrm{X}$ & & $x$ & & & & & $x$ & & & $X$ & & $\mathrm{X}$ & $\mathrm{X}$ & & \\
\hline
\end{tabular}

Figure 3. CB mid-test number writing matrix 


\begin{tabular}{|c|c|c|c|c|c|c|c|c|c|c|c|c|c|c|c|c|c|c|c|c|c|c|c|c|c|c|c|c|c|c|c|c|c|}
\hline Chil & & & & V & V & $S$ & S & S & $S$ & S & & S & & $S$ & & & $\mathrm{O}$ & $\mathrm{O}$ & $\mathrm{O}$ & $\mathrm{O}$ & $\mathrm{O}$ & & $\mathrm{O}$ & $\mathrm{O}$ & $\mathrm{D}$ & D & $\mathrm{D}$ & $\mathrm{D}$ & $\mathrm{D}$ & D & D & & \\
\hline ID & & 2 & 1 & 2 & 3 & 1 & 2 & 3 & & & & . & $\varepsilon$ & & & & & & 4 & 5 & 6 & 7 & 8 & 9 & 1 & 2 & 3 & 4 & 5 & 6 & 7 & & \\
\hline 11 & & $\mathrm{X}$ & $\mathrm{X}$ & $\mathrm{X}$ & $\mathrm{X}$ & $X$ & 2 & $\mathrm{X}$ & $X$ & & & $y$ & & $y_{2}$ & & $X$ & $X$ & & $\mathrm{X}$ & $\mathrm{X}$ & $\mathrm{X}$ & $\mathrm{X}$ & $\mathrm{X}$ & $\mathrm{X}$ & $\mathrm{X}$ & $\mathrm{X}$ & & & & $\mathrm{X}$ & $\mathrm{X}$ & & \\
\hline & & $\mathrm{X}$ & & $\mathrm{X}$ & $\mathrm{X}$ & $\mathrm{X}$ & & $\mathrm{X}$ & X & $\mathrm{X}$ & & & 2 & 1 & & $\mathrm{X}$ & $\mathrm{X}$ & $\mathrm{X}$ & $\mathrm{X}$ & $\mathrm{X}$ & $\mathrm{X}$ & & $\mathrm{X}$ & & $\mathrm{X}$ & $\mathrm{X}$ & $\mathrm{X}$ & $\mathrm{X}$ & $\mathrm{X}$ & $\mathrm{X}$ & & $\mathrm{X}$ & \\
\hline & & $\mathrm{X}$ & $\mathrm{X}$ & $\mathrm{X}$ & $\mathrm{X}$ & $\mathrm{X}$ & $Y$ & $\mathrm{X}$ & X & $\mathrm{X}$ & & $\Lambda$ & & Y & & $\bar{X}$ & $\mathrm{X}$ & $\mathrm{X}$ & $\mathrm{X}$ & $\mathrm{X}$ & $\mathrm{X}$ & $\mathrm{X}$ & $\mathrm{X}$ & & $\mathrm{X}$ & $\mathrm{X}$ & $\mathrm{X}$ & $\mathrm{X}$ & & $\mathrm{X}$ & $\mathrm{x}$ & $\mathrm{X}$ & \\
\hline 11805 & & $\mathrm{X}$ & $\mathrm{X}$ & $\mathrm{X}$ & $\mathrm{X}$ & $\mathrm{X}$ & & $\mathrm{X}$ & $\mathrm{X}$ & $X$ & & & & $\gamma$ & & $\mathrm{X}$ & $\mathrm{X}$ & $\mathrm{x}$ & $\mathrm{X}$ & $\mathrm{X}$ & $\mathrm{X}$ & $\mathrm{X}$ & $\mathrm{X}$ & $\mathrm{X}$ & & $\mathrm{X}$ & $\mathrm{X}$ & & & $\mathrm{X}$ & $\mathrm{X}$ & & \\
\hline & & $\mathrm{X}$ & $\mathrm{X}$ & $\mathrm{X}$ & $\mathrm{X}$ & $\mathrm{X}$ & $\lambda$ & $\mathrm{X}$ & $\mathrm{X}$ & $\mathrm{X}$ & & & & $Y$ & & $\mathrm{X}$ & $\mathrm{X}$ & $\mathrm{X}$ & $\mathrm{X}$ & $\mathrm{X}$ & $\mathrm{X}$ & $\mathrm{X}$ & $\mathrm{X}$ & $\mathrm{X}$ & $\mathrm{X}$ & $\mathrm{X}$ & $\mathrm{X}$ & $\mathrm{X}$ & & $\mathrm{X}$ & $\mathrm{X}$ & $\mathrm{X}$ & \\
\hline 11807 & X & $\mathrm{X}$ & $\mathrm{X}$ & $\mathrm{X}$ & $\mathrm{X}$ & $\mathrm{X}$ & $\mathrm{X}$ & $\mathrm{X}$ & $\mathrm{X}$ & $\mathrm{X}$ & X & $\bar{X}$ & $y$ & $Y$ & & $\mathrm{X}$ & $\mathrm{X}$ & $\mathrm{X}$ & $\mathrm{X}$ & $\mathrm{X}$ & $\mathrm{X}$ & $\mathrm{X}$ & $\mathrm{X}$ & $\mathrm{X}$ & $\mathrm{X}$ & $\mathrm{X}$ & $\mathrm{X}$ & \begin{tabular}{|l|}
$X$ \\
\end{tabular} & $\mathrm{X}$ & $\mathrm{X}$ & $\mathrm{X}$ & $\mathrm{X}$ & \\
\hline 11808 & $X$ & $\mathrm{X}$ & $\mathrm{X}$ & & $\mathrm{X}$ & $\mathrm{X}$ & $x$ & & $\mathrm{X}$ & $X$ & & $\bar{X}$ & 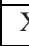 & $Y$ & & $\mathrm{X}$ & & & $\mathrm{X}$ & $\mathrm{X}$ & $\mathrm{X}$ & $\mathrm{X}$ & $\mathrm{X}$ & $\mathrm{X}$ & $\mathrm{X}$ & & & & $\mathrm{X}$ & $\mathrm{X}$ & & $\mathrm{X}$ & \\
\hline 11809 & 1 & $\mathrm{X}$ & $\mathrm{X}$ & & $\mathrm{X}$ & $\mathrm{X}$ & 1 & $\mathrm{X}$ & X & $\mathrm{X}$ & & 2 & & $y$ & & $\mathrm{X}$ & $\mathrm{X}$ & $\mathrm{X}$ & $\mathrm{X}$ & $\mathrm{X}$ & $\mathrm{X}$ & $\Lambda$ & $\mathrm{X}$ & $\mathrm{X}$ & $\mathrm{X}$ & $\mathrm{X}$ & $\mathrm{X}$ & $\mathrm{X}$ & & $\mathrm{X}$ & $\mathrm{X}$ & $\mathrm{X}$ & \\
\hline & $\bar{X}$ & $\mathrm{X}$ & $\mathrm{X}$ & & $\mathrm{X}$ & $\mathrm{X}$ & $\bar{X}$ & $\mathrm{X}$ & $\mathrm{X}$ & $\mathrm{X}$ & & & & $y$ & & $\mathrm{X}$ & & & & $\mathrm{X}$ & $\mathrm{X}$ & & $\mathrm{X}$ & & $\mathrm{X}$ & & & & & $\mathrm{X}$ & & $\mathrm{X}$ & \\
\hline & $X$ & $\mathrm{X}$ & & $\mathrm{X}$ & $\mathrm{X}$ & $\mathrm{X}$ & $\mathrm{X}$ & $\mathrm{X}$ & $X$ & $\mathrm{X}$ & & 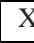 & & I & & $\mathrm{X}$ & $\mathrm{X}$ & $\mathrm{X}$ & $\mathrm{X}$ & $\mathrm{X}$ & $\mathrm{X}$ & & $\mathrm{X}$ & & $\mathrm{X}$ & $\mathrm{X}$ & $\mathrm{X}$ & $\mathrm{X}$ & & $\mathrm{X}$ & & $\mathrm{X}$ & \\
\hline 11812 & $\mathrm{X}$ & $\mathrm{X}$ & $X$ & $\mathrm{X}$ & $\mathrm{X}$ & $\mathrm{X}$ & $\mathrm{X}$ & $\mathrm{X}$ & $\mathrm{X}$ & $\mathrm{X}$ & & $X$ & & 2 & & X & $\mathrm{X}$ & $\mathrm{X}$ & $\mathrm{X}$ & $\mathrm{X}$ & $\mathrm{X}$ & & $\mathrm{X}$ & $\mathrm{X}$ & $\mathrm{X}$ & $\mathrm{X}$ & $\mathrm{X}$ & $\mathrm{X}$ & & $\bar{X}$ & $\mathrm{X}$ & $\mathrm{X}$ & \\
\hline & $\mathrm{X}$ & $\mathrm{X}$ & $\mathrm{X}$ & $\mathrm{X}$ & $\mathrm{X}$ & $X$ & $\mathrm{X}$ & $\mathrm{X}$ & $\bar{X}$ & $\mathrm{X}$ & & $x$ & & r & & $\mathrm{X}$ & $\mathrm{X}$ & $\mathrm{X}$ & $\mathrm{X}$ & $\mathrm{X}$ & $\mathrm{X}$ & $\mathrm{X}$ & $\mathrm{X}$ & & $\mathrm{X}$ & $\mathrm{X}$ & $\mathrm{X}$ & $\mathrm{X}$ & $\mathrm{X}$ & $\mathrm{X}$ & & $\mathrm{X}$ & \\
\hline 814 & $X$ & $\mathrm{X}$ & & & $\mathrm{X}$ & $\mathrm{X}$ & $\Lambda_{1}$ & $\mathrm{X}$ & X & $\mathrm{X}$ & & $\Lambda$ & & ) & & $\boldsymbol{\Lambda}$ & $\mathrm{X}$ & $\mathrm{X}$ & $\mathrm{X}$ & $\mathrm{X}$ & $\mathrm{X}$ & & $\mathrm{X}$ & & $\mathrm{X}$ & $\mathrm{X}$ & $\mathrm{X}$ & $\mathrm{X}$ & & & & & \\
\hline 815 & $\mathrm{X}$ & $\mathrm{X}$ & $\mathrm{X}$ & & $\mathrm{X}$ & $\mathrm{X}$ & $\Lambda_{1}$ & $\mathrm{X}$ & $\mathrm{X}$ & ${ }_{1}$ & & & & & & & $\mathrm{X}$ & $\mathrm{X}$ & $\mathrm{X}$ & $\mathrm{X}$ & & & $\mathrm{X}$ & $\mathrm{X}$ & $\mathrm{X}$ & $\mathrm{X}$ & $\mathrm{X}$ & \begin{tabular}{|l|}
$X$ \\
\end{tabular} & & $\mathrm{X}$ & & & \\
\hline 1816 & $\mathrm{X}$ & $\mathrm{X}$ & $\mathrm{X}$ & $\mathrm{X}$ & $\mathrm{X}$ & $\mathrm{X}$ & $x$ & $\mathrm{X}$ & & & & & & & & & $\mathrm{X}$ & & $X$ & & & & & & & & & & & & & & \\
\hline
\end{tabular}

Figure 4. CB post-test number writing matrix

In order to be able to write a number correctly, a child must go through all the different steps described above. In this analysis I draw from Robert Gagne's work on task analysis (Gagne, 1974) to analyze the steps the children have reached at the three different stages. According to Gagne (1974), task analysis works backwards from human performance to the desired learning outcomes by extrapolating the classes of performance leading up to the stimulus situation using information-processing mechanisms. Based on this and the observations by period shown above, I was able to identify the following five prerequisite skills or contributors for the task of number writing in preschool based on my observations: number knowledge (cardinal and ordinal), number recognition (of symbolic representations of numbers), visual-spatial skills (including left to orientation), sensory (tactile, muscle) memory related to the symbolic encoding of numbers, and fine motor skills (including pincer grasp). These skills are implicitly reflected in the number writing scale. Based on this, the desired learning outcome is an intellectual skill that reflects more than just a superficial task, but rather an internal knowledge that enables students to 
perform this task successfully. These skills help summarize the overall findings displayed above.

Analysis of all children's number writing at pre-test. In overview, at the beginning of the year, most of the children scored at a level 1 according to the number writing scale. Out of 15 children in the experimental group, only one scored a level 2 and three scored a level 3 at this point in the year. These scores indicate children with some previous knowledge of numbers and how to write them. The majority, however, demonstrate only a superficial knowledge of how to count to ten, but do not have a graphic representation engrained in their mind for each of the numbers, nor a tactile knowledge of how to bring this representation to fruition on a piece of paper.

A good example is Jose (pseudonym) who was excited but overwhelmed by the experience of being in school for the first time. Jose speaks only Spanish. When asked to write his numbers he begins to write a circular shape in the middle of the page, demonstrating that he does not understand the left to right convention of number writing. Directed to start on the right side of the page he begins a slow march of meandering circles, each one successively bigger than the next. He does not hesitate to write each number as it is counted out, making a deliberate circle for each number. When he is done, his page has a mix of small and large circles snaking across the page (see example below). This is one example of what Bleiker (2015) classifies as a level one number writing: "A level one shows random marks that show little relation to actual numbers. Marks are typically circles, hash marks, or scribbles" (see appendix X for the number writing scale). 


\section{$\therefore 9000000$}

Figure 5. Jose's pre-test

One explanation for Jose's use of a circle to represent all the numbers is that he doesn't know what the number symbols are, what order they go in, or even how to construct them. He seems to have a vague idea that a certain mark is supposed to accompany the number name. The mark he probably knows best is the circle. Once shown where to start he writes the subsequent numbers in a curvalinear sequence.

Jose has some pre-cursor skills needed to write his number. He knows how to draw curved lines. He can hold the pen between his thumb and forefinger, and he knows where to place each subsequent number. It is not his lack of small motor abilities that keeps him from writing his numbers, it is his lack of knowledge and familiarity with the symbols themselves, and his inability to connect them with the number name.

Maria's attempt at number writing at the beginning of the year was similar to Jose's, but with hash marks instead of circles.

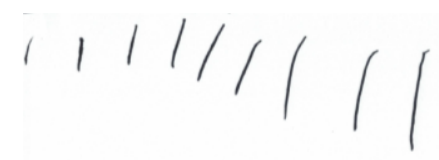

Figure 6. Maria's pre-test

Beatrice's attempt was a more complex version of the same phenomenon. She wrote number one well, and made the same squiggly markings from two onwards, and not in a linear sequence, but rather jumping all over the page. These markings somewhat resemble the symbol for a number three, meaning that Beatrice has some kind of 


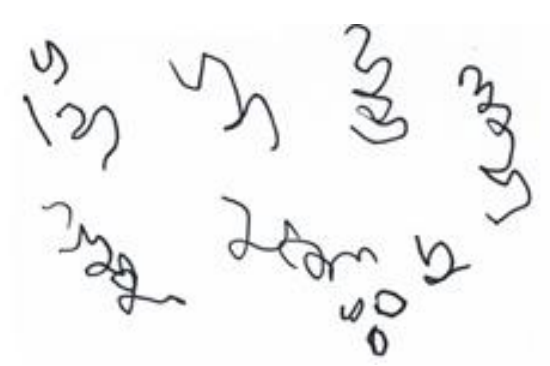

Figure 7. Beatrice's pre-test

Britney is another example of a level one. This time the markings are truly random, showing no relation to counting other than the student knowing that some kind of marking is expected of them. These were also not done in a linear fashion, but randomly scattered all over the page.

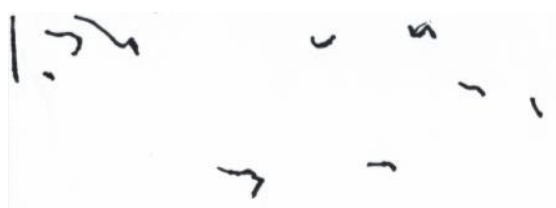

Figure 8. Britney's pre-test

Other level ones are not so random. Some students, such as Brian, only make one or two distinguishable numbers, but the other markings resemble letters (like an E for a 3, an $\mathrm{H}$ for a 4) or somewhat approach what a number symbol should look like instead of just being circles or hash marks.

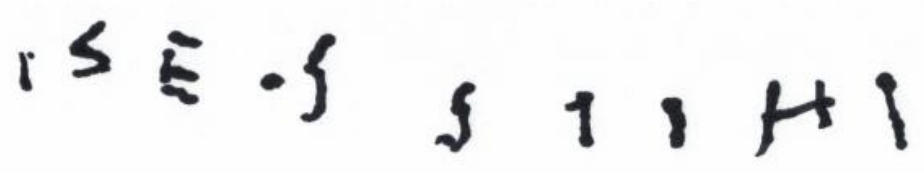

Figure 9. Brian's pre-test

A level two begins to incorporate more features. It has "at least number 1 and potentially 1 or 2 others that can reasonably be interpreted as a number. A combination of curved and straight lines should be present" (Bleiker, 2015). Cristina's pre-test number 
writing attempt is a clear example of what this would look like. Some but not all of the numerals are recognizable, but those that are clear representations of number symbols.

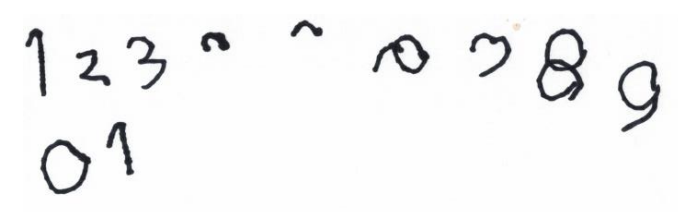

Figure 10. Cristina's pre-test

To meet the criteria for a level 3, "most numerals are recognizable; three or more errors of orientation (reversals, size, shape) are present" (Bleiker, 2015). In comparison, a level 3 Number Writing assessment is clearly distinguishable from a level 2, such as in Tony's initial writing attempt. He only wrote the digits up to 7, but he wrote them all correctly, without even errors of reversal.

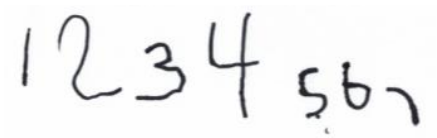

Figure 11. Tony's pre-test

In terms of number writing, only a couple of students had insufficient number knowledge to write number one. Of the rest, a few were only able to write number one and random drawings or markings for the rest of the numbers. Another small group made it up to number three with markings that were recognizable as relating to the numeral they are supposed to represent. The rest were able to represent at least five of the number symbols in a way that is fairly accurate, however, there were very few students that were able to do this.

In terms of body language, the majority of the students display signs of uneasiness and lack of adequate knowledge and skills to carry out the task assigned in the writing pretest. Many of them display poor grip of the marker. Many of them approach the task 
with enthusiasm, but as soon as they realize concretely what is required of them, they often respond with uncertainty. Some of them explicitly say, "I don't know" when asked to write numbers after one, others make markings or drawings of what they consider the numbers would look like and quickly looking up at the assessor for approval. Most of them wait for the assessor to prompt the next number before writing it, and after they write the number look around or smile bashfully, as if knowing that what they just did was not accurate.

Even the students that scored a bit better in the pretest demonstrated signs of uncertainty when asked to write their numbers. One of them asked the assessor, "Can you help me?" towards the beginning of the task. In one of the most telling videos in the pretest, a very talkative girl transparently speaks her mind as she attempts to write the numbers, and she clearly states, "I don't know how to write a number two," and "number six? A circle, I guess, two circles. Kind of looks like a snowman..." From her commentary, it is clear that she is guessing in her approach to drawing the numerals from one to nine. The difference, with the students that performed a bit better is that they demonstrate better number knowledge than their lower-performing peers. They do not require so much prompting by the assessor to know which number comes next. One even insisted on writing number ten when the assessor said the task was over at nine.

In reference to the contributors to the task of number writing identified through task analysis, number knowledge was lacking in most of the students. When prompted by the assessor on which number comes next, most were only able to respond up to number three. This generally resulted in children not being able to write the numbers that they were not able to name in a counting sequence. Only three students were able to respond 
successfully when prompted up to number nine, and two of them were not able to respond to any numbers after one.

With respect to visual-spatial skills, most of the students independently began in the top left-hand corner of the page, but two of them had to be prompted to begin there in order to write the numbers out from left to right. Even so, many of them did not apply top-to-bottom and left-to-right orientation when writing each number, especially for numbers after three. This is also related to the sensory memory that would enable students to automatically produce the numbers in the proper orientation, since this is usually something that is acquired with practice.

Concerning fine motor skills, it was very apparent that many of the students did not have a firm grasp on the marker that they were using, and would hold it halfway up the marker, instead of closer to the tip. This may even be linked to the uncertainty of not knowing how to write the numbers, letting the marker guide them instead of taking control of the writing utensil to produce the symbols they would know to correspond to the number being prompted. This is likely related to an overall lack of number recognition with respect to the numeric symbols. They may not know from memory what the number is supposed to look like and consequently cannot reproduce it. This accounts for the random markings and drawings that students drew because they knew some kind of marking was expected of them, but they knew not what it was supposed to look like. Only in some cases it appears that the student knows what the number symbol looks like and attempts to reproduce it without the sensory memory component that would enable automatic completion of the task and the result is a symbol that approximates the number although it may not be an exact representation. This was most common for numbers over 
three, although seven and eight seem to be easier to reproduce and these were close to correct in many cases as well.

One possible explanation for this phenomenon is that the first three numbers are easier to remember, and since memory plays an important role in number writing, until children develop a fluency in this skill through practice that leads to symbolic encoding, three is the limit of the working memory in producing number symbols.

Overall, the students performed at a very preliminary level at the beginning of the school year. This is natural for students entering preschool. This also leaves room for improvement throughout the school year.

Analysis of all children's number writing at mid-test. Overall, all of the students scored at a level 3 or 4 on the number writing scale, with a higher proportion of the students scoring at a level 4. This is a significant improvement from the previous testing period. The writing was qualitatively better than in the first attempt. There were many less random markings and many more purposeful number symbols present in the students' writing.

Jose, for example, showed a marked improvement from the first assessment period. He had scored a level 1 at the beginning, barely able to reproduce any symbols, except only circles. Now, most of the symbols are recognizable, although some still are not and others contain reversals.

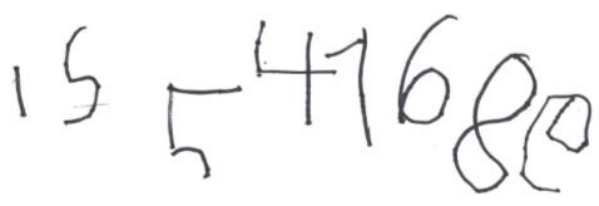

Figure 12. Jose's mid-test 
Another example of a level 3 comes from Maria's mid-test. She was only able to produce hash marks at the beginning of the school year and now most of the number symbols are present, although they are not in the correct order and some lack the correct orientation.

\section{$123456 \mathrm{~PB}$}

Figure 13. Maria's mid-test

Another example of a level 3 comes from Roxanne. She has all the number symbols present with two attempts at number two. She also has four reversals, which preclude her attempt from the next level.

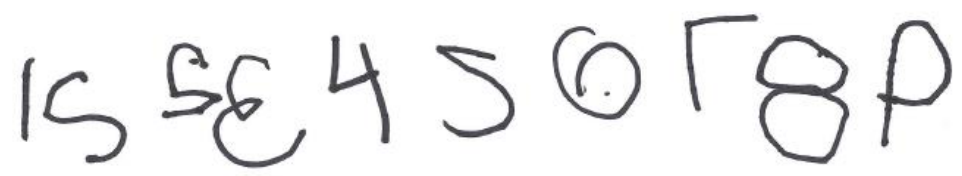

Figure 14. Roxanne's mid-test

The students performing at a level 3 in the mid-test demonstrate great gains, and even so, many more students performed at a level 4 at this point in the school year. A level 4 indicates that "All numerals are recognizable, but some have reversals (left to right or top to bottom) or irregularities. Sizes may vary between the numbers. Left to right orientation for the most part" (Bleiker, 2015). One example of a level 4 on the Number Writing assessment is Tony's Number Writing Mid-Test. All of the number symbols are present and recognizable. He has no reversals. However, the numbers are sloping upward and getting smaller, which leaves his attempt out from being a level 5 . 


\section{$12345678 \%$}

Figure 15. Tony's mid-test

A similar case is that of Abraham. He independently decided to continue the task to include the numbers up to 15 . He, too, had no reversals, but his numbers vary randomly in size, with the 5 reaching the second line of numbers. This is showing great progress from his previous attempt, which scored a level 2, but it is not at a level 5 yet.

\section{5
$1112131+578910$}

Figure 16. Abraham's mid-test

Another example of a level 4 is Cristina's performance on the Mid-Test. All her numerals are present, recognizable, in order, and she has only two reversals. In fact, they are almost in a straight line and almost all of them are approximately the same size. Hers is very close to being a level 5 , but is not quite there yet.

\section{$123456<8 e$}

Figure 17. Cristina's mid-test

During the mid-year assessment process, the students were also able to count higher than at the beginning of the school year. Even the two that counted only up to ten counted to higher number than they did at the beginning of the school year. This represents an increase in cardinal and ordinal knowledge which is clearly reflected in the number writing task. 
The body language of the students during the writing task at this testing period was much different from the previous testing period as well. Most of the students seemed very self-assured in their knowledge. They did not need to wait for prompting from the assessor, but rather wrote on without waiting to be asked what the next number would be. In fact, in five cases, the students independently continued the task up to higher numbers without being asked to do so. Two of these went so far to include the number 10 in the task, and the other three went up to 15 and in some cases 20.

Many of the students were silent throughout the number writing task, mostly nodding in understanding or calling out the next number and busying themselves with the task at hand. Unlike the first assessment period, there were no blank stares or looking out into space, and there were no helpless glances or calls for help. The students displayed knowledge of what was expected of them and eagerness to carry it out.

In terms of fine motor skills, all students displayed an adequate pincer grasp and an appropriate writing pressure with the marker used for the task. This shows a great improvement from the previous assessment period as well. This is something that is clearly acquired from practice.

Practice also fosters the sensory memory necessary to properly write the number symbols. To begin with, there were much less random markings and many more purposeful number symbols present in the students' writing. Even though in many cases the left-right orientation was lacking, as well as the writing direction for the numbers, the correct symbols were produced for at least 8 of the 9 nine digits by all the students. This is a very marked improvement from the previous testing session. 
As noted, though, the left-right orientation and writing direction were deficient, especially on numbers $2,3,7$, and 9 . Some students still write many of the numbers from bottom to top, and many of them write them from right to left. This is related to visualspatial skills as well as sensory memory, and this is the aspect of number writing that still left ample room for improvement in the second half of the school year. Mirror writing is considered quite common for the developmental stage of preschoolers (Fischer, 2011; McIntosh, Hillary, Brennan, \& Lechowicz, 2018), and perhaps a lack of maturity overall is the factor that limits their progress in this particular area.

Analysis of all children's number writing at post-test. By the time the students reached the post-test, more than half of the students scored a 5 by the number writing scale, four scored a 4, and only two scored a level 3. Most of the students showed improvement from their scores in the mid-test.

Even the students who remained at a level 3 for the Number Writing assessment at the end of the school year showed some signs of improvement qualitatively. They were mostly excluded from higher levels due to reversals in orientation, but the overall size of the numbers was approximately the same, and they were strung along a fairly straight line, as in the example of Amy.

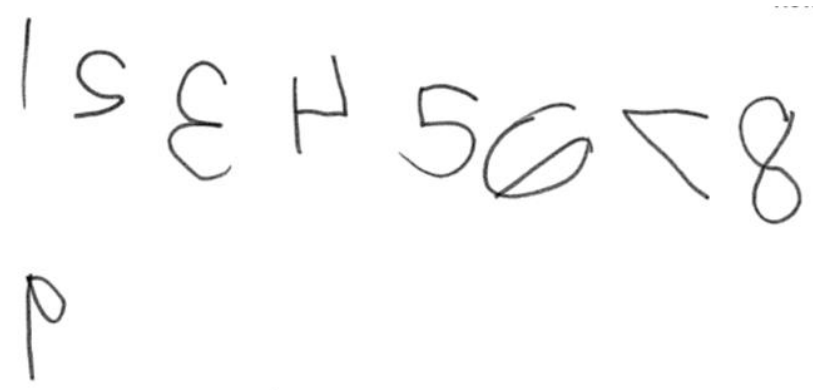

Figure 18. Amy's post-test 
A small group of students performed at a level 4 for the post-test. Jose was one of those, showing a marked improvement from the beginning of the school year. Jose wrote all the number symbols with only two reversals. With few exceptions, namely the five and the nine, the symbols look approximately the same size, evenly spaced on an almost straight line.

\section{$12345618^{p}$}

Figure 19. Jose's post-test

Roxanne also scored at a level 4 at the end of the school year, having improved from her mid-test number writing performance. Although the size of her numbers is more varied, the line appears straight and reversals in orientation are limited to only two.

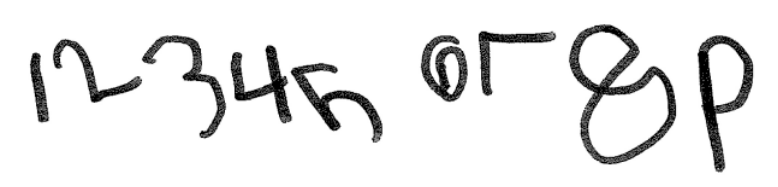

Figure 20. Roxanne's post-test

Most of the students were able to achieve a level 5 at the end of the school year. This is a sign of developmental progression, as there were no students performing at this level in the previous two assessment periods. Abraham's post-test is an example of a level 5. A level 5 denotes that "All numerals are recognizable. They are approximately the same size. They have left to right orientation. Line is strong and clear. No more than one reversal" (Bleiker, 2015). Although this sounds like perfection, it is not developmentally appropriate to expect perfection from five-year-olds. However, a level 5 is about as close as it can get. In Abraham's post-test it is clear that he has no reversals, the numbers are all approximately the same size, and the numbers that are primarily 
being assessed (1 through 9 ) are written on an approximately straight line. The symbols for 11 through 13 tend to slope a bit upward.

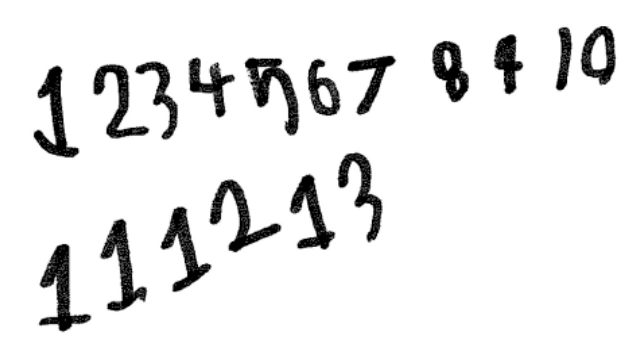

Figure 21. Abraham's post-test

Another example of a level 5 performance is Tony's post-test. He wrote all the number symbols almost the same size on a straight line that slopes slightly downwards. The symbols look practically flawless and do not contain any reversals.

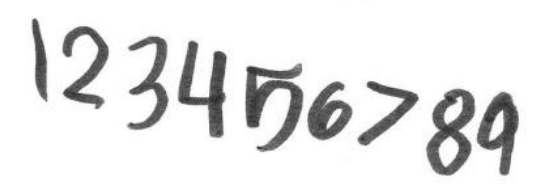

Figure 22. Tony's post-test

One more example of a level 5 is Cristina's post-test attempt. Her numbers are all the same size on a truly horizontal straight line, but number three has a reversal of orientation. For the most part, however, level 5 writing attempts are truly outstanding in symmetry and cohesiveness, which can be qualitatively appreciated.

\section{$12 \varepsilon 456789$}

Figure 23. Cristina's post-test

In the number counting task that precedes the number writing, the students demonstrated great improvement as well. All except for one were able to count successfully at least up to 30 , with two students counting up to the eighties and two more counting up to 100 . Together with the number writing, this means that their overall 
number knowledge, both cardinal and ordinal, increased since the middle of the school year, demonstrating a great overall improvement since the beginning of the school year.

Their fine motor skills had already improved significantly by mid-year, in terms of the pincer grasp and writing pressure. However, it is important to note that the overall size of the writing was much smaller compared to previous assessment periods. The ability to write the numbers approximately the same size and in an approximately straight line (on an unlined sheet of paper) improved very much as well. These important markers of visual-spatial skills were more present than they were earlier in the school year.

Once again, the body language of the students approaching the task was business as usual. They did not appear nervous or perplexed as they did at the beginning if the school year. Rather, they seemed to approach the task with greater care and attention to detail than they did even at the mid-test. They seemed to write more slowly, not because they did not know how to write the numbers, but because they wanted to accomplish the task as perfectly as possible.

As a matter of fact, the orientation of the written numbers improved since the previous assessment period, especially on the numbers 2 and 3 . The numbers 7 and 9 , however, still seem to be eluding them in terms of orientation. That said, directionality in writing improved very much since the mid-test. The figure eight, for example, went up to ten students that were able to correctly draw it from six that were able to do it in the midtest This means that overall, the students were using much more top to bottom and left to right orientation than they were at the beginning of the school year, and more than at the middle of the school year too. 
These changes, paired with the improvement in the size and linear arrangement of the numbers, amount to much better developed visual-spatial skills than the students were previously displaying. This was the area that left mot room improvement in the mid-test, and indeed, throughout the second half of the school year, the students did improve in it.

The improvements observed in the second half of the school year also point to improved sensory memory, which aids greatly in obtaining the proper orientation for the number symbols, but also enables the students to write the numbers with correct directionality effortlessly, without having to pause to think about which way they can produce the number symbol they know to be correct.

Conclusions. The overall number writing for the students demonstrated a progression from a low level at the beginning of the school year, with the majority of the students scoring at a level 1 and only very few at a level 2 or 3 , with some of them progressing to a level 3 by mid-year and most of them even higher, to a level 4 . By the end of the school year, most of the students achieved a level 5 on the number writing scale. These marked improvements were reflected in every aspect of number writing, from fine motor skills to visual-spatial skills to number symbol recognition and muscle memory recall. In general, the overall improvements in number writing are widely reflective of skills and pre-requisites necessary for number knowledge attainment, which was demonstrated in the other complementary measures, such as the number counting measure, as well as in their body language and approach to the task.

\section{Case Studies of Three Children}

For the purposes of the descriptive analysis of this study, three major categories have emerged from the data that represent major patterns observed in the video analysis. 
Each of these will be represented by one student. Their actual names will be withheld and will be identified by pseudonyms.

The first category will be represented by Amy, a student who was very lowperforming at the beginning of the year. Her initial performance across all the mathematics assessments conducted was substantially below level. Approximately five students in the experimental group fall into this category. Their learning process throughout the school year shared many characteristics with Amy. Make steady gains to finish the year at an intermediate level towards the end of the year, appropriate for her age.

The second category will be represented by Brian. Students in this category start at a low-middle level at the beginning of the year but make substantial gains and end at a favorable level at the end of the year. This category describes a typically developing child that enters prekindergarten with great potential for learning gains. About half of the children in the study fall into this category.

The third category will be represented by Cristina. Students in this category begin at a higher level than most of their peers and continue to make gains throughout the year to finish at a high level of competency. There are about three children who fit into this category. Curiously, children in this category do not necessarily outperform those in the second category. They just begin better prepared and make gains more steadily, instead of seeing markedly large learning gains as those in the second category.

Analysis of child 1. This section describes Amy, a girl who entered preschool at the age of four. Amy was in childcare prior to the beginning of her participation in the VPK program throughout the 2018-2019 school year. Amy is a girl who, like many 
students today, has separated parents. She lives with her mom on weekdays and with her dad on weekends. She has no siblings. Both of her parents are Hispanic immigrants with a low level of education and low-income jobs. The primary language spoken at her house is Spanish.

Upon entry to preschool, Amy performed very poorly on all different assessment measures. She was only able to count up to number seven from memory, performed very poorly on the Number Knowledge assessment, and performed below expectations across all measures of the VPK Assessment. In fact, she performed in the bottom quartile of all her classmates at the beginning of the school year.

Amy's number writing at the beginning of the school year was nearly indistinguishable. Her grip on the writing utensil was soft. Her form lacked up-down leftright orientation on the individual markings, although all the symbols were strung on a line from left to right thanks to prompting by the assessor. She appeared to be "drawing" the numbers rather than writing them precision. Her numbers were large, long, wavy, and not in a consistent line. She was constantly waiting for directions from the assessor. Her lack of self-direction is a sign of lack of self-assurance in her knowledge, meaning that her number knowledge was weak at best, and this is supported by the fact that she was only able to count up to seven from memory, where most of her classmates were able to count up to ten. This also points to a lack of the practice that builds the tactile memory to write numbers quickly and confidently from memory. 

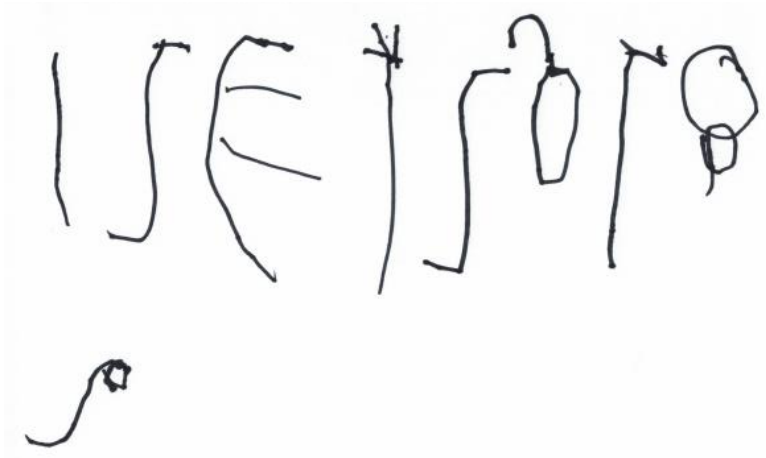

Figure 24. Amy's pre-test

By mid-year, Amy's performance had made slow but steady gains. She was able to count up to ten, and with more certainty than at the beginning of the school year. Her performance on the Number Knowledge assessment improved, as well as that on the VPK Assessment, although it still fell below expectations on three of four measures.

Her number writing also improved. The numbers are clearly distinguishable, and almost all of them are present. However, her left-right orientation is still messy, including reversals on the two, the three, the seven, and the nine. Also, she drew the number eight with two circles, instead of doing a figure eight with a single stroke, which denotes a lack of practice with this particular number. Regardless, this time she did not have to wait for the assessor to dictate the following number before writing, but rather readily jumped ahead and wrote it. This led her skip number four, but overall it shows a great improvement in her number knowledge. Her grip was much firmer than on the first number writing task and is it clear that her fine motor skills improved in the four months since the previous number writing task. Her sensory memory for writing numbers is much stronger than on the previous attempt as well, as she wrote the numbers clearly with precision almost without thinking. This indicates that she must have had practice writing numbers. 


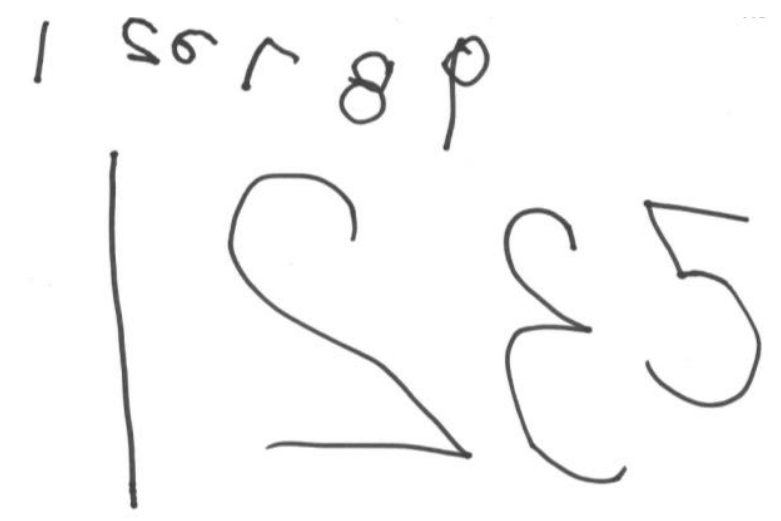

Figure 25. Amy's mid-test

At the end of the school year, Amy was performing at an average-high level on most of her assessments. Her improvements continued steadily. She was able to count to 39, which is more than the 30 required by the VPK program and indicates that she was able to recognize and apply the number naming pattern of adding 1-9 to name of the ten group. On her VPK Assessment, she scored meeting expectations on three of the measures, including the math, and exceeding expectations on the remaining one. Although she was by no means the highest performer in her class, her learning gains were steady, and she finished at a level acceptable for her age.

Her number writing at the end of the school year reflects this as well. Her leftright orientation was still struggling, with reversals on numbers two, three, four, seven, and nine. However, she wrote all the numbers properly from top to bottom, including a figure eight (as opposed to two circles) using broad, confident strokes with a firm grip. She demonstrated prompt and accurate knowledge of the numbers to which the assessor was referring. It is clear from watching her write the numbers that the number symbols, as well as the cardinal and ordinal characteristics they represent, have been successfully encoded in her memory. 

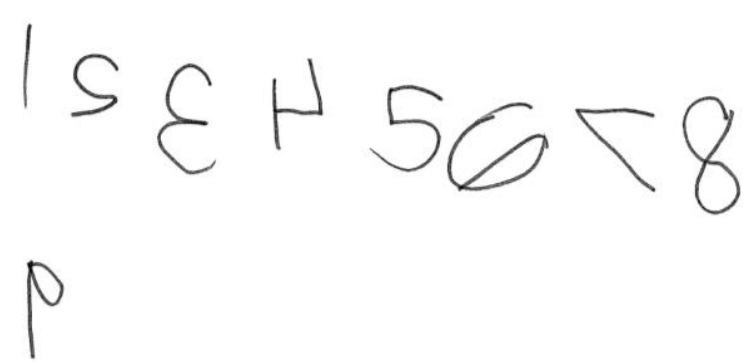

Figure 26. Amy's post-test

Amy's learning trajectory is one of a student who enters with little or no prior knowledge or skills in most academic areas, and progresses slowly to attain an averagehigh level of achievement at the end of preschool. In the area of math, in particular, she had a very limited proficiency in number knowledge and limited skills to carry out a basic number writing task at the beginning of the school year, but by making steady improvement throughout the school year, she was able to finish at an average level of proficiency in number knowledge and number writing at the end of the school year.

Analysis of child 2. This section describes Brian, a boy who entered preschool at the age of four. Brian also attended childcare prior to entering the VPK program. Brian lives with his mother, father, and an older brother. His parents are also Hispanic immigrants with a lower educational level and socioeconomic status. The language spoken at his home is Spanish as well. Much like Amy, Brian also began the school year at low level according to his assessment scores. However, his trajectory tells a different story, one in which the proper teaching, stimulation, and practice have unlocked the child's full potential, making large learning gains in the first half of the school year, and increasing steadily afterwards to finish at a very high level of proficiency in number knowledge and skills in number writing. 
In most of the assessments he performed quite poorly at the beginning of the school year. When asked to count from memory, he was only able to count up to seven. On the VPK Assessment, he scored below expectations on all the measures except one, print knowledge, in which he scored exceeding expectations. On the Number Knowledge assessment he scored very low, in the pre-dimensional area, as well.

Brian's number writing at the beginning of the school year was also very poor. Only the first three number symbols are recognizable as representing the correct number. The rest resemble random markings that that correspond to each number that the assessor prompted him to write. His grip on the writing utensil was somewhat awkward and weak, and this is evidenced in his writing as well. His writing orientation is very poor, as he draws many of his symbols from bottom to top. He spends a great deal of time looking down at his paper with a serious face and waiting for the assessor to tell him the number that follows. On the whole, he seems very uncertain, and demonstrates an overall lack of number knowledge, both cardinal and ordinal, and lack of sensory memory and fine motor skills required to successfully carry out the task of number writing.

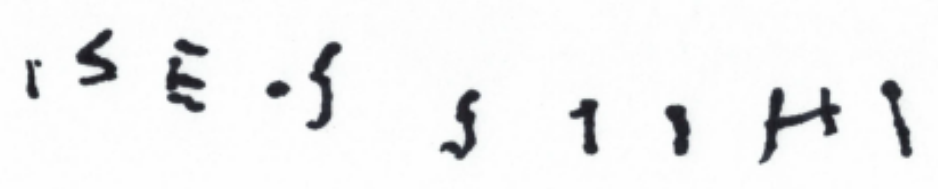

Figure 27. Brian's pre-test

By the middle of the school year, Brian demonstrated great progress. His VPK Assessment scores greatly improved from the beginning of the school year. In fact, he performed in the meeting expectations category on math, oral language and vocabulary, and phonological awareness, and exceeding expectations in print knowledge. This is 
quite a leap from the beginning of the school year, and one that most of his peers were not able to make. His performance on the Number Knowledge assessment also improved greatly, now scoring in the one-dimensional category, also higher than most of his peers. He was also able to count up to 24 confidently, which demonstrates a greater number knowledge, and shows that he overcame the hurdle of the teens and was beginning to learn the pattern of naming tens with the digits one through nine attached at the end.

His number writing also improved substantially. His grip was much firmer and closer to the tip of the writing utensil, which shows an improvement in fine motor skills from the beginning of the school year. His top-down orientation was fine, as he did not write any number from the bottom up, but his left-right orientation still had room for improvement. He had reversals on numbers two, three, four, and seven. He did, however, make a figure eight for number eight, as opposed to two circles, which is the tendency for children who know what number eight looks like but have not had practice with writing it correctly. He was more secure in approaching the writing of each number directly without pausing much to think about what the number looks like and how to achieve producing the symbol, which means that he was developing the sensory memory necessary to write the number symbols automatically. He was well able to tell the assessor which number comes next, which also demonstrates an increase in number knowledge from the beginning of the school year.

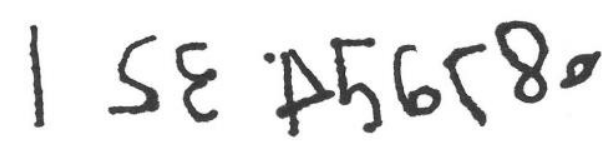

Figure 28. Brian's mid-test 
By the end of the year, Brian was performing at a very high level in all his assessments, including in math. Although his Number Knowledge assessment score remained the same, his VPK Assessment scores improved even more than at mid-year, which means he was not stagnant in his learning. He got scores in the exceeding expectations category across all four measures. Moreover, he was able to count up to 100 without skipping a beat, easily mastering the patterned structure of the number after twenty.

In terms of the number writing, he did quite excellent on this task as well. His fine motor skills were excellent, as displayed not only in his grip, but also in the way he commanded the writing utensil to write small, clear number symbols in an almost straight line. His left-right orientation improved greatly since the mid-year assessment. He only had one reversal on number nine. He wrote a figure eight for number eight. Moreover, he wrote all the numbers quickly and concisely, pausing only on number five, presumably to determine the direction for the number. Overall, it is clear from watching Brian write his numbers that he has the number knowledge and sensory memory necessary to complete this task successfully.

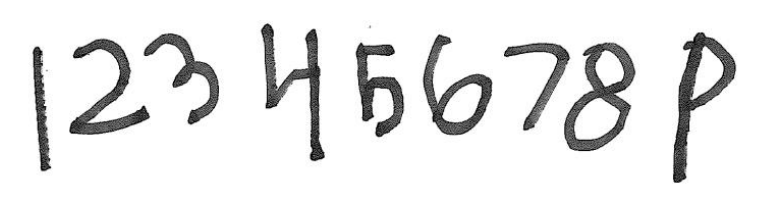

Figure 29. Brian's post-test

Brian's learning path was one that began at a very low level, comparable to most of his peers, but made its way quickly to high learning gains, making large gains in the first half of the year and even more steady gains in the second half. Brian represents 
students with a high latent potential who flourish when given the proper educational stimulation, especially in the area of math.

Analysis of child 3. This section describes Cristina, a student who performed above average at the beginning of the school year. Like Amy and Brian, her parents are Hispanic immigrants. However, her mother lived in New York for several years before moving to Miami, and she learned English there. Her father also speaks some English. As such, English is one of the languages spoken at her home. This gives her a key advantage over many of her classmates. Besides this, it appears Cristina entered preschool with some prior mathematical knowledge and skills that enabled her to perform better than most of her peers at the beginning of the school year.

The assessments at the beginning of the school year reveal that Cristina performed quite well for the pretest. She managed to count up to ten, like the better-performing half of the class on the number counting assessment. She scored better than three quarters of her peers on the Number Knowledge assessment, which objectively is still in the predimensional category, but reveals a slight advantage in number knowledge. In the VPK Assessment, she scored meeting expectations on three of four measures, and below expectations on the fourth measure. It is clear that she is performing at an overall better level than most of the students at this point in the year.

In her number writing, she also performed much better than her peers. She was able to tell the assessor which number comes next for writing. She had a firm grip on the writing instrument and great top-down left-right orientation. She was able to confidently write numbers one through three, but when she got to number four, she said, "I don't know how," and made scribbles for numbers four and five, looking perplexed from side 
to side. When she reached number six, it appears that she knew what the number symbols look like and was guessing how to draw them. She verbalized her thinking, saying for number eight, for example, "Ummm, two circles..." She was able to draw the number symbols for six through nine correctly, albeit with some awkwardness. Her number writing demonstrates greater number knowledge than many of her peers. Her sensory memory for writing, though, is limited to the first three numbers, clearly lacking practice in the rest of the numerals. Her recognition of the number symbols is a bit more advanced than many of her peers, but it is still limited in some respects.

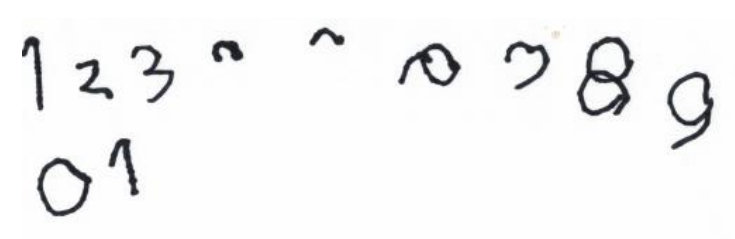

Figure 30. Cristina's pre-test

By mid-year, Cristina was performing even better than at the beginning, meaning that her initial position did not remain stagnant, but rather learning gains were made, putting her in an even more advantageous position learning-wise than she was at the beginning of the school year. On the VPK Assessment, she scored exceeding expectations on the math and print knowledge sections, meeting expectations on the oral language and vocabulary section, and below expectations on phonological awareness, which shows an improvement across most of the assessment. She was able to count independently up to 39 , which was the second highest counting score in the class. Her number knowledge score made huge leap from the beginning of the school year into the one-dimensional category. 
Her mid-year number writing also shows great improvement. Her fine motor skills were acceptable at the beginning of the school year, but they continued to improve. Her numbers were small, growing a bit larger from number four onward, but very mature compared to her peers. Her top to bottom orientation was flawless, but her left-right orientation still has room for improvement. She had reversals on numbers seven and nine, and she drew number eight with two circles. She did not need to be told the following number to be written, but rather jumped on the task without hesitation. This means that her number knowledge, number symbol recognition and her sensory memory greatly improved since the previous assessment. Although she began at a high level, she still made significant gains in the first half of the school year.

\section{$123456<8 e$}

Figure 31. Cristina's mid-test

By the end of the year, Cristina was performing even better, although her learning gains were not as great as in the first half of the school year. Her number counting went up to 49 , which is among the highest-scoring third of the class, but it not a huge increase from her previous 39. This was actually due to an error in which she skipped the fifties and jumped to the sixties. Had it not been for this careless mistake, she was actually able to count to 100 . Her Number Knowledge assessment score increased slightly, still scoring the one-dimensional area, which is appropriate for her age. On the VPK Assessment, she scored exceeding expectations on three of four measures and meeting expectations on the fourth, which is a significant improvement from the mid-year assessment. 
Her number writing also improved towards the end of the year. Her fine motor skills were exceptional, not only displaying a good grip on the writing tool, but also writing small, evenly spaced numbers, typical of an older child. Her left-right orientation showed improvement, with only one reversal on number three. This also demonstrates improved sensory memory from practice, except that she still draws two circles for number eight. Much like on the mid-test, she showed no hesitation in approaching the task, and her self-assurance is a sign that her number knowledge, both cardinal and ordinal, and her number symbol recognition were very high.

\section{$12 \varepsilon 456789$}

Figure 32. Cristina's post-test

Conclusions. Overall, it appears there are three trajectories that account for student's mathematical learning in preschool. There are students who begin at a low level and make slow steady gains to finish at an average level, students who begin at a low level and make significant gains to end at a high-achieving level, and students who begin with some preparation at an above average level and make steady gains to finish at a high-achieving level. Even those in the first category finished the school year at a level acceptable for their age and developmental level, and those in the third category made significant learning gains, which is a credit to the NumberWays program.

Although the evolution of number writing is somewhat varied, this analysis has shed light on the valuable identifiers of the number writing process that help trace its development. The presence of factors such as fine motor skills, visual-spatial skills, sensory memory, number knowledge, recognition of number symbols is undeniable. 
These factors are prerequisites to the successful completion of the number writing task in Pre-K, and they work together to bring about the semantic encoding that embeds numbers in children's brains to allow further development and progression in mathematics.

\section{Comparison of Number Writing Post-Test with Matched Group}

To determine the effectiveness of the intervention on number writing, the students in the intervention group must be compared to the control group. The control group actually came from four separate RCMA centers in the southern part of Miami-Dade County. These centers have a similar demographic composition to the center that received the intervention group - largely Hispanic, primarily Spanish-speaking homes with low-income, low education parents - described in more detail in the Methodology section.

One of the most salient features of the Number Writing post-test performance of the RCMA group is that of the 46 students that were of preschool age in the four RCMA centers, only one scored a level 5 in the number writing. The near absence of level-5performing students indicates that this is trait that requires the right kind of educational stimulation in order to develop. Moreover, there were two students that performed at a level 1 and five students that performed at a level 2. The Calvary Baptist (CB) group did not have any students performing at a level 1 or 2 even in the mid-test. Twenty-five students from RCMA, the largest portion of the students, performed at a level 3, a score of which the CB group had some in the mid-test, and only two in the post-test. Finally, 13 students from RCMA performed at a level 4, which was a frequently occurring score in the CB group post-test. This means that overall, the scores for the RCMA group were lower than for the CB group. This will be further analyzed in the quantitative section. 
Descriptively, it means that the entire number writing developmental spectrum was displayed by the RCMA group in the post-test. A clearer picture of this phenomenon is portrayed in the Post-Test Number Writing Matrix for RCMA group below. At a glance, the table appears similar to the CB Mid-Test, with most of the fine motor (M), visual-spatial $(\mathrm{V})$, and symbol $(\mathrm{S})$ boxes, about half of the orientation $(\mathrm{O})$ boxes, and very few of the directional (D) boxes filled in. It is also clear that for some students, more than half of the boxes are empty, whereas for others, more than half of the boxes are filled in. This is in contrast to the CB group at post-test, which has most of the boxes filled in for most of the students, denoting adequate performance in all the areas mentioned above.

\section{Legend}

M1: Uses Pincer Grasp

M2: Applies Appropriate Writing Pressure

V1: Numbers Approximately the Same Size

V2: Numbers in a Straight Line

V3: Writing Starts at Top Left Corner and Continues to the Right

S1-S9: Produces Correct Symbol for Each Number

O1-O9: Correct Orientation for Each Number

D1-D9: Correct Direction in Writing Each Number 


\begin{tabular}{|c|c|c|c|c|c|c|c|c|c|c|c|c|c|c|c|c|c|c|c|c|c|c|c|c|c|c|c|c|c|c|}
\hline $\begin{array}{l}\text { Child } \\
\text { ID }\end{array}$ & $\begin{array}{l}\mathrm{M} \\
1\end{array}$ & & & $\begin{array}{l}\mathrm{v} \\
2\end{array}$ & $\begin{array}{l}\mathrm{v} \\
3\end{array}$ & & & $\begin{array}{l}5 \\
3\end{array}$ & $\begin{array}{l}S \\
4 \\
\end{array}$ & $\begin{array}{l}5 \\
5\end{array}$ & $\begin{array}{l}S \\
6\end{array}$ & $\begin{array}{l}S \\
7\end{array}$ & $\begin{array}{l}5 \\
8\end{array}$ & $\begin{array}{l}S \\
9 \\
\end{array}$ & $\begin{array}{l}\mathrm{O} \\
1\end{array}$ & \begin{tabular}{l|l}
$\mathrm{O}$ \\
2
\end{tabular} & $\begin{array}{l}\mathrm{O} \\
3\end{array}$ & $\begin{array}{l}\mathrm{O} \\
4\end{array}$ & $\begin{array}{l}\mathrm{O} \\
5\end{array}$ & \begin{tabular}{l|l}
$\mathrm{O}$ & 3 \\
6 & 7 \\
\end{tabular} & & $\begin{array}{lll}0 & 0 \\
3 & 9\end{array}$ & \begin{tabular}{|l}
$\mathrm{D}$ \\
1
\end{tabular} & \begin{tabular}{|l|}
$\mathrm{D}$ \\
2
\end{tabular} & $\begin{array}{l}D \\
3\end{array}$ & & & \begin{tabular}{l|l}
$\mathrm{D}$ & $\mathrm{I}$ \\
6 & 7
\end{tabular} & & \begin{tabular}{|l|}
$\mathrm{D}$ \\
9 \\
\end{tabular} \\
\hline 21801 & $\mathrm{X}$ & & & & $\mathrm{X}$ & $\mathrm{x}$ & $\mathrm{X}$ & & $\mathrm{X}$ & & $\mathrm{X}$ & $\mathrm{X}$ & $\mathrm{x}$ & $\mathrm{X}$ & $\mathrm{X}$ & $\mathrm{X}$ & $\mathrm{x}$ & $\mathrm{X}$ & & $\mathrm{X}$ & & \begin{tabular}{l|l}
$X$ & $X$ \\
\end{tabular} & $X$ & $\mathrm{X}$ & $\mathrm{X}$ & & & & & \\
\hline 21803 & $\mathrm{X}$ & & $\mathrm{X}$ & & $\mathrm{X}$ & $\mathrm{x}$ & $\mathrm{X}$ & & $\mathrm{X}$ & $x$ & $\mathrm{X}$ & $\mathrm{x}$ & $\mathrm{x}$ & $\mathrm{X}$ & $\mathrm{x}$ & $\mathrm{X}$ & & $\bar{x}$ & $\mathrm{x}$ & \begin{tabular}{l|l}
$X$ & 7 \\
\end{tabular} & & \begin{tabular}{ll|l}
$X$ & $X$ \\
\end{tabular} & $\mathrm{X}$ & & & & & $\begin{array}{lll}x \\
\end{array}$ & & $\mathrm{X}$ \\
\hline 21804 & $\mathrm{X}$ & & & & $\mathrm{X}$ & $\mathrm{X}$ & $\mathrm{X}$ & & $\mathrm{X}$ & $\mathrm{x}$ & & $\mathrm{X}$ & & & $\mathrm{x}$ & & & $\mathrm{x}$ & $\mathrm{x}$ & 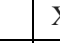 & & & & & & & & & & \\
\hline 21805 & $\mathrm{X}$ & $\mathrm{x}$ & $\mathrm{X}$ & $\mathrm{x}$ & $\mathrm{X}$ & $\mathrm{x}$ & $\mathrm{X}$ & $\mathrm{x}$ & $\mathrm{X}$ & $\mathrm{x}$ & $\mathrm{X}$ & $\mathrm{X}$ & $\mathrm{x}$ & $\mathrm{X}$ & $\mathrm{x}$ & $\mathrm{x}$ & $x$ & & $\mathrm{x}$ & \begin{tabular}{l|l}
$X$ & 5 \\
\end{tabular} & & $\begin{array}{l}X \\
X\end{array}$ & $\mathrm{X}$ & $\mathrm{X}$ & $\mathrm{X}$ & & & & & $x$ \\
\hline 21806 & $\mathrm{X}$ & & $\mathrm{X}$ & $\mathrm{x}$ & $\mathrm{X}$ & $\mathrm{X}$ & $\mathrm{X}$ & & $\mathrm{X}$ & $\mathrm{x}$ & $\mathrm{X}$ & $\mathrm{X}$ & $\mathrm{x}$ & $\mathrm{X}$ & & & & & $\mathrm{x}$ & $X$ & & $\begin{array}{l}X \\
X\end{array}$ & & & & & & & $x$ & \\
\hline 21807 & $\mathrm{X}$ & $\mathrm{X}$ & & & & $x$ & $\mathrm{X}$ & & $\mathrm{X}$ & $\mathrm{x}$ & $\mathrm{X}$ & & $\mathrm{X}$ & $\mathrm{X}$ & $\mathrm{x}$ & $\mathrm{X}$ & & & $\mathrm{x}$ & & & $\begin{array}{ll}X \\
X\end{array}$ & & $\mathrm{X}$ & & & & & & \\
\hline 21809 & $\mathrm{X}$ & & $\mathrm{X}$ & $\mathrm{x}$ & $\mathrm{X}$ & $\mathrm{x}$ & $\mathrm{X}$ & $\mathrm{x}$ & $\mathrm{X}$ & $\mathrm{x}$ & & & & & $\mathrm{x}$ & $\mathrm{x}$ & $x$ & & $x$ & & & & & $\mathrm{X}$ & & & & & & \\
\hline 21810 & $\mathrm{X}$ & & & $\mathrm{X}$ & $X$ & $\mathrm{X}$ & & & & & & & & & $\mathrm{X}$ & & & & & & & & $\mathrm{X}$ & & & & & & & \\
\hline 21811 & $\mathrm{X}$ & & $\mathrm{X}$ & & $\mathrm{X}$ & $\mathrm{X}$ & $\mathrm{X}$ & $\mathrm{X}$ & $\mathrm{X}$ & $\mathrm{X}$ & & & & & $\mathrm{X}$ & & $\mathrm{X}$ & & $\mathrm{X}$ & & & & & & & & & & & \\
\hline 21812 & $\mathrm{X}$ & $\mathrm{x}$ & & $\mathrm{x}$ & $\mathrm{X}$ & $\mathrm{x}$ & $\mathrm{X}$ & $\mathrm{x}$ & & & & & & & & & $\mathrm{x}$ & & & & & & & & & & & & & \\
\hline 21813 & $\mathrm{X}$ & & $\mathrm{X}$ & $\mathrm{X}$ & $X$ & $\mathrm{x}$ & $\mathrm{X}$ & $\mathrm{X}$ & $\mathrm{X}$ & $\mathrm{X}$ & & $\mathrm{X}$ & $\mathrm{x}$ & $\mathrm{X}$ & $\mathrm{x}$ & $\mathrm{x}$ & $\mathrm{x}$ & $\mathrm{x}$ & $\mathrm{X}$ & & & \begin{tabular}{r|r}
$X$ \\
\end{tabular} & $x$ & $\mathrm{X}$ & $\mathrm{X}$ & & & & \begin{tabular}{l|l}
$x$ & $X$ \\
\end{tabular} & \\
\hline 21814 & $\mathrm{X}$ & & $\mathrm{X}$ & & $\mathrm{X}$ & $\mathrm{x}$ & $\mathrm{X}$ & $\mathrm{X}$ & $\mathrm{X}$ & $\mathrm{x}$ & $\mathrm{X}$ & $\mathrm{x}$ & $\mathrm{x}$ & & $\mathrm{X}$ & & & $\bar{x}$ & $\mathrm{X}$ & 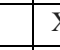 & \begin{tabular}{l|l}
$x$ & 2 \\
\end{tabular} & $\begin{array}{l}\mathrm{X} \\
\end{array}$ & \begin{tabular}{|l}
$X$ \\
\end{tabular} & & & & & & & \\
\hline 21815 & $\mathrm{X}$ & $\mathrm{X}$ & & $\mathrm{X}$ & & $\mathrm{X}$ & & $\mathrm{X}$ & $\mathrm{X}$ & $\mathrm{x}$ & $\mathrm{X}$ & $\mathrm{X}$ & $\mathrm{x}$ & & & & & & $\mathrm{X}$ & $\lambda$ & \begin{tabular}{l|l}
$x$ & 5 \\
\end{tabular} & & & & & & & & & \\
\hline 21816 & $\mathrm{X}$ & $\mathrm{x}$ & & & $\mathrm{X}$ & $x$ & & & & & & & & & $x$ & & & & & & & & $X$ & & & & & & & \\
\hline 21817 & $\mathrm{X}$ & & $X$ & & $X$ & $\mathrm{x}$ & $\mathrm{X}$ & $\mathrm{X}$ & $\mathrm{X}$ & $\mathrm{X}$ & & $\mathrm{X}$ & $\mathrm{x}$ & $\mathrm{X}$ & $\mathrm{X}$ & & & $\mathrm{X}$ & $\mathrm{X}$ & & & $\mathrm{X}$ & $x$ & & & & $\mathrm{X}$ & & & \\
\hline 21818 & $\mathrm{X}$ & $\mathrm{x}$ & $\mathrm{X}$ & $\mathrm{X}$ & $\mathrm{X}$ & $\mathrm{x}$ & $\mathrm{X}$ & $\mathrm{X}$ & $\mathrm{X}$ & $x$ & $\mathrm{X}$ & & $\mathrm{x}$ & & $\mathrm{X}$ & $\mathrm{X}$ & $\mathrm{X}$ & & & $\mathrm{X}$ & & $\mathrm{X}$ & $x$ & \begin{tabular}{|l|}
$X$ \\
\end{tabular} & $\mathrm{X}$ & & & & & \\
\hline 21819 & $x$ & & $\mathrm{X}$ & & $\mathrm{X}$ & $x$ & & $\mathrm{x}$ & $\mathrm{X}$ & $x$ & $\mathrm{X}$ & $\mathrm{x}$ & $x$ & $\mathrm{x}$ & $\mathrm{X}$ & & & & $\mathrm{x}$ & \begin{tabular}{l|l}
$X$ & 7 \\
\end{tabular} & \begin{tabular}{l|l}
$x$ & 1 \\
\end{tabular} & $\mathrm{X}$ & $x$ & & & & & & & \\
\hline 21820 & $\mathrm{X}$ & $\mathrm{X}$ & & $x$ & & $\mathrm{x}$ & $\mathrm{X}$ & $\mathrm{X}$ & $X$ & $\mathrm{x}$ & $X$ & $\mathrm{X}$ & $x$ & $X$ & $x$ & & & $x$ & $\mathrm{x}$ & $\mathrm{X}$ & & $\bar{x}$ & $x$ & & & $X$ & $\mathrm{x}$ & $\mathrm{X}$ & $X$ & \\
\hline 21821 & $\mathrm{X}$ & $\mathrm{x}$ & $\mathrm{X}$ & & $X$ & $\mathrm{x}$ & $\mathrm{X}$ & $\mathrm{X}$ & $\mathrm{X}$ & $\mathrm{x}$ & $\mathrm{X}$ & $\mathrm{x}$ & $\mathrm{x}$ & $\mathrm{X}$ & $\mathrm{X}$ & $\mathrm{X}$ & $\mathrm{x}$ & $\mathrm{X}$ & & $\mathrm{X}$ & & \begin{tabular}{l|l|}
$X$ & $X$ \\
\end{tabular} & $\mathrm{X}$ & $\mathrm{X}$ & $\mathrm{X}$ & $\mathrm{X}$ & & $\mathrm{X}$ & & \\
\hline 21822 & $\mathrm{X}$ & $x$ & $X$ & & $X$ & $x$ & $X$ & $\mathrm{x}$ & $X$ & $\mathrm{x}$ & $X$ & & & & $\mathrm{X}$ & $\mathrm{x}$ & $\mathrm{X}$ & $\mathrm{X}$ & & & & & $X$ & $\mathrm{X}$ & $\mathrm{X}$ & $\mathrm{X}$ & & & & \\
\hline 21823 & $\mathrm{X}$ & $\mathrm{x}$ & $\mathrm{X}$ & $\mathrm{x}$ & $\mathrm{X}$ & $\mathrm{x}$ & $\mathrm{X}$ & $\mathrm{x}$ & $\mathrm{X}$ & $\mathrm{x}$ & $\mathrm{X}$ & $\mathrm{X}$ & $\mathrm{X}$ & $\mathrm{X}$ & & & & $\bar{X}$ & $\mathrm{x}$ & $\mathrm{X}$ & & $\mathrm{x}$ & & & & $\mathrm{X}$ & $\mathrm{x}$ & $\mathrm{X}$ & & \\
\hline 21824 & $\mathrm{X}$ & $x$ & $X$ & $x$ & $X$ & $x$ & $\mathrm{X}$ & $x$ & $\mathrm{X}$ & $x$ & $\mathrm{X}$ & $\mathrm{X}$ & $\mathrm{X}$ & & $\mathrm{X}$ & $X$ & & & & & 2 & $x$ & $x$ & $\mathrm{X}$ & & & & & $x$ & \\
\hline 21825 & $\mathrm{X}$ & $\mathrm{x}$ & $X$ & $x$ & $X$ & $\mathrm{x}$ & $X$ & & $\mathrm{X}$ & $\mathrm{x}$ & $\mathrm{X}$ & $\mathrm{X}$ & $\mathrm{x}$ & & $\mathrm{x}$ & $x$ & & & $x$ & \begin{tabular}{l|l}
$X$ & 5 \\
\end{tabular} & $\begin{array}{l}x \\
\end{array}$ & $\mathrm{X}$ & $\mathrm{X}$ & $\mathrm{X}$ & & & & & \begin{tabular}{l|l}
$X$ & $X$ \\
\end{tabular} & \\
\hline 21826 & $x$ & $\mathrm{x}$ & $X$ & & $\mathrm{X}$ & $x$ & $\mathrm{X}$ & $\mathrm{X}$ & $X$ & $\mathrm{X}$ & $X$ & $\mathrm{X}$ & $\mathrm{x}$ & $\mathrm{X}$ & $\mathrm{X}$ & & $\mathrm{X}$ & $\mathrm{X}$ & $\mathrm{x}$ & $\begin{array}{ll}x \\
\end{array}$ & \begin{tabular}{l|l}
$x$ \\
$X$
\end{tabular} & $\mathrm{X}$ & $x$ & & $\mathrm{x}$ & $\mathrm{X}$ & $\mathrm{X}$ & $\mathrm{X}$ & & \\
\hline 21827 & $\mathrm{X}$ & $\mathrm{x}$ & & $x$ & $\mathrm{X}$ & $\mathrm{x}$ & $\mathrm{X}$ & $\mathrm{X}$ & & $x$ & $X$ & $\mathrm{X}$ & & $\mathrm{X}$ & $x$ & $\mathrm{x}$ & $x$ & & $\mathrm{x}$ & $\mathrm{X}$ & & $x$ & $x$ & $X$ & $x$ & & & & & \\
\hline 21828 & $\mathrm{X}$ & $\mathrm{x}$ & $\mathrm{X}$ & $\mathrm{X}$ & $\mathrm{X}$ & $\mathrm{x}$ & $\mathrm{X}$ & $\mathrm{x}$ & $\mathrm{X}$ & & $\mathrm{X}$ & $\mathrm{X}$ & $\mathrm{x}$ & $\mathrm{X}$ & $\mathrm{x}$ & $\mathrm{x}$ & $\mathrm{x}$ & $X$ & & $\mathrm{X}$ & 2 & $\begin{array}{l}x \\
\end{array}$ & $X$ & $\mathrm{X}$ & $x$ & & & $x$ & & \\
\hline 21829 & $\mathrm{X}$ & $\mathrm{x}$ & & $\mathrm{X}$ & $\mathrm{X}$ & $\mathrm{x}$ & $\mathrm{X}$ & & $\mathrm{X}$ & $\mathrm{x}$ & $\mathrm{X}$ & $\mathrm{X}$ & $\mathrm{x}$ & $\mathrm{X}$ & $\mathrm{x}$ & & & & $\mathrm{x}$ & $\mathrm{X}$ & & $\begin{array}{l}X \\
X\end{array}$ & $x$ & & & & & $\bar{x}$ & & $\mathrm{X}$ \\
\hline 21830 & $\mathrm{X}$ & $\mathrm{x}$ & & $\mathrm{x}$ & $\mathrm{X}$ & $\mathrm{x}$ & $\mathrm{X}$ & $\mathrm{X}$ & $\mathrm{X}$ & & & & & & $\mathrm{X}$ & $\mathrm{X}$ & $x$ & $\mathrm{X}$ & & & & & $x$ & $\mathrm{X}$ & $\mathrm{x}$ & $\mathrm{X}$ & & & & \\
\hline 21838 & $\mathrm{X}$ & $\mathrm{x}$ & $\mathrm{X}$ & $x$ & $\mathrm{X}$ & $\mathrm{x}$ & $x$ & $\mathrm{x}$ & $\mathrm{X}$ & & & & & & $x$ & $\mathrm{X}$ & $\mathrm{x}$ & & & & & & $X$ & $\mathrm{X}$ & $\mathrm{x}$ & & & & & \\
\hline 21839 & $\mathrm{X}$ & $\mathrm{x}$ & $\mathrm{X}$ & & $\mathrm{X}$ & $x$ & $\mathrm{X}$ & $\mathrm{X}$ & $\mathrm{X}$ & & $X$ & $\mathrm{X}$ & $\mathrm{x}$ & $\mathrm{X}$ & $\mathrm{x}$ & $\bar{x}$ & $\mathrm{x}$ & $\mathrm{X}$ & & 2 & $x \mid$ & $\begin{array}{lll}X & X \\
\end{array}$ & $x$ & $\mathrm{X}$ & $\mathrm{X}$ & & & & & \\
\hline 21840 & $\mathrm{X}$ & & & & $\mathrm{X}$ & $\mathrm{x}$ & $\mathrm{X}$ & $\mathrm{X}$ & $\mathrm{X}$ & $\mathrm{x}$ & $\mathrm{X}$ & $x$ & $x$ & & $\mathrm{X}$ & $\mathrm{X}$ & $\mathrm{x}$ & & $\mathrm{x}$ & \begin{tabular}{l|l}
$X$ & \\
\end{tabular} & & $\begin{array}{l}x \\
\end{array}$ & $\mathrm{X}$ & $\mathrm{X}$ & $x$ & & & & & \\
\hline 21841 & $\mathrm{X}$ & $\mathrm{x}$ & & & $\mathrm{X}$ & $\mathrm{x}$ & $\mathrm{X}$ & $\mathrm{X}$ & $\mathrm{X}$ & $\mathrm{x}$ & & & $\mathrm{x}$ & & $\mathrm{X}$ & $\mathrm{X}$ & & & $\mathrm{x}$ & & 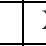 & $\bar{x}$ & $\bar{x}$ & $\mathrm{X}$ & & & & & & \\
\hline 21842 & $\mathrm{X}$ & $\mathrm{x}$ & $\mathrm{X}$ & $\mathrm{x}$ & $\mathrm{X}$ & $x$ & $\mathrm{X}$ & $\mathrm{x}$ & $\mathrm{x}$ & $x$ & $\mathrm{X}$ & $\mathrm{X}$ & $\mathrm{x}$ & $\mathrm{X}$ & $\mathrm{x}$ & & & & $\mathrm{x}$ & $\mathrm{X}$ & 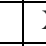 & $\bar{x}$ & $\mathrm{X}$ & & & & & $\mathrm{X}$ & & \\
\hline 21843 & $\mathrm{X}$ & $\mathrm{X}$ & & $\mathrm{X}$ & $\mathrm{X}$ & $\mathrm{x}$ & $\mathrm{X}$ & $\mathrm{X}$ & $\mathrm{X}$ & $\mathrm{x}$ & $\mathrm{X}$ & $x$ & $\mathrm{x}$ & $\mathrm{X}$ & $\mathrm{X}$ & & $x$ & & $\mathrm{x}$ & \begin{tabular}{l|l}
$X$ & 2 \\
\end{tabular} & & \begin{tabular}{l|l}
$X$ & $X$ \\
\end{tabular} & $X$ & & $\mathrm{X}$ & & & $x$ & & $x$ \\
\hline 21844 & $\mathrm{X}$ & $\mathrm{X}$ & & & $\mathrm{X}$ & $\mathrm{x}$ & $\mathrm{X}$ & $\mathrm{X}$ & $\mathrm{X}$ & $\mathrm{x}$ & $\mathrm{X}$ & $x$ & $\mathrm{x}$ & $\mathrm{X}$ & $\mathrm{X}$ & $\mathrm{X}$ & $\mathrm{x}$ & $\mathrm{X}$ & $\mathrm{x}$ & & & $\begin{array}{l}X \\
X\end{array}$ & $x$ & $\mathrm{X}$ & $\mathrm{X}$ & & & & & $X$ \\
\hline 21845 & $\mathrm{X}$ & $\mathrm{X}$ & & $\mathrm{X}$ & $\mathrm{X}$ & $x$ & $\mathrm{X}$ & $\mathrm{X}$ & $\mathrm{X}$ & $\mathrm{x}$ & $\mathrm{X}$ & $\mathrm{X}$ & $x$ & $\mathrm{X}$ & $\mathrm{X}$ & $\mathrm{X}$ & $\mathrm{x}$ & & $\mathrm{X}$ & & & $\begin{array}{l}X \\
\end{array}$ & $x$ & $\mathrm{X}$ & $\mathrm{x}$ & & & & & \\
\hline 21846 & $\mathrm{X}$ & & & & & $\mathrm{x}$ & $\mathrm{X}$ & $\mathrm{x}$ & $\mathrm{x}$ & $x$ & $\mathrm{X}$ & $\mathrm{X}$ & $\mathrm{x}$ & $\mathrm{X}$ & $\mathrm{x}$ & $\mathrm{X}$ & $\mathrm{x}$ & $\mathrm{X}$ & & $X$ & & $\mathrm{X}$ & $\mathrm{X}$ & $x$ & $\mathrm{x}$ & & & $\mathrm{X}$ & & \\
\hline 21847 & $\mathrm{X}$ & & & $\mathrm{X}$ & & $\mathrm{x}$ & $\mathrm{X}$ & $\mathrm{X}$ & $\mathrm{X}$ & & $\mathrm{X}$ & $\mathrm{X}$ & $\mathrm{x}$ & $\mathrm{X}$ & $\mathrm{X}$ & $\mathrm{X}$ & $\mathrm{x}$ & $\mathrm{X}$ & & $\mathrm{X}$ & & $\mathrm{X}$ & $x$ & $\mathrm{X}$ & & & & & & \\
\hline 21848 & $\mathrm{X}$ & $\mathrm{X}$ & & $\mathrm{X}$ & $\mathrm{X}$ & $\mathrm{x}$ & $\mathrm{X}$ & $\mathrm{X}$ & $\mathrm{X}$ & $\mathrm{x}$ & $\mathrm{X}$ & $\mathrm{X}$ & $x$ & $\mathrm{X}$ & $\mathrm{X}$ & & & $\mathrm{x}$ & $\mathrm{x}$ & & 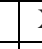 & $\bar{x}$ & $\mathrm{X}$ & & & & & & $X$ & \\
\hline 21849 & $\mathrm{X}$ & $\mathrm{x}$ & $\mathrm{X}$ & $x$ & $\mathrm{X}$ & $\mathrm{x}$ & $\mathrm{X}$ & $\mathrm{x}$ & $\mathrm{x}$ & $x$ & $\mathrm{X}$ & $\mathrm{X}$ & $\mathrm{x}$ & $\mathrm{x}$ & $\mathrm{x}$ & $\mathrm{X}$ & $\mathrm{x}$ & $\mathrm{X}$ & & & $x$ & \begin{tabular}{l|l}
$X$ & $X$ \\
\end{tabular} & & & & & & & & \\
\hline 21850 & $\mathrm{X}$ & $\mathrm{x}$ & $\mathrm{X}$ & $\mathrm{x}$ & $\mathrm{X}$ & $\mathrm{x}$ & $\mathrm{X}$ & $\mathrm{x}$ & $\mathrm{x}$ & $x$ & $\mathrm{X}$ & $\mathrm{x}$ & $\mathrm{x}$ & $\mathrm{X}$ & $\mathrm{x}$ & & & $\mathrm{X}$ & $\mathrm{x}$ & $\begin{array}{lll}x \\
\end{array}$ & & \begin{tabular}{l|l}
$X$ & $X$ \\
\end{tabular} & $x$ & & & & & $\mathrm{X}$ & & \\
\hline 21851 & $\mathrm{X}$ & $x$ & & & $\mathrm{X}$ & $x$ & $\mathrm{X}$ & & & & & & & & $\mathrm{x}$ & $\mathrm{X}$ & & & & & & & $\mathrm{X}$ & $x$ & & & & & & \\
\hline 21852 & $\mathrm{X}$ & $\mathrm{X}$ & & & $\mathrm{X}$ & $\mathrm{x}$ & 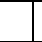 & & & & & & & & $\mathrm{x}$ & & & & & & & & $\mathrm{X}$ & & & & & & & \\
\hline 21855 & $\mathrm{X}$ & $\mathrm{x}$ & $\mathrm{X}$ & $\mathrm{x}$ & $\mathrm{X}$ & $\mathrm{x}$ & $\mathrm{X}$ & $\mathrm{X}$ & $\mathrm{X}$ & $\mathrm{X}$ & $\mathrm{X}$ & $X$ & $\mathrm{X}$ & $\mathrm{X}$ & & & $\mathrm{x}$ & $\mathrm{x}$ & $\mathrm{x}$ & & & $\begin{array}{lll}X & X \\
\end{array}$ & & $\mathrm{X}$ & $\mathrm{x}$ & & $\mathrm{X}$ & & & $\mathrm{X}$ \\
\hline 21856 & $\mathrm{X}$ & & & & $\mathrm{X}$ & $\mathrm{x}$ & $\mathrm{X}$ & & $\mathrm{X}$ & & & & & & $\mathrm{X}$ & $\mathrm{X}$ & & & & & & & & \begin{tabular}{|l|}
$\mathrm{X}$ \\
\end{tabular} & $\mathrm{X}$ & & & & & \\
\hline 21857 & $\mathrm{X}$ & $x$ & $\mathrm{X}$ & & $\mathrm{X}$ & $\mathrm{x}$ & $\mathrm{X}$ & & $\mathrm{X}$ & $x$ & $\mathrm{X}$ & $\mathrm{X}$ & $\mathrm{X}$ & $x$ & $x$ & $x$ & & $\mathrm{X}$ & & $\mathrm{X}$ & & & $x$ & $\mathrm{X}$ & $\mathrm{x}$ & $\mathrm{X}$ & & $\mathrm{X}$ & & $X$ \\
\hline
\end{tabular}

Figure 33. RCMA post-test number writing matrix 
As varied as the students' individual entries appear on the matrix, they were just as varied when scored with the Number Writing Scale (Bleiker, 2015). There were a couple of students performing at a level 1, such as Natasha. Natasha's post-test was similar to many of the pre-tests observed from the CB group. The symbols are random, some of them resemble letters, and they are not recognizable as being linked to any particular number. It is possible that this child entered preschool late in the school year and this has hindered her development in number writing, because her attempt is very rudimentary. However, there is a symbol corresponding to each number prompted by the assessor, although they are not in a straight line.

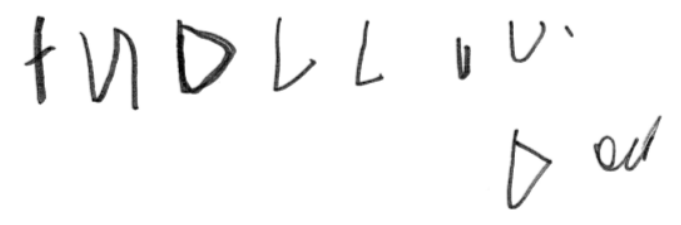

Figure 34. Natasha's post-test

There was also a small number of students who performed at a level 2, such as Christopher. These were not many, but they are also under-developed in their number writing for this stage in the school year. Not all of the numerals are present in his attempt, but the number symbols from 1 to 5 are there, and they are mostly recognizable, although they do contain reversals in orientation from left to right and from top to bottom. There are also no symbols present, random or otherwise, for the number 6 to 9 , which indicates at least a deficiency in the mental image of these digits.

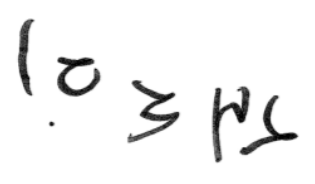

Figure 35. Christopher's post-test 
Another similar example is that of Lily. Her attempt at number writing includes only some of the numerals as well. However, these are a bit clearer than in the previous example. The line of writing slopes downwards a bit, but it is a bit straighter. The inclusion of some non-number symbols indicates a superficial knowledge of writing but a lack of number recognition and sensory memory. It also indicates a lack of overall number knowledge in the sense that there was not at least a random symbol produced for each number up to 9 .

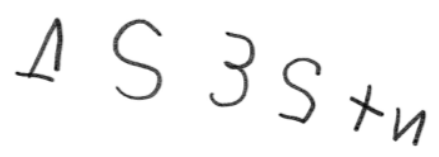

Figure 36. Lily's post-test

The most frequently occurring Number Writing post-assessment score for the RCMA group is a level 3, most readily represented by examples such as Juan. He was able to write most of the number symbols correctly except for number 5, and most of them are recognizable, with a reversal on number 7 . However, the numbers begin to appear similar in size and are strung mostly along an almost straight line. This is a more mature example of number writing, and more similar to those seen in the CB group at the end of the school year.

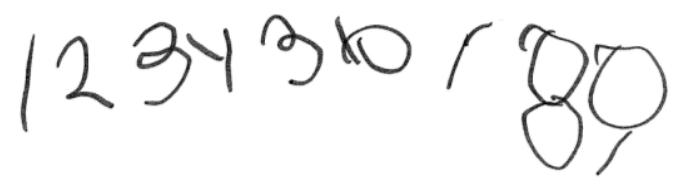

Figure 37. Juan's post-test

Another example of a level 3 on the Number Writing post-test from this group is that of Veronica. Veronica included all the number symbols except for the number nine. They are mostly accurate but contain four reversals in orientation. The numbers are 
approximately the same size and written on an almost straight line. Had it not been for the missing number and the reversals, this attempt would have scored at a higher level. This writing is indicative of advanced visual-spatial skills, but the student is lacking in recall of the number symbol and sensory memory for writing the missing number 9 , as well as for the number with reversals.

\section{$I_{2} 2+5 \partial \Gamma 8$}

Figure 38. Veronica's post-test

There was a sizable group of students from RCMA performing at a level 4 on the Number Writing post-test. This is much more consistent with what was seen on the posttest from the CB group, although in a much smaller proportion. One example is Alice's Number Writing post-test. Alice wrote all the numerals from 1 to 9 , and they are plainly

recognizable. She had only two reversals, but there are fluctuations in size, and the line of writing slopes downward greatly, although they are written in order properly from left to right.

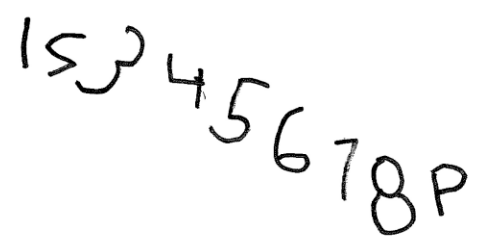

Figure 39. Alice's post-test

Another example of a level 4 performance in number writing is Raquel's posttest. Like the previous example, she included all the numerals from 1 to 9 with only two reversals in orientation. However, Raquel's line of writing is much straighter than Alice's, with only a slight downward slope, although her numbers to get progressively 
larger in size. In any case, all the numbers are present and drawn correctly, and the limited number of reversals indicates an advanced number symbol recall and tactile memory to write the numbers, which together point to adequate number knowledge.

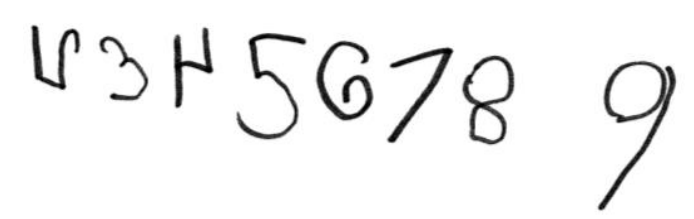

Figure 40. Raquel's post-test

The only level 5 score on the Number Writing post-test in the entire RCMA group is that of Jennifer. Jennifer met the requirements for a level 5 by having all the number symbols from 1 to 9 present and in order, approximately the same size, written on an approximately straight line, and with only one reversal in orientation on number 4 .

\section{9}

Figure 41. Jennifer's post-test

As is apparent from the number writing, but even more so from the videos, the fine motor skills for many RCMA students at the end of the school year are adequate, with almost all students dominating a pincer grip and a vast majority of them using a firm grip on the writing utensil. Only a few students were noted to have a very weak grasp about halfway up the marker, similar to that which most of the CB students had at the pre-test.

In terms of body language, most of the children were observed to approach the number writing task with enthusiasm, but once it began their reactions were interesting. Apparently, the students from the RCMA group are not accustomed to being asked to write their numbers, because one child, as the assessor said, "Now I need you to write..." 
he quickly interjected "My name?" Even so, they played along well until they realized, for some, that they were incapable of completing the task.

For the lowest-performing bunch, as soon as they got past number 1, they began hesitating, giving diverted glances, and for some, asking for help or verbalizing that they did not know how to write the number being asked of them. These were the ones that mostly scored at a level 1 or 2 by the Number Writing scale (Bleiker, 2015). For some this occurred as early as number 2 , while for others it was around number 5 . In some cases, these children were not able to tell the assessor which number came next and had to wait to be prompted before attempting to continue, which denotes a lack of cardinal and ordinal number knowledge. These also did not have the symbolic encoding or tactile memory to recall the number symbol and write it.

Those that performed at an average to high level behaved differently during the task. Those who were very self-assured in their number knowledge and ability to carry out the task continued ahead of the assessor without waiting for prompting, which signifies a high level of cardinal and ordinal number knowledge. These tended to perform better in the Number Writing assessment. They displayed signs of possessing both the symbolic encoding and the tactile memory that allowed them to complete the task efficiently and with accuracy. Students with this level of performance did not represent a large portion of the RCMA group.

Those with average performance were able to carry out the task with some prompting, often confessing that they did not know how to write a particular number, but well able to write the rest. These students had cardinal and ordinal number knowledge to the degree that most of them were able to determine which number came next without 
help, and many produced the correct symbol but without the dexterity that comes with sensory memory from practice. These students seemed to have symbolic encoding of the number symbols without the sensory memory aspect, which would denote a lack of practice writing the numbers. The students hesitated throughout the number writing task, taking time before writing each number symbol, as if trying to figure out what they were trying to write, comparable to the pre-test and mid-test from the CB group. Many of the students in the RCMA group performed at this level in the post-test.

Curiously, the students from the RCMA group demonstrated appropriate writing skills for their age. Most of the students had suitable fine motor skills with respect to writing for their age. Besides this, in this task, many of the students wrote numbers, even those that wrote numbers with random symbols for the ones they did not know, that were approximately the same size or in an approximately straight line, or both. Almost all students independently began in the top-left corner of the page, except for a couple of peculiar cases which wrote along the bottom of the page starting on the left and others that began somewhere in the middle of the page. Overall, however, the visual-spatial skills observed in the RCMA group were not under-developed, but rather ageappropriate. Apparently, they lack practice in writing numbers in particular.

This can be deduced by the absence of correct directionality for most students in the Number Writing assessment. More than just a few students drew numbers from bottom to top and had several errors of orientation in at least half of their numbers. Most of them were lacking correct directionality in at least six number symbols. Most students were not able to produce a number 8 by drawing a figure eight. 
Overall, the Number Writing post-test for the RCMA group was varied. It contained some samples on the lower end of the Number Writing Scale and some from the higher end. Most of the samples, however, resembled the CB group's mid-test, having a higher concentration in the level 3 and level 4 stages. The development of number writing in this group is present, but at the end of the school year it was lacking in key areas compared to the CB group. Although a large portion of the group had adequate fine motor skills, visual-spatial skills, and the cardinal and ordinal number knowledge required to carry out the task, many lacked the symbolic encoding of number symbols critical for success, and the sensory memory to perform the task efficiently was absent in most students in the RCMA group.

Based on these observations, the NumberWays intervention appears to be effective in helping children develop some of the skills important to umber writing found lacking in the comparison group, such as symbolic encoding and sensory memory necessary for writing numbers. Also, it helps a higher proportion of preschool children in a classroom develop cardinal and ordinal number knowledge. Overall, this intervention is very beneficial to the development of students' early math skills and knowledge.

\section{Quantitative Data}

This section reports the quantitative findings in this study. The quantitative part of this study should expand the findings from the qualitative section to produce a better understanding of students' development in number writing.

It should be noted that the sample sizes in this study are small. The CB group, which received the intervention, has 15 students, and the RCMA group has 45 students. The RCMA group was not assessed on measures such as Number Writing, Number 
Knowledge assessment, and Number Counting at pre- and mid-test, only at post-test. This is a limitation in this study. This limits the use of the standard statistical tests generally used in this type of study, such as ANOVAs and ANCOVAs, which function based on assumptions of normality, independence of errors, and equal variances (Meyers, Gamst, \& Guarino, 2013). With such a small sample size, normality of the variables cannot always be assumed. In cases in which the variables do not comply with normality, alternative statistical tests will be used.

\section{Equivalence of Groups at Pre-Test}

First, to establish equivalency between the CB group and the RCMA group as being comparatively equal, an independent samples T-test was used to compare means from the CB group to the RCMA group on four pre-test measures from the VPK Assessment, Print Knowledge, Phonological Awareness, Math, and Oral Language/Vocabulary.

\begin{tabular}{|c|c|c|c|c|c|c|c|}
\hline Tests of Normality $f c$ & $V P K$ & nt Pre- & $M$ & res & & & \\
\hline Measure & & $\underline{\text { Koln }}$ & rov- & $\mathrm{OV}^{\mathrm{a}}$ & & jiro- & \\
\hline & Group & $\underline{\text { Statistic }}$ & $\underline{\mathrm{df}}$ & Sig. & $\underline{\text { Statistic }}$ & $\underline{\mathrm{df}}$ & Sig. \\
\hline Print Knowledge & $\mathrm{CB}$ & .208 & $\overline{15}$ & .081 & .904 & $\overline{15}$ & .111 \\
\hline & RCMA & .176 & 45 & .001 & .921 & 45 & .005 \\
\hline Phonological Awareness & $\mathrm{CB}$ & .192 & 15 & .140 & .928 & 15 & .252 \\
\hline & RCMA & .169 & 45 & .002 & .930 & 45 & .009 \\
\hline Math & $\mathrm{CB}$ & .201 & 15 & .104 & .915 & 15 & .160 \\
\hline & RCMA & .112 & 45 & .195 & .961 & 45 & .129 \\
\hline Oral Language/Vocabulary & $\mathrm{CB}$ & .151 & 15 & $.200^{*}$ & .904 & 15 & .109 \\
\hline & RCMA & .096 & 45 & $.200^{*}$ & .966 & 45 & .207 \\
\hline
\end{tabular}

Most of the variables passed the Shapiro-Wilk test of normality, which is most appropriate for small samples, except for the Print Knowledge and the Phonological Awareness measures for the RCMA group. 


\begin{tabular}{|lllc|}
\hline \multicolumn{4}{|l|}{ Table 3 } \\
\multicolumn{4}{|l|}{ Descriptives of Variables for Print Knowledge and Phonological } \\
Awareness for RCMA & Group at Pre-Test & & \\
\hline Measure & Descriptive & $\frac{\text { Statistic }}{7.40}$ & Std. Error \\
\hline Print Knowledge & Mean & .490 \\
& Median & 8.00 & \\
& Variance & 10.791 & \\
& Std. Deviation & 3.285 & \\
& Skewness & -.296 & .354 \\
Khonological Awareness & Mean & -1.262 & .695 \\
& Median & 4.62 & .400 \\
& Variance & 7.195 & \\
& Std. Deviation & 2.682 & \\
& Skewness & .698 & .354 \\
& Kurtosis & .109 & .695 \\
\hline
\end{tabular}

The skewness for the Print Knowledge measure for the RCMA group was -0.296 , which is approximately symmetrical, for the Phonological Awareness measure was 0.698, which is moderately skewed, so the normality assumption will be made in order to run a T-test, which is considered robust enough to assimilate this matter. The results were as follows:

Table 4

Group Statistics for VPK Assessment Pre-Test Measures

\begin{tabular}{|c|c|c|c|c|c|}
\hline Measure & Group & $\underline{\mathrm{N}}$ & Mean & Std. Deviation & Std. Error Mean \\
\hline \multirow[t]{2}{*}{ Print Knowledge } & $\overline{\mathrm{CB}}$ & $\overline{15}$ & $\overline{4.80}$ & 3.098 & .800 \\
\hline & RCMA & 45 & 7.40 & 3.285 & .490 \\
\hline \multirow[t]{2}{*}{ Phonological Awareness } & $\mathrm{CB}$ & 15 & 3.13 & 2.066 & .533 \\
\hline & RCMA & 45 & 4.62 & 2.682 & .400 \\
\hline \multirow[t]{2}{*}{ Math } & $\mathrm{CB}$ & 15 & 6.47 & 2.134 & .551 \\
\hline & RCMA & 45 & 8.56 & 4.170 & .622 \\
\hline \multirow[t]{2}{*}{ Oral Language/Vocabulary } & $\mathrm{CB}$ & 15 & 10.47 & 5.139 & 1.327 \\
\hline & RCMA & 45 & 14.16 & 3.931 & .586 \\
\hline
\end{tabular}




\begin{tabular}{|c|c|c|c|c|c|}
\hline $\begin{array}{l}\text { Table } 5 \\
\text { Independent }\end{array}$ & mples T- & or VPK & ssessme & $r e-T e s$ & easures \\
\hline & $\begin{array}{r}\text { Levene's } \\
\text { of } \\
\end{array}$ & $\begin{array}{l}\text { Equality } \\
\text { es }\end{array}$ & & r Equali & Means \\
\hline$\frac{\text { Measure }}{\text { Print Knowledge }}$ & 1.381 & $\frac{\text { Sig. }}{.245}$ & $\begin{array}{c}\frac{\mathrm{t}}{} \\
-2.691 \\
-2.772\end{array}$ & $\begin{array}{c}\frac{\mathrm{df}}{58} \\
25.325\end{array}$ & $\begin{array}{c}\text { Sig. (2-tailed) } \\
.009 \\
.010\end{array}$ \\
\hline $\begin{array}{l}\text { Phonological } \\
\text { Awareness }\end{array}$ & 2.853 & .097 & $\begin{array}{l}-1.961 \\
-2.234\end{array}$ & $\begin{array}{c}58 \\
31.042\end{array}$ & $\begin{array}{l}.055 \\
.033\end{array}$ \\
\hline Math & 10.318 & .002 & $\begin{array}{l}-1.853 \\
-2.515\end{array}$ & $\begin{array}{c}58 \\
47.728\end{array}$ & $\begin{array}{l}.069 \\
.015\end{array}$ \\
\hline $\begin{array}{l}\text { Oral Language/ } \\
\text { Vocabulary }\end{array}$ & 2.532 & .117 & $\begin{array}{l}-2.908 \\
-2.543\end{array}$ & $\begin{array}{c}58 \\
19.754\end{array}$ & $\begin{array}{l}.005 \\
.019\end{array}$ \\
\hline
\end{tabular}

On the Print Knowledge measure, there was a significant difference in the scores for the CB group $(M=4.80, S D=3.10)$ and RCMA group $(M=7.40, S D=3.29) ; t(59)$ $=-2.691, p=0.009$. These results suggest that the RCMA group performed better than the $\mathrm{CB}$ group on this measure at the beginning of the school year.

On the Phonological Awareness measure, there was not a significant difference in the scores for the CB group $(M=3.13, S D=2.07)$ and RCMA group $(M=4.62, S D=$ $2.68) ; t(58)=-1.961, p=0.055$. These results suggest that there is no significant difference in performance between the two groups on this measure.

On Oral Language/Vocabulary measure, there was a significant difference in the scores for the CB group $(M=10.47, S D=5.14)$ and RCMA group $(M=14.16, S D=$ $3.93) ; t(58)=-2.908, p=0.005$. These results suggest that the RCMA group performed better than the CB group on this measure at the beginning of the school year as well.

The VPK Assessment Math portion violated Levene's test of homogeneity of variances $(p=0.002)$. This may be due to the unbalanced size of the two groups, $\mathrm{CB}(N=$ 15) and RCMA $(N=45)$. A Mann-Whitney U nonparametric test will be used to compare the scores between the two groups. 


\begin{tabular}{|c|c|c|c|c|c|c|c|c|}
\hline $\begin{array}{l}\text { Table } 6 \\
\text { Descriptive Statisti }\end{array}$ & for & $P K A s$ & essment & re-Test $\Lambda$ & Math Mea & & & \\
\hline & & & & & & & Percentiles & \\
\hline & $\underline{\mathrm{N}}$ & Mean & $\frac{\text { Std. }}{\text { Deviation }}$ & Minimum & Maximum & $25^{\text {th }}$ & $\begin{array}{c}\text { 50th } \\
\text { (Median) }\end{array}$ & $75^{\text {th }}$ \\
\hline VPK Assessment Math 1 & $\overline{60}$ & $\overline{8.03}$ & 3.857 & $\frac{2}{2}$ & 18 & $\overline{5.00}$ & 7.00 & 11.00 \\
\hline CB (1) or RCMA (2) & 61 & 1.75 & .434 & 1 & 2 & 1.50 & 2.00 & 2.00 \\
\hline
\end{tabular}

\begin{tabular}{|c|c|c|c|}
\hline \multicolumn{4}{|c|}{ Table 7} \\
\hline \multicolumn{4}{|c|}{ Ranks for VPK Assessment Pre-Test Math Measure } \\
\hline Group & $\underline{\mathrm{N}}$ & Mean Rank & Sum of Ranks \\
\hline $\mathrm{CB}$ & $\overline{15}$ & 24.27 & 364.00 \\
\hline RCMA & 45 & 32.58 & 1466.00 \\
\hline Total & 60 & & \\
\hline
\end{tabular}

\begin{tabular}{|c|c|}
\hline \multicolumn{2}{|l|}{ Table 8} \\
\hline \multicolumn{2}{|c|}{ Test Statistics for VPK Assessment Pre-Test Math Measure } \\
\hline Statistic & Value \\
\hline Mann-Whitney U & $2 \overline{44.000}$ \\
\hline Wilcoxon W & 364.000 \\
\hline $\mathrm{Z}$ & -1.604 \\
\hline Asymp. Sig. (2-tailed) & .109 \\
\hline
\end{tabular}

For the VPK Math pre-test measure, the Mann-Whitney U test indicated that there was no significant difference between the CB group $(M d n=6.00)$ and the RCMA group $(M d n=8.00)$ on the VPK Assessment Math $1, U=244.000, p=0.109$. This suggests that the two groups were on an approximately equal starting level in math knowledge according to the VPK assessment.

In any case, the t-tests and the nonparametric tests reveal that overall, the two groups are approximately equal in the math measure, and that the RCMA group has a slight advantage over the $\mathrm{CB}$ group on some of the measures not related to math, which are not the most relevant to the present study. For the aim of evaluating the effect of the NumberWays curriculum, a slight advantage in the control group at the beginning of the 
school year on language measures does not pose a great threat to the effectiveness of the intervention. On the contrary, if the intervention group performs better than the control group at the end of the school year despite these shortcomings, it gives more power to the results of the intervention.

\section{Performance Comparison at Post-Test}

Next, in order to determine the effect of the NumberWays intervention, it is necessary to determine if the Number Writing scores of the CB children at post-test are significantly higher than the children at RCMA at post-test, as well as on other post-test measures such as Number Knowledge, Number Counting, and the VPK Assessment math measure. Measures of effect size were also observed.

\begin{tabular}{|c|c|c|c|c|c|c|c|}
\hline \multirow{3}{*}{$\frac{\text { Measure }}{\text { Number Writino }}$} & \multirow[b]{2}{*}{ Group } & \multicolumn{3}{|c|}{ Kolmogorov-Smirnova } & \multicolumn{3}{|c|}{ Shapiro-Wilk } \\
\hline & & Statistic & $\underline{\mathrm{df}}$ & $\underline{\text { Sig. }}$. & Statistic & $\underline{\mathrm{df}}$ & $\underline{\text { Sig. }}$. \\
\hline & $\overline{\mathrm{CB}}$ & .363 & $\overline{15}$ &.$\overline{000}$ & .716 & $\overline{15}$ & $\overline{.000}$ \\
\hline & RCMA & 299 & 41 & .000 & .829 & 41 & .000 \\
\hline \multirow[t]{2}{*}{ Number Counting } & $\mathrm{CB}$ & .238 & 15 & .022 & .904 & 15 & .110 \\
\hline & RCMA & .146 & 41 & .028 & .930 & 41 & 014 \\
\hline \multirow[t]{2}{*}{ Number Knowledge } & $\mathrm{CB}$ & .222 & 15 & .045 & .875 & 15 & .040 \\
\hline & RCMA & .149 & 41 & .023 & .963 & 41 & .195 \\
\hline \multirow[t]{2}{*}{ VPK Assessment Math } & $\mathrm{CB}$ & 271 & 15 & .004 & .786 & 15 & .002 \\
\hline & RCMA & .141 & 41 & .039 & .896 & 41 & .001 \\
\hline
\end{tabular}

An exploration of the data yielded that most of the post-test data did not conform to normality $(p>0.05)$, using the Shapiro-Wilk test. Therefore, it was determined that the data would be analyzed using a Mann-Whitney U nonparametric test to compare medians from the CB group to the RCMA group on four post-test measures, Number Counting, Number Writing (based on the Number Writing Scale) (Bleiker, 2015), Number Knowledge assessment, and VPK assessment Math 3. The results were as follows: 


\begin{tabular}{|c|c|c|c|c|c|c|c|c|}
\hline $\begin{array}{l}\text { Table } 10 \\
\text { Descriptive Statist }\end{array}$ & for & Variou & Math Me & sures at & ost-Test & & & \\
\hline \multirow[b]{2}{*}{ Measure } & \multirow[b]{2}{*}{$\underline{\mathrm{N}}$} & \multirow[b]{2}{*}{ Mean } & \multirow[b]{2}{*}{$\underline{\text { Std. }}$} & \multirow[b]{2}{*}{ Minimum } & \multirow[b]{2}{*}{ Maximum } & \multicolumn{3}{|c|}{ Percentiles } \\
\hline & & & & & & 25th & $\begin{array}{c}\text { 50th } \\
\text { (Median) }\end{array}$ & 75th \\
\hline Number Knowledge & 61 & 6.13 & 2.225 & 2 & 11 & 4.50 & 6.00 & 8.00 \\
\hline Number Counting & 61 & 29.95 & 21.167 & 6 & 100 & 15.00 & 27.00 & 39.00 \\
\hline Number Writing & 61 & 3.46 & .976 & 1 & 5 & 3.00 & 3.00 & 4.00 \\
\hline VPK Assessment Math & 56 & 14.23 & 3.562 & 4 & 18 & 13.00 & 15.00 & 17.00 \\
\hline CB (1) or RCMA (2) & 61 & 1.75 & .434 & 1 & 2 & 1.50 & 2.00 & 2.00 \\
\hline
\end{tabular}

\begin{tabular}{|c|c|c|c|c|}
\hline \multicolumn{5}{|c|}{$\begin{array}{l}\text { Table } 11 \\
\text { Ranks for Various Math Measures at Post-Test }\end{array}$} \\
\hline Number Knowledge 3 & $\begin{array}{l}\text { Group } \\
\text { CB } \\
\text { RCMA } \\
\text { Total }\end{array}$ & $\begin{array}{l}\frac{N}{15} \\
46 \\
61\end{array}$ & $\begin{array}{c}\text { Mean Rank } \\
41.70 \\
27.51\end{array}$ & $\begin{array}{c}\text { Sum of Ranks } \\
625.50 \\
1265.50\end{array}$ \\
\hline Number Counting 3 & $\begin{array}{l}\text { CB } \\
\text { RCMA } \\
\text { Total }\end{array}$ & $\begin{array}{l}15 \\
46 \\
61\end{array}$ & $\begin{array}{l}50.10 \\
24.77\end{array}$ & $\begin{array}{c}751.50 \\
1139.50\end{array}$ \\
\hline Number Writing 3 & $\begin{array}{l}\text { CB } \\
\text { RCMA } \\
\text { Total }\end{array}$ & $\begin{array}{l}15 \\
46 \\
61\end{array}$ & $\begin{array}{l}48.17 \\
25.40\end{array}$ & $\begin{array}{c}722.50 \\
1168.50\end{array}$ \\
\hline VPK Assessment Math 3 & $\begin{array}{l}\text { CB } \\
\text { RCMA } \\
\text { Total }\end{array}$ & $\begin{array}{l}15 \\
41 \\
56\end{array}$ & $\begin{array}{l}33.07 \\
26.83\end{array}$ & $\begin{array}{c}496.00 \\
1100.00\end{array}$ \\
\hline
\end{tabular}

\section{Table 12}

Test Statistics for Various Math Measures at Post-Test

\begin{tabular}{lccccc|}
\cline { 2 - 3 } Statistic & Number Knowledge 3 & Number Counting 3 & Number Writing 3 & VPK Assessment Math 3 \\
\cline { 2 - 3 } Mann-Whitney U & 184.500 & 58.500 & 87.500 & 239.000 \\
Wilcoxon W & 1265.500 & 1139.500 & 1168.500 & 1100.000 \\
Z & -2.713 & -4.819 & -4.579 & -1.278 \\
Asymp. Sig. (2-tailed) & .007 & .000 & .000 & .201 \\
\hline
\end{tabular}

On the Number Writing measure, there was a significant difference in the scores for the CB group $(M d n=5.00)$ and RCMA group $(M d n=3.00) ; U=87.500, p=0.000, r$ $=0.586$. These results suggest that the NumberWays intervention was effective in increasing students' performance in number writing. The effect size of 0.586 is considered a large effect size $(r>0.5)$. 
On the Number Knowledge assessment, there was a significant difference in the scores for the CB group $(M d n=8.00)$ and RCMA group $(M d n=6.00) ; U=184.500, p=$ $0.007, r=0.347$. These results suggest that the NumberWays intervention was also effective in increasing students' number knowledge as measured in this assessment. The effect size of 0.347 is a medium effect size $(r>0.3)$.

From this data, it can be concluded that there was no significant difference between the CB group $(M d n=16.00)$ and the RCMA group $(M d n=14.00)$ on the VPK Assessment Math 3, $U=239.000, p=0.201$. This finding suggests that the NumberWays intervention had no effect on the students' scores on the VPK Assessment Math measure at the end of the school year.

The Mann-Whitney U test indicated that the Number Counting score was greater for the CB group $(M d n=50.00)$ than for the RCMA group $(M d n=20.00), U=58.50, p=$ $0.000, r=0.617$. The effect size of 0.681 is considered large $(r>0.5)$. These results suggest that the NumberWays intervention had a positive effect in increasing students' performance on the Number Counting measure at the end of the school year.

Overall, it appears the NumberWays intervention had a large positive effect on the post-test scores of students in the CB group compared to the RCMA group on the Number Writing, Number Knowledge, and Number Counting measures.

\section{Predictivity of Number Writing}

After comparing the posttest scores, it is necessary to dig deeper with respect to number writing. Does number writing have predictive value in relation to number knowledge? In order to answer this question, it must be seen if there exists a correlation between competency in number writing and achievement in early math scores at the 
beginning, middle, and end of the year of the preschool year. A linear regression analysis was used to determine the relationship between the score on the Number Writing assessment and on the Number Knowledge assessment for each assessment period. This might show that there are underlying factors supporting both and give support to the idea that number writing is a fundamental part of number knowledge.

Let us begin at the beginning of the school year. For the pre-test as well as the mid-test, number writing and number knowledge data is only available from the $\mathrm{CB}$ group $(N=15)$. First, to test the direct relationship of each number writing attempt to its contingent Number Knowledge assessment score, a simple linear regression was done at pre-, mid-, and post-test individually. Then the overall ability of number writing to predict number knowledge from all assessment periods was tested using stacked data.

The linear regression analysis for the pre-test is as follows:

\begin{tabular}{|lccc|}
\hline Table 13 & & \\
& & \\
Descriptive Statistics for Number Knowledge & and Number & Writing at & Pre-Test \\
\hline & $\frac{\text { Mean }}{2.93}$ & $\frac{\text { Std. Deviation }}{1.387}$ & $\underline{\mathrm{N}}$ \\
Number Knowledge & 1.47 & .743 & 15 \\
Number Writing & & & \\
\hline
\end{tabular}

\begin{tabular}{|llcc|}
\hline Table 14 & & & \\
\multicolumn{4}{|l}{ Correlations Between Number Knowledge and Number Writing at Pre-Test } \\
\hline \multirow{3}{*}{ Pearson Correlation } & Number Knowledge & Number Knowledge & Number Writing \\
& Number Writing & 1.000 & .725 \\
Sig. (1-tailed) & Number Knowledge & .725 & 1.000 \\
& Number Writing & .001 & .001 \\
$\mathrm{~N}$ & Number Knowledge & 15 &. \\
& Number Writing & 15 & 15 \\
\hline
\end{tabular}




\begin{tabular}{|lllllll|}
\hline \multicolumn{1}{|l|}{ Table 15} \\
\multicolumn{7}{|l|}{ ANOVA } \\
\hline
\end{tabular}

\section{Table 16}

Model Summary for Correlation Between Number Knowledge and Number Writing at Pre-Test

\begin{tabular}{|c|c|c|c|c|c|c|c|c|c|}
\hline \multirow[b]{3}{*}{ Model } & \multirow[b]{3}{*}{$\underline{\mathrm{R}}$} & \multirow[b]{2}{*}{$\underline{\mathrm{R}}$} & \multirow[b]{2}{*}{$\underline{\text { Adjusted R }}$} & \multirow[b]{2}{*}{$\underline{\text { Std. Error of }}$} & \multicolumn{5}{|c|}{ Change Statistics } \\
\hline & & & & & $\underline{\text { R Square }}$ & $\underline{F}$ & & & Sig. F \\
\hline & & $\underline{\text { Square }}$ & Square & the Estimate & Change & Change & $\underline{\text { df1 }}$ & $\underline{\mathrm{df} 2}$ & Change \\
\hline 1 & $.7 \overline{2} 5^{\mathrm{a}}$ & .526 & .490 & .991 & .526 & 14.424 & $\overline{1}$ & $\overline{13}$ & .002 \\
\hline
\end{tabular}

\begin{tabular}{|c|c|c|c|c|c|c|c|c|c|}
\hline $\begin{array}{l}\text { Tabl } \\
\text { Coef. } \\
\text { at } P r\end{array}$ & $\begin{array}{l}17 \\
\text { icients } \\
\text { e-Test }\end{array}$ & ear $R$ & ession B & tween Num & er $K$ & vled & ind $N$ & ber W & \\
\hline & & $\frac{\mathrm{Uns}}{\underline{\mathrm{Cc}}}$ & $\begin{array}{l}\text { ardized } \\
\text { cients }\end{array}$ & $\begin{array}{l}\text { Standardized } \\
\text { Coefficients } \\
\end{array}$ & & & & rrelation & \\
\hline $\begin{array}{l}\text { Mode } \\
1\end{array}$ & (Constant) & $\frac{\mathrm{B}}{.948}$ & $\frac{\text { Std. Error }}{.582}$ & Beta & 1.630 & $\frac{\text { Sig. }}{.127}$ & $\begin{array}{l}\text { Zero- } \\
\text { order }\end{array}$ & $\underline{\text { Partial }}$ & $\underline{\text { Part }}$ \\
\hline & $\begin{array}{l}\text { Number } \\
\text { Writing } 1\end{array}$ & 1.353 & .356 & .725 & 3.798 & .002 & .725 & .725 & .725 \\
\hline
\end{tabular}

Number writing was used to predict number knowledge at pre-test using ordinary least squares regression. A statistically significant degree of prediction was obtained, $F(1$, 14) $=14.424, p=0.001, R^{2}=0.526$ Adjusted $R^{2}=0.490$. The standardized regression coefficient was 0.725 , the raw regression coefficient was $1.353(S E=0.356)$, and the intercept was 0.948 . Number writing explained almost one half of the variance of number knowledge at mid-test.

Next, the linear regression analysis for the mid-test is as follows: 
Table 18

Descriptive Statistics for Number Knowledge and Number Writing at Mid-Test

\begin{tabular}{|c|c|c|c|}
\hline & Mean & Std. Deviation & $\underline{\mathrm{N}}$ \\
\hline Number Knowledge & 6.47 & 1.552 & $\overline{15}$ \\
\hline Number Writing & 3.60 & .507 & 15 \\
\hline
\end{tabular}

\begin{tabular}{|c|c|c|c|}
\hline $\begin{array}{l}\text { Table } 19 \\
\text { Correlations Be }\end{array}$ & en Number Kno & and Number Wri & at Mid-Test \\
\hline & & $\underline{\text { Number Knowledge }}$ & Number Writing \\
\hline Pearson Correlation & Number Knowledge & 1.000 & .345 \\
\hline & Number Writing & .345 & 1.000 \\
\hline Sig. (1-tailed) & Number Knowledge & & .104 \\
\hline & Number Writing & .104 & \\
\hline $\mathrm{N}$ & Number Knowledge & 15 & 15 \\
\hline & Number Writing & 15 & 15 \\
\hline
\end{tabular}

Table 20

ANOVA ${ }^{a}$ Table for Number Knowledge and Number Writing at Mid-Test

\begin{tabular}{|c|c|c|c|c|c|c|}
\hline \multirow{3}{*}{$\begin{array}{l}\text { Model } \\
1\end{array}$} & & $\underline{\text { Sum of Squares }}$ & $\frac{\mathrm{df}}{1}$ & Mean Square & $\frac{F}{754}$ & $\frac{\text { Sig. }}{208^{b}}$ \\
\hline & $\begin{array}{l}\text { Regression } \\
\text { Residual }\end{array}$ & $\begin{array}{l}4.011 \\
29.722\end{array}$ & $\begin{array}{c}1 \\
13\end{array}$ & $\begin{array}{l}4.011 \\
2.286\end{array}$ & & \\
\hline & Total & 33.733 & 14 & & & \\
\hline
\end{tabular}

a. Dependent Variable: Number Knowledge

b. Predictors: (Constant), Number Writing

\begin{tabular}{|c|c|c|c|c|c|c|c|c|c|}
\hline \multicolumn{10}{|c|}{$\begin{array}{l}\text { Model Summary for Correlation Between Number Knowledge and Number Writing at } \\
\text { Mid-Test }\end{array}$} \\
\hline \multirow[b]{2}{*}{$\frac{\text { Model }}{1}$} & \multirow[b]{2}{*}{$\frac{\mathrm{R}}{345^{\mathrm{a}}}$} & \multirow[b]{2}{*}{$\frac{\underline{\mathrm{R}}}{\text { Square }}$} & \multirow[b]{2}{*}{$\frac{\frac{\text { Adjusted R }}{\text { Square }}}{.051}$} & \multirow[b]{2}{*}{$\frac{\underline{\text { Std. Error of }}}{\frac{\text { the Estimate }}{1.512}}$} & \multicolumn{5}{|c|}{$\begin{array}{l}\text { Change Statistics } \\
\end{array}$} \\
\hline & & & & & $\frac{\text { R Square }}{\frac{\text { Change }}{.119}}$ & $\frac{\underline{F}}{\text { Change }} \frac{1.754}{1.75}$ & $\frac{\mathrm{df} 1}{1}$ & $\frac{\mathrm{df} 2}{13}$ & $\frac{\frac{\text { Sig. F }}{\text { Change }}}{.208}$ \\
\hline
\end{tabular}




\begin{tabular}{|c|c|c|c|c|c|c|c|c|c|}
\hline \multicolumn{10}{|c|}{$\begin{array}{l}\text { Coefficients }{ }^{a} \text { for Linear Regression Between Number Knowledge and Number Writing } \\
\text { at Mid-Test }\end{array}$} \\
\hline \multirow{3}{*}{$\frac{\text { Model }}{1}$} & \multirow[b]{2}{*}{ (Constant) } & \multicolumn{2}{|c|}{$\frac{\text { Unstandardized }}{\text { Coefficients }}$} & \multirow{2}{*}{$\begin{array}{c}\frac{\text { Standardized }}{\text { Coefficients }} \\
\text { Beta }\end{array}$} & \multirow[b]{2}{*}{$\frac{\mathrm{T}}{.921}$} & \multirow[b]{2}{*}{$\frac{\text { Sig. }}{.374}$} & \multicolumn{3}{|c|}{ Correlations } \\
\hline & & $2 . \frac{\mathrm{B}}{667}$ & $\frac{\text { Std. Error }}{2.895}$ & & & & $\begin{array}{l}\text { Zero- } \\
\underline{\text { order }}\end{array}$ & $\underline{\text { Partial }}$ & $\underline{\text { Part }}$ \\
\hline & $\begin{array}{l}\text { Number } \\
\text { Writing } 2\end{array}$ & 1.056 & .797 & .345 & 1.325 & .208 & .345 & .345 & .345 \\
\hline
\end{tabular}

Number writing was used to predict number knowledge at mid-test using ordinary least squares regression. A statistically significant degree of prediction was not obtained, $p=0.208$. Number writing did not explain the variance of number knowledge at mid-test.

The linear regression analysis for the post-test includes data from both the $\mathrm{CB}$ group and the RCMA group $(N=60)$. The analysis is as follows:

\begin{tabular}{|c|c|c|c|}
\hline \multicolumn{4}{|l|}{ Table 23} \\
\hline Number Knowledge & $\frac{\text { Mean }}{6.13}$ & $\frac{\text { Std. Deviation }}{2.225}$ & $\frac{N}{61}$ \\
\hline
\end{tabular}

\begin{tabular}{|llcc|}
\hline Table 24 & & & \\
\multicolumn{4}{|l}{ Correlations Between Number Knowledge and Number Writing at Post-Test } \\
\hline \multirow{3}{*}{ Pearson Correlation } & Number Knowledge & Number Knowledge 3 & Number Writing 3 \\
& Number Writing & 1.000 & .540 \\
Sig. (1-tailed) & Number Knowledge & .540 & 1.000 \\
& Number Writing & .000 & .000 \\
N & Number Knowledge & 61 &.. \\
& Number Writing & 61 & 61 \\
\hline
\end{tabular}


Table 25

ANOVA ${ }^{a}$ Table for Number Knowledge and Number Writing at Post-Test

\begin{tabular}{|c|c|c|c|c|c|c|}
\hline \multirow{3}{*}{$\frac{\text { Model }}{1}$} & & Sum of Squares & df & Mean Square & $\underline{F}$ & $\underline{\text { Sig. }}$. \\
\hline & $\begin{array}{l}\text { Regression } \\
\text { Residual }\end{array}$ & $\begin{array}{c}86.548 \\
210.403\end{array}$ & $\begin{array}{c}\overline{1} \\
59\end{array}$ & $\begin{array}{c}86.548 \\
3.566\end{array}$ & 24.269 & $.000^{\mathrm{b}}$ \\
\hline & Total & 296.951 & 60 & & & \\
\hline
\end{tabular}

a. Dependent Variable: Number Knowledge

b. Predictors: (Constant), Number Writing

\begin{tabular}{|c|c|c|c|c|c|c|c|c|c|}
\hline \multicolumn{10}{|c|}{$\begin{array}{l}\text { Model Summary for Correlation Between Number Knowledge and Number Writing at } \\
\text { Post-Test }\end{array}$} \\
\hline \multirow[b]{3}{*}{ Model } & \multirow[b]{3}{*}{$\underline{\mathrm{R}}$} & \multirow[b]{3}{*}{$\underline{\mathrm{R} \text { Square }}$} & \multirow[b]{2}{*}{ Adjusted R } & \multirow[b]{2}{*}{$\underline{\text { Std. Error of }}$} & \multicolumn{5}{|c|}{ Change Statistics } \\
\hline & & & & & $\underline{\text { R Square }}$ & $\underline{F}$ & & & $\underline{\text { Sig. F }}$ \\
\hline & & & $\underline{\text { Square }}$ & the Estimate & Change & Change & $\underline{\text { df1 }}$ & $\underline{\mathrm{d} f 2}$ & Change \\
\hline 1 & $.540^{\mathrm{a}}$ & .291 & .279 & 1.888 & .291 & 24.269 & 1 & 59 & .000 \\
\hline
\end{tabular}

\section{Table 27}

Coefficients $^{a}$ for Linear Regression Between Number Knowledge and Number Writing at Post-Test

\begin{tabular}{|c|c|c|c|c|c|c|}
\hline \multirow{3}{*}{$\frac{\text { Model }}{1}$} & \multirow[b]{2}{*}{ (Constant) } & \multicolumn{2}{|c|}{ Unstandardized Coefficients } & \multirow{2}{*}{$\frac{\frac{\text { Standardized }}{\text { Coefficients }}}{\underline{\text { Beta }}}$} & \multirow{3}{*}{$\begin{array}{c}\underline{\mathrm{t}} \\
2.089 \\
4.926\end{array}$} & \multirow[b]{2}{*}{$\frac{\text { Sig. }}{.041}$} \\
\hline & & $\frac{\mathrm{B}}{1.874}$ & $\frac{\text { Std. Error }}{.897}$ & & & \\
\hline & Number Writing 3 & 1.231 & .250 & .540 & & .000 \\
\hline
\end{tabular}

Number writing was used to predict number knowledge at post-test using ordinary least squares regression. A statistically significant degree of prediction was obtained, $F(1$, $60)=30.349, p<0.001, R^{2}=0.291$, Adjusted $R^{2}=0.279$. The standardized regression coefficient was 0.540 , the raw regression coefficient was $1.231(S E=0.250)$, and the intercept was 1.874 . Number writing explained approximately one quarter of the variance of number knowledge at post-test. 
Since the results at the different testing periods were mixed, the variables were transformed into stacked data, allowing computation that includes results from the three assessment periods. Stacked data refers to a method of re-organizing data commonly used with cross-sectional data (Le Thi Phuong \& Geskus, 2019). In this case, instead of integrating the assessment period into each assessment, a separate variable was created for assessment period, enabling the combination of results from all three assessment periods together to compute the statistics. These were used to determine the overall ability of number writing to predict number knowledge using a linear regression analysis. The results were as follows:

\begin{tabular}{|c|c|c|c|}
\hline $\begin{array}{l}\text { Table } 28 \\
\text { Descriptive Statistics }\end{array}$ & Know & d Number W & erall \\
\hline Number Knowledge Stacked & $\frac{\text { Mean }}{5.66}$ & $\frac{\text { Std. Deviation }}{2.339}$ & $\frac{\mathrm{N}}{91}$ \\
\hline Number Writing Stacked & 3.15 & 1.154 & 91 \\
\hline
\end{tabular}

\begin{tabular}{|c|c|c|c|}
\hline $\begin{array}{l}\text { Table } 29 \\
\text { Correlations Be }\end{array}$ & Number Knowledge & nd Number Writi & g Overall \\
\hline & & Number Knowledge & Number Writing \\
\hline & & Stacked & Stacked \\
\hline Pearson Correlation & Number Knowledge Stacked & 1.000 & .691 \\
\hline & Number Writing Stacked & .691 & 1.000 \\
\hline Sig. (1-tailed) & Number Knowledge Stacked & & .000 \\
\hline & Number Writing Stacked & .000 & \\
\hline $\mathrm{N}$ & Number Knowledge Stacked & 91 & 91 \\
\hline & Number Writing Stacked & 91 & \\
\hline
\end{tabular}

Table 30

ANOVA ${ }^{a}$ Table for Number Knowledge and Number Writing Overall

\begin{tabular}{llccccc}
$\underline{\text { Model }}$ & & Sum of Squares & $\underline{\mathrm{df}}$ & $\underline{\text { Mean Square }}$ & $\underline{\mathrm{F}}$ & $\underline{\underline{\text { Sig. }}}$ \\
\cline { 3 - 6 } & Regression & 234.855 & 1 & 234.855 & 81.147 & $.000^{\mathrm{b}}$ \\
& Residual & 257.584 & 89 & 2.894 & & \\
& Total & 492.440 & 90 & & &
\end{tabular}

a. Dependent Variable: Number Knowledge Stacked

b. Predictors: (Constant), Number Writing Stacked 


\begin{tabular}{|c|c|c|c|c|c|c|c|c|c|}
\hline \multicolumn{10}{|c|}{$\begin{array}{l}\text { Model Summary for Correlation Between Number Knowledge and Number Writing } \\
\text { Overall }\end{array}$} \\
\hline & & & & & & & $\mathrm{St}$ & & \\
\hline$\frac{\text { Model }}{1}$ & $\frac{\mathrm{R}}{.691^{\mathrm{a}}}$ & $\frac{\stackrel{\mathrm{R}}{\text { Square }}}{.477}$ & $\frac{\frac{\text { Adjusted R }}{\text { Square }}}{.471}$ & $\frac{\text { Std. Error of }}{\frac{\text { the Estimate }}{1.701}}$ & $\frac{\frac{\text { R Square }}{\text { Change }}}{.477}$ & $\begin{array}{l}\underline{\mathrm{F}} \\
\frac{\text { Change }}{81.147}\end{array}$ & $\frac{\mathrm{df} 1}{1}$ & $\frac{\mathrm{df} 2}{89}$ & $\frac{\text { Sig. F }}{\frac{\text { Change }}{.000}}$ \\
\hline
\end{tabular}

\begin{tabular}{|c|c|c|c|c|c|c|}
\hline \multicolumn{7}{|c|}{$\begin{array}{l}\text { Coefficients }{ }^{a} \text { for Linear Regression Between Number Knowledge and Number Writing } \\
\text { Overall }\end{array}$} \\
\hline \multirow{3}{*}{$\begin{array}{l}\text { Model } \\
1\end{array}$} & \multirow{3}{*}{$\begin{array}{l}\text { (Constant) } \\
\text { Number Writing All }\end{array}$} & \multicolumn{2}{|c|}{ Unstandardized Coefficients } & \multirow{2}{*}{$\frac{\text { Standardized }}{\underline{\text { Coefficients }}}$} & \multirow[b]{2}{*}{2.386} & \multirow[b]{2}{*}{$\frac{\text { Sig. }}{.019}$} \\
\hline & & $1 . \frac{\mathrm{B}}{244}$ & $\frac{\text { Std. Error }}{.522}$ & & & \\
\hline & & 1.400 & .155 & .691 & 9.008 & .000 \\
\hline
\end{tabular}

Overall number writing was used to predict overall number knowledge using ordinary least squares regression. A statistically significant degree of prediction was obtained, $F(1,90)=81.147, p<0.001, R^{2}=0.477$, Adjusted $R^{2}=0.471$. The standardized regression coefficient was 0.691 , the raw regression coefficient was 1.400 $(S E=0.155)$, and the intercept was 1.244 . Overall number writing scores explained nearly one half (47\%) of the variance of the overall Number Knowledge assessment scores. 


\section{CHAPTER V}

\section{DISCUSSION}

The topic for this dissertation emerged from working on a larger study of children's math readiness. In the larger study, an early math intervention was taught to a group of Pre-K children with the goal of raising their math readiness scores. The intervention, NumberWays, focused on 4 essential elements of number knowledge: naming, equating, writing, and sequence. In the course of teaching this curriculum I was surprised by the difficulty that many children had with writing their numbers. Some had issues of size and orientation. Others had small motor control problems. Still others said they couldn't remember how to write the number. By the end of the year, most of the children were able to quickly and clearly transcribe the numeric symbols from memory.

In the course of teaching, I also observed children spontaneously writing their numbers during free drawing time. One child filled her page up with $3 \mathrm{~s}$, seeming to enjoy the effects of the double curve adorning the page. In writing the numbers, the children seemed to be discovering the aesthetic properties of the symbols, as well as its potential to embody information. Learning to write their numbers seemed less a rote act of copying, and more a discovery of a powerful set of tools for expression.

When you start analyzing the act of number writing it becomes clear that a number of elements must be coordinated. First the child must remember the distinct symbols and the invariant sequence in which they appear. Next the child needs to perceive the left-right and up-down orientation of the distinct numbers. Finally, the child needs to be able to control the small motor movements required to transcribe the mental 
image on to the paper. After instruction and a significant amount of practice these deliberate and volitional steps become automatic and routine.

Automating the act of number writing frees children up to think more conceptually about meaning and function of number. The number symbols then become the tools for higher order math, rather than extra freight on an already confusing subject.

The number symbols and the means to make them do not however come to the children in a dream. They must be taught. This study demonstrated that number writing can be successfully taught to Pre-K children in a way that does not betray good pedagogy. The numbers were learned, not in isolation, but in the service of the different games. Children wrote the numbers for their board games, wrote the numbers for the score sheets, and wrote the number for the cards used in the various card games. They also learned to write their numbers as they were learning how to say them, how to compare them, and how to sequence them.

When it comes to preparing children for school, there is always a debate about whether to teach content or process. This study showed that you can and need to do both. The children benefit from explicit instruction and practice, but as they internalize the process, they are better able to understand the content. Numbers can be operated on only after it is understood, and it cannot be understood unless it can be constructed. Through the year that I observed, I watched children move from making squiggles for numbers, to painfully tracing the outlines, to in the end confidently reproducing a proud line of digits all in a row. Further, each child built their numbers a little differently, and at a different pace. I saw this not only as an accomplishment of the hand and the eye, but also a triumph of attention and self-regulation. This is connected to findings from previous 
studies that found that self-regulation is associated with early math skills (McClelland, Acock, \& Morrison, 2006; von Suchodoletz et al., 2013), even more so with working memory, which was found to work more efficiently as children were better able to produce the number symbols from memory, allowing them to craft their numbers more precisely (Harvey \& Miller, 2017; Shaul \& Schwartz, 2014).

When children from high poverty backgrounds enter kindergarten, it is a time of great hope but also of great peril. If they come without the skills to keep up, they risk being labeled, held back or weighted down with low expectations. If they come ready to learn with a strong foundation of process and content knowledge, they will be perceived as intelligent and given the external boost of higher expectations and the internal push of high self-efficacy. Knowing how to write the numbers quickly and legibly sends a message to others that the child is ready to learn math and has the right skills to succeed. Understanding the path that children take to number writing mastery is important, but I wanted to investigate whether this accomplishment was not just a means to an end, but an end in itself. In my years as an early childhood educator, I have thought of number writing as the utilitarian part of getting children to think about numbers, not as a coequal and integrated part of a larger conceptual structure. Therefore, I set out to see if children's number writing scores tracked with their overall number knowledge. The fact that number writing predicts early math readiness itself suggests that it is fundamental to the understanding of the concepts of quantity, cardinality, invariance, reversibility, universality, and even space and time, lending support not only to studies that draw a connection between children's ability to represent number symbols and their number sense (Zhou \& Wang, 2004), but also linking our findings to number theorists such as 
Case (Case et al., 1996), identifying number writing as an integral part in the process through which children conceptualize their early understanding of numbers.

The final important piece of this dissertation has to do with access and equity to early math instruction. Children from low-income neighborhoods are at risk for school failure partly due to lack of high-quality early childhood education. Math education is an area of early childhood curriculum that has consistently lagged behind other subjects. Early Childhood Educators are required by most colleges of education to take several courses in children's literacy, compared to a single course in math education. Math curricula is taught after literacy. Parents are told to read to their children at night but not to play math games with them. Middle class parents are more likely to use number and math in their jobs, and to have taken higher math in their studies. If children from poor neighborhoods whose parents have only a basic education are going to be able to keep up with the increasing demands of school standards and competition from more privileged children, then they need early preparation in math that includes a large helping of number writing, and the findings from this study have demonstrated one possible avenue to this end.

\section{Addressing the Research Questions}

The results of this study support the notion that number writing is an important skill that develops in early childhood and is intricately linked with number knowledge. The quantitative data revealed that number writing is predictive of number knowledge. This remarks the importance of number writing and its influence on early math readiness. However, the qualitative data in this study truly reveals how this might be so. 
The study traced the different paths of pre-kindergarten students in their number writing. Most children began at a low level in their writing. Some progressed most rapidly in the first half of the school year, making steady gains in the second half of the school year and finishing at a high level of number writing achievement. Others make steady gains throughout the year to attain an adequate level of number writing achievement. A small group of students began at a relatively higher level of number writing and made steady gains throughout the school year attain a high level of number writing achievement. Overall, the improvements were seen first in areas such as fine motor skills cardinal and ordinal number knowledge, and number symbol recognition first, and then in sensory tactile memory, with visual-spatial skills improving mostly towards the end of the school year. The development of visual-spatial skills paves the way for bi-dimensional thought.

These trends were observed in the group that participated in the NumberWays intervention. This was not observed in the comparison group. In fact, the performance at the end of the school year for the comparison group was widely varied, but it was mostly comparable to the performance of the intervention group in the first half of the school year. The intervention group significantly outperformed the comparison group in both number writing and number knowledge.

The research questions stated at the beginning investigate different aspects of this development and its relationship to early math in general. The qualitative and quantitative analyses of the data in this research project have revealed much about the development of number writing in preschool-aged children and have greatly informed the research questions stated at the beginning. 
The first of these is: Does teaching number writing through math games produce better number knowledge development as well as number writing improvement than only traditional teaching methods?

This question can be answered both quantitatively and qualitatively. Statistically, it was demonstrated that the children that received the NumberWays intervention performed better on measures of number writing, number knowledge at the end of the school year and even number counting, although the VPK Assessment math measure showed no significant difference between the two groups. Even so, the question asks specifically about number knowledge and number writing, and those were the two measures that showed the most definite advantage in the CB group.

However, that is just the yes or no aspect of the question. It also asks about "better...development" and "improvement," which are words that denote aspects of quality. Thus, the qualitative data obtained in this study complements the answer to this question. It has revealed that with the intervention, number knowledge improves in ways that can be perceived through number writing as well as assessed directly.

With the NumberWays intervention, number knowledge development improves to a greater degree than with conventional teaching methods, and it shows qualitatively on their number writing. These students produced the number symbols with the dexterity of knowing which number comes next, and often proceeding to write numbers beyond what is expected of them. They demonstrate an increased counting ability that exceeds that of their peers and demonstrated dominance of the pattern recognition that comes with the ability to see that counting involves a pattern of tens and ones. 
The improvement of the number writing itself is remarkable in the intervention group compared to the other group. Most of the students in the intervention group attained a level of performance on the number writing task that was unequaled by almost any of the children in the other group, despite the fact that the other group was three times as large. The students in the comparison group performed at a level that could be placed somewhere between pre- and mid-test for the intervention group. Such was the improvement seen in number writing through this program. Descriptively, these children were able to complete the task more efficiently, with appropriate fine motor skills, excellent visual perception skills that allowed them to write small, neat numbers that were approximately the same size and written on a nearly straight line. Most importantly, they demonstrated a sensory memory with respect to number writing that allowed them to write the numbers without hesitation, correctly and in the right direction.

To summarize, the short and the long answer to this question is yes, teaching number writing through math games produces better number knowledge development and number writing improvement than only traditional teaching methods.

The next research question to be answered is: What level of number writing do atrisk pre-kindergarten students have at the beginning and end of their pre-kindergarten year in a school that offers Florida's VPK?

This question can also be answered quantitatively and qualitatively. In terms of quantitative data to support the answer to this question, we must look to the number writing scale. At the beginning of the school year, the mean number writing score was 1.47. As a matter of fact, almost all students scored a level one or two, with the bulk of the students performing at a level one. At the end of the school year, the overall mean 
was 3.46 , but it actually differed with statistical significance between the intervention group and the comparison group, with means of 4.47 and 3.17 respectively. This means that at the end of the school year the number writing level of most children is between levels three and five. The children in the intervention group scored within the level four to five range, while those in the comparison group scored more within the three to four range.

However, without the qualitative data, these numbers have an empty value tied to a superficial description. The qualitative data collected in this study gives these numbers depth and meaning. The level of number writing for at-risk preschool children at the beginning of the school year is as follows: poor fine motor skills, weak grip on writing utensil, deficient knowledge of number symbols and deficient sensory memory to produce them, often resulting in the use of circles, tick marks, or random symbols, especially after the number three, and deficient overall number knowledge to allow for discerning the following number or how to write it. All this shown through body language that demonstrates insecurity and ignorance.

At the end of the school year, the level of the children was more varied. Those in the comparison group scored close to a level three. Qualitatively, the children demonstrated adequate fine motor skills, and adequate number knowledge, but their ability to reproduce the number symbols is limited. Those performing a bit better were able to produce all the number symbols, but with many errors of orientation, hinting at a lack of sensory memory to produce the number symbols correctly. Those performing more poorly were not able to produce all the number symbols clearly, especially those 
after the number five. Visual-spatial skills are also very deficient, with the numbers being written in different sizes and not arranged in a straight line.

The children in the intervention group fared much better. They scored closer to a level five. The fine motor skills in this group were just as adequate. The number knowledge exceeded that in the group described above, with several instances of children writing numbers past what was asked of them. The number writing itself for the most part was small, even-sized, along an approximately straight line, demonstrating greatly developed visual-spatial skills. The number symbols were all recognizable and, unlike the comparison group, the orientation of the numbers was almost all correct, and the writing was done quickly, demonstrating advanced sensory memory for writing numbers.

In contrast to the level of writing at the beginning of the school year, even the writing from the lower-performing group was much improved. If nothing else, children's overall writing skills improve over the length of a school year, and this reflects in the number writing. The direct instruction of the NumberWays intervention accounts for the difference between improved writing skills reflected in number writing and targeted improvement in number knowledge and number writing.

The following question is: Is there a correlation between competency in number writing and achievement in early math scores at the beginning, middle, and end of the year of the preschool year?

This question implies a strictly quantitative response based on the notion of correlation. To answer this question, ordinary least squares regression was run to identify any correlation between number writing and number knowledge, which is the test that specifically monitors early math skills. The results of the statistical tests revealed a strong 
correlation between number writing and number knowledge at pre-test $(R=0.725)$ and a moderate one at post-test $(R=0.540)$, but no statistically significant correlation between these two variables at mid-test $(p=0.208)$.

In order to better ascertain the predictivity of number writing in general, the same statistical test was run on all the data (pre-, mid-, and post-test) to get a better idea since this increases the sample size to 90 , and a moderately strong correlation was found $(R=$ 0.691). This clarifies the notion of whether number writing predicts number knowledge, but it remains unclear why this was not shown to be predictive at mid-test, since it was predictive at pre- and post-test.

It may simply be due to small sample size having a large degree of variation on the number knowledge scores and less so on the number writing so the scores corresponded less with each other as they did in the other assessment periods. This may indicate that since the students were at mid-development at mid-year, the number writing advanced more solidly at this stage than the number knowledge and this hindered the presence of a correlation between the scores. Following this line of logic, this would mean that at pre-test, both measures are equally deficient and correlate with each other, and at post-test, the RCMA group's scores followed a pattern similar to the pre-test, and the $\mathrm{CB}$ group had equally corresponding high performance on both measures.

It is interesting to note that the correlation found at pre-test was strong, but that found at post-test was only moderate. This suggests that number writing is predictive of number knowledge, but perhaps only to a certain degree. In practical terms, perhaps number writing is predictive of the number knowledge that falls into the pre-dimensional 
area of the assessment, but not so much of one-dimensional number knowledge and onwards.

Either way, it can be safely assumed that number writing is predictive of number knowledge, and this has significant repercussions. This means that direct instruction in number writing through games, as taught through the NumberWays program, not only improves the actual number writing, but also number knowledge in general. To take this a step further, this supports the notion that there is a symbolic encoding component in number writing that links this activity to other early math knowledge.

The final research question addressed in this study is: What developmental stages can be observed in pre-kindergarten students' number writing?

This question must be answered from a purely qualitative angle. As noted in the three representative case studies, there are several different paths of development through which children may progress, but sooner or later, they all traverse the same stages.

All students, whether at Pre-K or before Pre-K begin at the earliest stage that corresponds to a level one on the Number Writing scale. This stage is one of poor performance in number writing. It denotes poor fine motor skills, limited number knowledge, limited number symbol recognition, deficient visual-spatial skills, and limited tactile memory to write the number symbols. At this early level, children are often able to produce very few of the number symbols correctly and resort to random symbols and markings for the ones that they do not know, including circles and hash marks. This was the stage observed at pre-test for most of the CB students and some of the RCMA students at post-test. 
Independently of how quickly or slowly children progress unto the following stage, the next stage is one of marked improvement in fine motor skills demonstrated by a firmer grip with pincer grasp on the writing utensil. The number knowledge improves substantially, but the number writing lags behind it a bit. Children may be better able to recognize the number symbols, but they still struggle to reproduce them, still lacking in tactile memory to carry this out correctly and efficiently. Visual-spatial skills are still lacking, with most students unable to write all the numbers the same size, although many can write them along an approximately straight line. This stage was observed at mid-test for the CB group and for a large part of the children in the RCMA group at post-test.

The final stage is one where children attain a very high level of success in number writing. The fine motor skills reach their ceiling in the previous stage. However, number knowledge continues to improve, as well as number symbol recognition, learning to apply the pattern of tens and ones to number symbols beyond 10 . The greatest improvements upon entering this stage can be seen in the areas of tactile memory and visual-spatial skills. Children in this stage are well able to write the number symbols quickly and with the correct orientation because they have clearly developed tactile memory on which they rely to carry out this task and which greatly reduces the cognitive load. This allows them to focus on other aspects of their writing. Thus, the writing becomes noticeably smaller, more even-sized, and written across a straight line. This stage was observed for most of the children from the CB group at post-test.

These are the main stages of number writing that were observed. There is variation in the speed at which children progress through these stages, even though all children traverse all of them. By identifying these stages, it becomes easier to determine 
at which stage of number writing a preschool-aged child may be at any given time. This, in turn, informs best teaching practices.

\section{Significance of the Findings}

The findings of this study have a fair amount of significance. To name one, tracking the development of number writing in preschool is fascinating, and makes an informative contribution to the somewhat limited body of knowledge that exists on this topic. It also informs on the underlying processes that are present as children learn to write their numbers, which is strongly associated with the quantification associated with numbers and how this is represented symbolically. It also helps identify the possible trajectories students may take to reach a certain level of number writing, which being linked to number knowledge, is an important goal to reach.

The important knowledge gained in the present study is possible due to another significant aspect of this study, which is also one of its greatest strengths, and that is the mixed-methods nature of the study. As previously noted, the sample size in this study was limited, making statistical calculations difficult. However, the qualitative feature of this study provides the ideal complement to the shortcomings of the quantitative data. The qualitative data in this study provides a richness of detail and a depth of analysis that highlights the most important characteristics of the results and makes the aforementioned significance of the results possible.

Another highly significant result of this study is the support for the notion that number writing predicts number knowledge. This confirms the existence of the relationship between number writing and number knowledge and identifies number writing as a key factor in the development of number knowledge and children's early 
math readiness in general. Through this study, it was ascertained that not only does writing play an important role in the way students learn and internalize number symbols, cardinal and ordinal number knowledge, and one-to-one correspondence, but also that this is a skill that must be taught directly, and this leads to the next significant finding of this study.

Teaching number writing in connection to these other skills though math games produces excellent results, and leaves children much better prepared to enter kindergarten. This is a highly significant outcome of this study. That the students who participated in the NumberWays program had a significantly higher performance on measures of number writing and number knowledge than the comparison group is an influential feat. This not only sheds light on the positive effects of teaching number writing in preschool through math games, but also harkens that this method can be easily incorporated into classrooms to produce this effect in similar groups to help alleviate the risk of these students underperforming in math upon entry to kindergarten.

Given the importance of number writing to young children's mathematical development, it is important to address the fact that writing by hand is an activity in danger of becoming extinct due to the increasing use of technology. Technology is being used as an aid in classrooms worldwide, and in almost every age group. Tablets, in particular, are considered very interactive for young children. Research has shown that when technology is integrated in the classroom from an early age, student achievement increases in the long term (Aronin \& Floyd, 2013). There are many apps available for children to hone a variety of mathematical skills using technology, and there are many ways to use technological devices within the classroom. An analysis of models for math 
technology use in preschool classrooms yielded various designs that account for the ways in which technology may be used in the classroom to teach math, including a model in which there is a limited number of devices and students rotate their use, and one in which each student has his own device (Craig, 2000). Either way, teachers are seeking ways to integrate technology into the way children learn, as well as prepare them to enter school with certain technological skills that are necessary in today's educational system. In fact, the state of Florida has adopted a computer-based school readiness assessment upon entry into kindergarten, discarding the orally administered one that was formerly used. If students lack the skills necessary to demonstrate their knowledge through technological means, they may score lower than their actual level.

There are many apps designed for young children to learn math skills that require them to trace numbers with their finger using correct movements (top to bottom and left to right), such as Monkey Math (Aronin \& Floyd, 2013). In this sense, this sort of apps can serve to reinforce number writing. However, this is just one example within a myriad of uses of technology. Sadly, it is likely that technology will slowly replace the need to write, and with it the benefits that writing numbers can bring to children's early development in mathematics. Literacy instruction has had to adapt to the influx of technology, and this is affecting the way children are learning to write, in terms of composition. However, it does promote student interest and motivation, even in young students, since they are naturally drawn to technology (Beam \& Williams, 2015). Hopefully mathematics instruction will also be able to adapt in such a way that it will not leave out aspects as important as number writing, but rather incorporate them in new, creative ways that enhance the overall learning experience for young students. 


\section{Limitations of the Study}

Although the findings in this study were impactful and significant, it had a few limitations that must be noted in order to keep the study in perspective.

One of the greatest limitations of this study is the sample size. The fact that the group that participated in the intervention was of only fifteen children and the comparison group was three times that size limits the statistical tests that can be performed on the data. In some cases, the data does not meet assumptions of normality or equal variances, and this limits the use of the usual, robust statistical tests on this data set. A limited data set also limits the conclusions that can be drawn from the results because the effect sizes tend to be narrower. However, this study is ongoing, and the researchers hope to build on the body of data collected in this study to amplify its findings.

Another limitation in this study is that the sample used in this study is very specific. The study was based on poor, Hispanic students attending preschool. This limits the generalizability of the study to other populations, such as children from a higher socioeconomic status or children who are not bilingual. Even so, the sample is representative of a very large sector of children in preschools in America that are of interest in targeting for improved early math readiness because they are at a large risk of underperforming as soon as they enter elementary school and of significantly falling behind their peers from higher socioeconomic status.

\section{Conclusions}

The current study attempted to answer specific important research questions despite limitations such as reduced sample size. The study is ongoing, and there are plans to unify the data to increase the sample size and be able to run more appropriate statistical 
tests to verify the results of the present study. Other questions have arisen as well that can be explored by future research, including whether the results observed hold true in a different socioeconomic status, what exactly are the limits of the predictivity of number writing with respect to number knowledge, and would practicing number writing through digital media yield similar results. Also, the validation and standardization of the number writing scale is proposed for the future.

In conclusion, the present study investigated the role of number writing in early math readiness through an intervention named NumberWays that taught number writing through math games throughout the school year. It traced the development of number writing in preschool-aged children, established a relationship between number writing and number knowledge, and determined the effectiveness of the intervention in improving number writing in comparison to a control group.

Despite limitations such as small sample size and generalizability limited to lowincome, bilingual students, the study is ongoing, and its results are significant. They support the notion set forth by Case and other theorists that symbolic encoding is an essential part of early number knowledge and this can be developed through number writing. This study establishes number writing as the key that unlocks number knowledge development and identifies the NumberWays intervention as a way to foster development in number writing to achieve better number knowledge in preschool.

Hopefully, teachers and policymakers alike will be able to recognize and stress the importance of number writing in the digital age, taking into account its vital importance to the learning and development of early mathematics in general. 


\section{References}

Aronin, S., \& Floyd, K. K. (2013). Using an iPad in Inclusive Preschool Classrooms to Introduce STEM Concepts. Teaching Exceptional Children, 45(4), 34-39.

Baker, S., Gersten, R., Flojo, J., Katz, R., Chard, D. J., \& Clarke, B. (2002). Preventing mathematics difficulties in young children: Focus on effective screening of early number sense delays (0305). Retrieved from Eugene, OR:

Barrouillet, P., Camos, V., Perruchet, P., \& Seron, X. (2004). ADAPT: A Developmental, Asemantic, and Procedural Model for Transcoding From Verbal to Arabic Numerals. Psychological Review, 111(2), 368-394. doi:10.1037/0033295X.111.2.368

Bassok, D., Miller, L. C., \& Galdo, E. (2016). The effects of universal state prekindergarten on the child care sector: The case of Florida's voluntary prekindergarten program. Economics of Education Review, 53, 87-98. doi:https://doi.org/10.1016/j.econedurev.2016.05.004

Beam, S., \& Williams, C. (2015). Technology-Mediated Writing Instruction in the Early Literacy Program: Perils, Procedures, and Possibilities. Computers in the Schools, 32(3), 18.

Bermejo, V., Morales, S., \& Garcia deOsuna, J. (2004). Supporting children's development of cardinality understanding (Vol. 14).

Bleiker, C. (2015). Number Writing Scale. College of Education. Florida International University.

Bob, B., \& Threlfall, J. (2004). One, Two, Three and Counting. Educational Studies in Mathematics, 55(1/3), 3-26.

Bonny, J. W., \& Lourenco, S. F. (2013). The approximate number system and its relation to early math achievement: Evidence from the preschool years. Journal of Experimental Child Psychology, 114(3), 375-388. doi:https://doi.org/10.1016/j.jecp.2012.09.015 
Burkham, J. M. (2019). The Geography of Underrepresentation: Latino Student Success and Absence at a Predominantly White Public University. Journal of Hispanic Higher Education, 18(3), 187-205. doi:10.1177/1538192717730125

Camos, V. (2008). Low working memory capacity impedes both efficiency and learning of number transcoding in children. Journal of Experimental Child Psychology, 99(1), 37-57. doi:https://doi.org/10.1016/j.jecp.2007.06.006

Case, R., Okamoto, Y., Griffin, S., McKeough, A., Bleiker, C., Henderson, B., . . . Keating, D. P. (1996). The Role of Central Conceptual Structures in the Development of Children's Thought. Monographs of the Society for Research in Child Development, 61(1/2), i-295. doi:10.2307/1166077

Cavanagh, S. (2008). Playing Games in Class Helps Students Grasp Math. Education Digest: Essential Readings Condensed for Quick Review, 74(3), 43-46.

Chard, D. J., Clarke, B., Baker, S., Otterstedt, J., Braun, D., \& Katz, R. (2005). Using Measures of Number Sense to Screen for Difficulties in Mathematics: Preliminary Findings. Assessment for Effective Intervention, 30(2), 3-14. doi:10.1177/073724770503000202

Chi, M. T. H., Slotta, J. D., \& Leeuw, N. d. (1994). From Things to Processes: A Theory of Conceptual Change for Learning Science Concepts. Learning and Instruction, $4(1), 17$.

Clark, C. A. C., Sheffield, T. D., Wiebe, S. A., \& Espy, K. A. (2013). Longitudinal Associations Between Executive Control and Developing Mathematical Competence in Preschool Boys and Girls. Child Development, 84(2), 662-677. doi:10.1111/j.1467-8624.2012.01854.x

Comuk-Balci, N., Bayoglu, B., Tekindal, A., Kerem-Gunel, M., \& Anlar, B. (2016). Screening preschool children for fine motor skills: environmental influence. In (Vol. 28, pp. 1026-1031).

Craig, D. V. (2000). Technology, math, and the early learner: Models for learning. Early Childhood Education Journal, 27(3), 179-184. doi:http://dx.doi.org/10.1007/BF02694232 
Duncan, G. J., Dowsett, C. J., Claessens, A., Magnuson, K., Huston, A. C., Klebanov, P., ... Japel, C. (2007). School readiness and later achievement. Dev Psychol, 43(6), 1428-1446. doi:http://dx.doi.org/10.1037/0012-1649.43.6.1428

F. de Saussure's Theory of Language. (1984). Cahiers Ferdinand de Saussure(38), 83-97.

Fischer, J.-P. (2011). Mirror writing of digits and (capital) letters in the typically developing child. Cortex, 47(6), 759-762. doi:https://doi.org/10.1016/j.cortex.2011.01.010

Fosshage, J. L. (2011). How Do We 'Know' What We 'Know?' And Change What We 'Know?'. Psychoanalytic Dialogues, 21(1), 55-74. doi:10.1080/10481885.2011.545328

Gagne, R. M. (1974). Task Analysis - Its Relation to Content Analysis. In (pp. 1-17).

Garcia, E. E., \& Miller, L. S. (2008). Findings and Recommendations of the National Task Force on Early Childhood Education for Hispanics. Child Development Perspectives, 2(2), 53-58. doi:10.1111/j.1750-8606.2008.00042.x

Gavens, N., \& Barrouillet, P. (2004). Delays of retention, processing efficiency, and attentional resources in working memory span development. Journal of Memory and Language, 51(4), 644-657. doi:https://doi.org/10.1016/j.jm1.2004.06.009

Gelman, R., \& Gallistel, C. R. (1978). The child's understanding of number. Cambridge, Mass ; London: Harvard University Press.

Goodman, N. (1976). Languages of art : an approach to a theory of symbols (2d ed. ed.): Hackett.

Harvey, H. A., \& Miller, G. E. (2017). Executive Function Skills, Early Mathematics, and Vocabulary in Head Start Preschool Children. Early Education and Development, 28(3), 290-307.

Hildreth, G. (1932). The Success of Young Children in Number and Letter Construction. Child Development, 3(1), 1. 
Huang, F. L., \& Invernizzi, M. A. (2013). Birthday effects and preschool attendance. Early Childhood Research Quarterly, 28(1), 11-23. doi:10.1016/j.ecresq.2012.03.002

Huang, Y. T., Spelke, E., \& Snedeker, J. (2013). What Exactly do Numbers Mean? Language Learning \& Development, 9(2), 105-129. doi:10.1080/15475441.2012.658731

Johansson, B. S. (2005). Number-word sequence skill and arithmetic performance. Scandinavian Journal of Psychology, 46(2), 157-167. doi:10.1111/j.14679450.2005.00445.x

Kellogg, R. (1973). Misunderstanding Children's Art. Art Education, 26(6), 7-9. doi: $10.2307 / 3191793$

Laski, E., \& Siegler, R. (2007). Is 27 a Big Number? Correlational and Causal Connections Among Numerical Categorization, Number Line Estimation, and Numerical Magnitude Comparison (Vol. 78).

Laupa, M., \& Becker, J. (2004). Coordinating Mathematical Concepts with the Demands of Authority: Children's Reasoning about Conventional and Second-Order Logical Rules. Cognitive Development, 19(2), 147-168.

Le Thi Phuong, T., \& Geskus, R. (2019). A comparison of model selection methods for prediction in the presence of multiply imputed data. In (Vol. 61, pp. 343-356).

Lee, Y.-S., Lembke, E., Moore, D., Ginsburg, H. P., \& Pappas, S. (2012). Item-Level and Construct Evaluation of Early Numeracy Curriculum-Based Measures. Assessment for Effective Intervention, 37(2), 107-117. doi: $10.1177 / 1534508411431255$

Locuniak, M. N., \& Jordan, N. C. (2008). Using Kindergarten Number Sense to Predict Calculation Fluency in Second Grade. Journal of Learning Disabilities, 41(5), 451-459.

Lonigan, C. J. (2011). Florida VPK Assessment Measures. In F. C. f. R. Research (Ed.), Office of Early Learning. 
Luo, Z., Jose, P. E., Huntsinger, C. S., \& Pigott, T. D. (2007). Fine motor skills and mathematics achievement in East Asian American and European American kindergartners and first graders. British Journal of Developmental Psychology, 25(4), 595-614. doi:10.1348/026151007X185329

McClelland, M. M., Acock, A. C., \& Morrison, F. J. (2006). The impact of kindergarten learning-related skills on academic trajectories at the end of elementary school. Early Childhood Research Quarterly, 21(4), 471-490. doi:https://doi.org/10.1016/j.ecresq.2006.09.003

McIntosh, R. D., Hillary, K., Brennan, A., \& Lechowicz, M. (2018). Developmental mirror-writing is paralleled by orientation recognition errors. Laterality, 23(6), 664-683. doi:10.1080/1357650X.2018.1445748

Meyers, L. S., Gamst, G., \& Guarino, A. J. (2013). Applied multivariate research: Design and interpretation, 2nd ed. Thousand Oaks, CA, US: Sage Publications, Inc.

Moenikia, M., \& Zahed-Babelan, A. (2010). A study of simple and multiple relations between mathematics attitude, academic motivation and intelligence quotient with mathematics achievement. Procedia - Social and Behavioral Sciences, 2(2), 15371542. doi:https://doi.org/10.1016/j.sbspro.2010.03.231

Molfese, V. J., Beswick, J., Molnar, A., \& Jacobi-Vessels, J. (2006). Alphabetic Skills in Preschool: A Preliminary Study of Letter Naming and Letter Writing. Developmental Neuropsychology, 29(1), 5-19. doi:10.1207/s15326942dn2901_2

Molfese, V. J., Beswick, J. L., Jacobi-vessels, J. L., Armstrong, N. E., Culver, B. L., White, J. M., . . Molfese, D. L. (2011). Evidence of alphabetic knowledge in writing: connections to letter and word identification skills in preschool and kindergarten. Reading and Writing, 24(2), 133-150. doi:http://dx.doi.org/10.1007/s11145-010-9265-8

NIEER. (2013). Florida Ranks First in Nation for Pre-K Access But Quality Remains Low Says National Report [Press release]

Nutbrown, C. (Ed.) (2011). High Scope Preschool Curriculum (2nd ed. ed.). London, UK: Sage UK. 
Passolunghi, M. C., Vercelloni, B., \& Schadee, H. (2007). The precursors of mathematics learning: Working memory, phonological ability and numerical competence. Cognitive Development, 22(2), 165-184. doi:https://doi.org/10.1016/j.cogdev.2006.09.001

Piaget, J. (1952). The child's conception of number. London,: Routledge \& Paul.

Rhodes, K. T., Branum-Martin, L., Washington, J. A., \& Fuchs, L. S. (2017). Measuring arithmetic: A psychometric approach to understanding formatting effects and domain specificity. Journal of Educational Psychology, 109(7), 956-976. doi:http://dx.doi.org/10.1037/edu0000189

Rosenblatt, E., \& Winner, E. (1988). The Art of Children's Drawing. Journal of Aesthetic Education, 22(1), 3-15. doi:10.2307/3332960

Sarnecka, B. W., \& Carey, S. (2008). How Counting Represents Number: What Children Must Learn and When They Learn It.

Sarnecka, B. W., \& Wright, C. E. (2013). The idea of an exact number: children's understanding of cardinality and equinumerosity. Cognitive Science, 37, 1493+.

Sasanguie, D., Göbel, S. M., Moll, K., Smets, K., \& Reynvoet, B. (2013). Approximate number sense, symbolic number processing, or number-space mappings: What underlies mathematics achievement? Journal of Experimental Child Psychology, 114(3), 418-431. doi:https://doi.org/10.1016/j.jecp.2012.10.012

Shaul, S., \& Schwartz, M. (2014). The role of the executive functions in school readiness among preschool-age children. Reading and Writing, 27(4), 749-768. doi:http://dx.doi.org/10.1007/s11145-013-9470-3

Siegler, R. S. (2016). Magnitude Knowledge: The Common Core of Numerical Development. Grantee Submission, 70.

Simmons, F. R., Willis, C., \& Adams, A.-M. (2012). Different Components of Working Memory Have Different Relationships with Different Mathematical Skills. Journal of Experimental Child Psychology, 111(2), 139-155. 
Sophian, C. (1988). Early Developments in Children's Understanding of Number: Inferences about Numerosity and One-to-One Correspondence. Child Development, 59(5), 1397-1414. doi:10.2307/1130502

Stoianov, I., Zorzi, M., \& Umiltà, C. (2004). The Role of Semantic and Symbolic Representations in Arithmetic Processing: Insights from Simulated Dyscalculia in a Connectionist Model. Cortex, 40(1), 194-196. doi:https://doi.org/10.1016/S0010-9452(08)70948-1

Tolchinsky Landsmann, L. (2003). The Cradle of Culture and What Children Know About Writing and Numbers Before Being. Mahwah, N.J.: Psychology Press.

Vandecandelaere, M., Speybroeck, S., Vanlaar, G., De Fraine, B., \& Van Damme, J. (2012). Learning environment and students' mathematics attitude. Studies in Educational Evaluation, 38(3), 107-120. doi:https://doi.org/10.1016/j.stueduc.2012.09.001

Viljaranta, J., Lerkkanen, M.-K., Poikkeus, A.-M., Aunola, K., \& Nurmi, J.-E. (2009). Cross-lagged relations between task motivation and performance in arithmetic and literacy in kindergarten. Learning and Instruction, 19(4), 335-344. doi:10.1016/j.learninstruc.2008.06.011

von Suchodoletz, A., Gestsdottir, S., Wanless, S. B., McClelland, M. M., Birgisdottir, F., Gunzenhauser, C., \& Ragnarsdottir, H. (2013). Behavioral self-regulation and relations to emergent academic skills among children in Germany and Iceland. Early Childhood Research Quarterly, 28(1), 62-73. doi:https://doi.org/10.1016/j.ecresq.2012.05.003

What Works, C. (2009). The Creative Curriculum[R] for Preschool. WWC Intervention Report. Retrieved from http://ezproxy.fiu.edu/login?url=http://search.ebscohost.com/login.aspx?direct=tr $\underline{\text { ue } \& \mathrm{db}=\text { eric } \& A N=E D 506156 \& \text { site}=e d s-l i v e}$

Yamagata, K. (2007). Differential Emergence of Representational Systems: Drawings, Letters, and Numerals. Cognitive Development, 22(2), 244-257.

Zhao, Y. (2017). What works may hurt: Side effects in education. Journal of Educational Change, 18(1), 1-19. doi:http://dx.doi.org/10.1007/s10833-016-9294-4 
Zhou, X., \& Wang, B. (2004). Preschool children's representation and understanding of written number symbols. Early Child Development and Care, 174(3), 253-266. doi:10.1080/0300443032000153570 
APPENDICES 


\section{Appendix A}

VPK Standards (2011)

from the Florida Early Learning and Developmental Standards for Four-Year-Olds

\section{OVERVIEW OF MATHEMATICAL THINKING STANDARDS}

\section{A. Mathematical Thinking}

\section{a. Number Sense}

1. Demonstrates understanding of one-to-one correspondence

Benchmark a: Child demonstrates one-to-one correspondence when counting. Benchmark b: Child demonstrates one-to-one correspondence to determine if two sets are equal.

2. Shows understanding of how to count and construct sets

Benchmark a: Child counts sets in the range of 10 to 15 objects.

Benchmark b: Child constructs sets in the range of 10 to 15 objects.

3. Shows understanding by participating in the comparison of quantities

Benchmark a: Child compares two sets to determine if they are equal.

Benchmark b: Child compares two sets to determine if one set has more.

Benchmark c: Child compares two sets to determine if one set has fewer.

Benchmark d: Child determines one set of objects is a lot more than another set of objects.

4. Assigns and relates numerical representations among numerals (written), sets of objects, and number names (spoken) from zero to 10

5. Counts and knows the sequence of number names (spoken)

Benchmark a: Child counts and recognizes number names (spoken) in the range of 10 to 15.

Benchmark b: Child counts up through 31 by understanding the pattern of adding by one, with teacher support and multiple experiences over time.

6. Shows understanding of and uses appropriate terms to describe ordinal positions Benchmark a: Child demonstrates the concept of ordinal position with concrete objects (e.g., children or objects).

Benchmark b: Child names ordinal positions (e.g., first, second, third, fourth, fifth).

\section{b. Number and Operations}

1. Shows understanding of how to combine sets and remove from a concrete set of objects (receptive knowledge)

Benchmark a: Child indicates there are more when combining (adding) sets of objects.

Benchmark b: Child indicates there are less (fewer) when removing (subtracting) objects from a set.

2. Shows understanding of addition and subtraction using a concrete set of objects (expressive knowledge) or story problems found in everyday classroom activities Benchmark a: Child combines sets of objects to equal a set no larger than 10 . 
Benchmark b: Child removes objects from a set no larger than 10 .

Benchmark c: Child uses concrete objects (e.g., fingers, blocks) to solve complex problems.

3. Begins to develop an understanding of separating a set into a maximum of four parts, with teacher support and multiple experiences over time

\section{c. Patterns and Seriation}

1. Understands characteristics of patterns and non-patterns and begins to reproduce them with at least two elements (e.g., red/blue, red/blue versus a non-pattern like a rainbow)

Benchmark a: Child recognizes patterns and non-patterns.

Benchmark b: Child duplicates identical patterns with at least two elements.

Benchmark c: Child recognizes pattern units (e.g., red/blue is the pattern unit of a $\mathrm{red} / \mathrm{blue} / \mathrm{red} / \mathrm{blue} / \mathrm{red} / \mathrm{blue}$ pattern; dog/cat/cow is the pattern unit of a dog/cat/cow/dog/cat/cow pattern)

Benchmark d: Child begins to independently produce patterns with at least two elements (e.g., red/blue, red/blue), with teacher support and multiple experiences over time.

2. Sorts, orders, compares, and describes objects according characteristics or attribute(s) (seriation)

Benchmark a: Child places objects in increasing order of size where the increasing unit is constant (e.g., unit blocks).

Benchmark b: Child verbalizes why objects were placed in order (e.g., describes process of how and why), with teacher support and multiple experiences over time.

\section{d. Geometry}

1. Understands various two-dimensional shapes, including circle, triangle, square, rectangle, oval, and other less common shapes (e.g., trapezoid, rhombus)

Benchmark a: Child categorizes (sorts) examples of two-dimensional shapes.

Benchmark b: Child names two-dimensional shapes.

Benchmark c: Child constructs examples of two-dimensional shapes.

Benchmark d: Child identifies the number of sides of two-dimensional shapes.

2. Shows understanding that two-dimensional shapes are equivalent (remain the same) in different orientations

Benchmark a: Child slides shapes, with teacher support and multiple experiences over time.

Benchmark b: Child flips shapes, with teacher support and multiple experiences over time.

Benchmark c: Child rotates shapes, with teacher support and multiple experiences over time.

3. Understands various three-dimensional shapes, including sphere, cube, cone, and other less common shapes (e.g., cylinder, pyramid)

Benchmark a: Child categorizes (sorts) examples of three-dimensional shapes.

Benchmark b: Child names three-dimensional shapes. 
4. Analyzes and constructs examples of simple symmetry and non-symmetry in two dimensions, using concrete objects.

\section{e. Spatial Relations}

1. Shows understanding of spatial relationships and uses position words (e.g., above, below, next to, beside, on top of, inside, outside)

Benchmark a: Child shows understanding of positional words (receptive knowledge).

Benchmark b: Child uses the positional terms verbally (expressive knowledge ) (e.g., in front of, behind, between, over, through, under), with teacher support and multiple experiences over time.

2. Describes relative position from different perspectives (e.g., "I am on top of the climber and you are below me.")

3. Understands and can tell the difference between orientation terms (e.g., horizontal, diagonal, vertical)

4. Uses directions to move through space and find spaces in place (e.g., obstacle courses, Simon Says, Mother May I?, hop scotch, giving simple directions)

\section{f. Measurement}

1. Engages in activities that explore measurement

2. Compares continuous quantities using length, weight, and height

Benchmark a: Child measures or compares the length of one or more objects using a non-standard reference (e.g., paper clips), with teacher support and multiple experiences over time.

Benchmark b: Child measures or compares the weight of one or more objects using non-standard reference (e.g., beans), with teacher support and multiple experiences over time.

Benchmark c: Child measures or compares the height of one or more objects using non-standard reference (e.g., pencils), with teacher support and multiple experiences over time.

Benchmark d: Child uses measurement vocabulary (e.g., length, weight, height) and comparative terminology (e.g., more, less, shorter, longer, heaviest, lightest), with teacher support and multiple experiences over time.

3. Represents and analyzes data

Benchmark a: Child assists with collecting and sorting materials to be graphed.

Benchmark b: Child works with teacher and small groups to represent mathematical relations in charts and graphs.

Benchmark c: Child analyzes, with teacher and small groups, the relationship between items/objects represented by charts and graphs.

4. Child predicts the results of a data collection, with teacher support and multiple experiences over time 


\section{Appendix B}

\section{Math Games and Descriptions}

The following is a description of the math games that make up the NumberWays curriculum. The games follow a pattern that builds the students' knowledge by tens. There are eight games, two each from four categories: board games, active games, activities, and card games. The four categories are cycled twice with different games for each set numbers targeted for learning - 0-9, 10-19, and 20-29. After these are completed, a few enrichment activities that introduce the numbers up to 100 are taught. In total, the students are taught 26 different number games. The games are taught in small groups of three to four children for one hour. Each group receives a one-hour session per week.

\begin{tabular}{|l|l|l|}
\hline Game & Type & Description \\
\hline 1. Frog Race & Board & $\begin{array}{l}\text { A board game in which each player takes } \\
\text { turns rolling a die and counting spaces } \\
\text { numbered with the target numbers to move } \\
\text { a frog piece to see which player reaches the } \\
\text { target number first. Each player must count } \\
\text { and write the number rolled by the die on } \\
\text { each turn. }\end{array}$ \\
\hline 2. Bowling & $\begin{array}{l}\text { Active } \\
\text { A game played with 10 0.5L water bottles } \\
\text { filled to 1/3 capacity arranged as bowling } \\
\text { pins with the target numbers written on } \\
\text { papers by the players and stuck to the floor } \\
\text { underneath each pin. Each player takes } \\
\text { turns rolling a ball to try to knock the pins } \\
\text { down and must then count and write the } \\
\text { numbers of the pins that were knocked } \\
\text { down on each turn. }\end{array}$ \\
\hline
\end{tabular}




\begin{tabular}{|l|l|l|}
\hline 3. Beads & Activity & $\begin{array}{l}\text { Each player uses a pipe cleaner to string } \\
\text { beads of different colors in different } \\
\text { amounts according to the target numbers. } \\
\text { The players then draw the design of their } \\
\text { bracelet on a sheet of paper and write the } \\
\text { number of each color of beads. The pipe } \\
\text { cleaner is then closed to make a bracelet or } \\
\text { necklace. }\end{array}$ \\
\hline 4. Cards & Cards & $\begin{array}{l}\text { Each player must make a deck of cards by } \\
\text { writing the target numbers and cutting them } \\
\text { out. These cards are then used to play. }\end{array}$ \\
\hline 5. Monkey Money & Board & $\begin{array}{l}\text { Each player must write the target numbers } \\
\text { and cut them out in squares to create bills } \\
\text { ("monkey money"). These bills are then } \\
\text { used to purchase bananas that correspond to } \\
\text { the amount represented by the bills. }\end{array}$ \\
\hline 6. Ball Toss & Active & $\begin{array}{l}\text { Each player is given the target amount of } \\
\text { tennis balls to be thrown inside a box from } \\
\text { a short length away. Later each player must } \\
\text { count and write how many balls were } \\
\text { successfully thrown inside the box in each } \\
\text { attempt. }\end{array}$ \\
\hline 7. Rainbow Ruler & Activity & $\begin{array}{l}\text { Each player must cut a sheet of paper in } \\
\text { half and draw a line and write in numbers } \\
\text { up to the target number in different colors } \\
\text { to create a ruler. The ruler is then used to } \\
\text { measure things around the classroom and } \\
\text { the measurements are written down. }\end{array}$ \\
\hline $\begin{array}{l}\text { Each player designs memory cards by } \\
\text { writing and cutting out two sets of cards } \\
\text { with the target numbers and then plays a } \\
\text { memory card game with the cards. }\end{array}$ \\
\hline Cards
\end{tabular}




\section{Appendix C}

Number Writing Scale (Bleiker, 2015)

\begin{tabular}{|c|c|c|c|c|}
\hline Level 1 & Level 2 & Level 3 & Level 4 & Level 5 \\
\hline $\begin{array}{l}\text { A level one } \\
\text { shows random } \\
\text { marks that show } \\
\text { little relation to } \\
\text { actual numbers. } \\
\text { Marks are } \\
\text { typically circles, } \\
\text { hash marks, or } \\
\text { scribbles. }\end{array}$ & $\begin{array}{l}\text { A level two has } \\
\text { marks that have } \\
\text { at least number } \\
1 \text { and potentially } \\
1 \text { or } 2 \text { others that } \\
\text { can reasonably } \\
\text { be interpreted as } \\
\text { a number. A } \\
\text { combination of } \\
\text { curved and } \\
\text { straight lines } \\
\text { should be } \\
\text { present. }\end{array}$ & $\begin{array}{l}\text { Most numerals } \\
\text { are recognizable. } \\
\text { Three or more } \\
\text { errors of } \\
\text { orientation } \\
\text { (reversals, size, } \\
\text { shape) are } \\
\text { present. }\end{array}$ & $\begin{array}{l}\text { All numerals are } \\
\text { recognizable, but } \\
\text { some have } \\
\text { reversals (left to } \\
\text { right or top to } \\
\text { bottom) or } \\
\text { irregularities. } \\
\text { Sizes may vary } \\
\text { between the } \\
\text { numbers. Left to } \\
\text { right orientation } \\
\text { for the most part. }\end{array}$ & $\begin{array}{l}\text { All numerals are } \\
\text { recognizable. } \\
\text { They are } \\
\text { approximately } \\
\text { the same size. } \\
\text { They have left to } \\
\text { right orientation. } \\
\text { Line is strong } \\
\text { and clear. No } \\
\text { more than one } \\
\text { reversal. }\end{array}$ \\
\hline
\end{tabular}


VITA

GISELLE HERNANDEZ

Born, Miami, Florida

2011

B.S., Early Childhood Education, Development Track

Honors College

Florida International University

Miami, Florida

2012

M.S., Early Childhood Education

Florida International University

Miami, Florida

2012-

Adjunct Professor

Florida International University

Miami, Florida

$2017-2019$

Doctoral Candidate

Florida International University

Miami, Florida

\section{PUBLICATIONS AND PRESENTATIONS}

Bleiker, C., \& Hernandez, G. (2015, March). Gaming the system: Teaching preschool children number knowledge through games. Poster session presented at the meeting of the Society for Research on Child Development, Philadelphia, PA.

Bleiker, C., \& Hernandez, G. (2018, May). Thinking in numbers: Number writing and the development of numerical thinking. Research panel conducted at the meeting of the International Conference on Thinking, Miami, FL. 